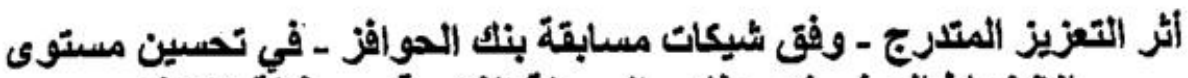

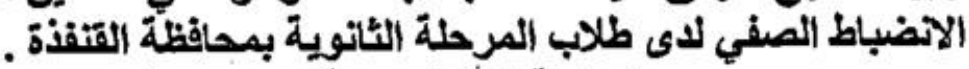
(دراسة شبئه تجريبية)

د / علي أحمد الثيخي

\title{
ملخص الأراسة:
}

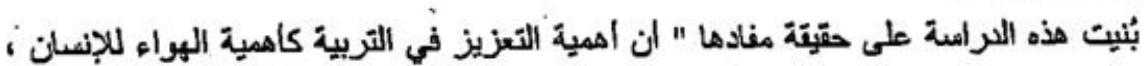

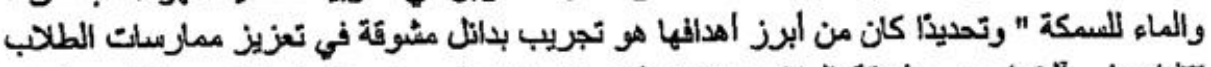

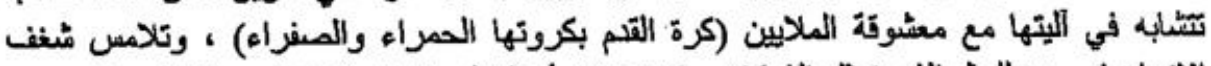

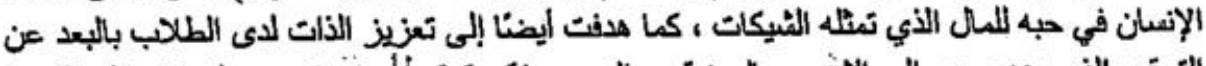

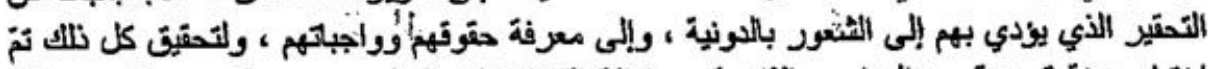

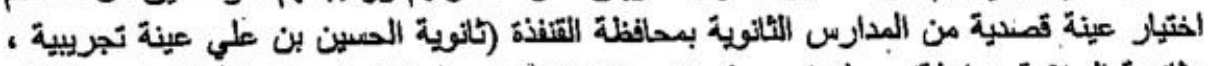

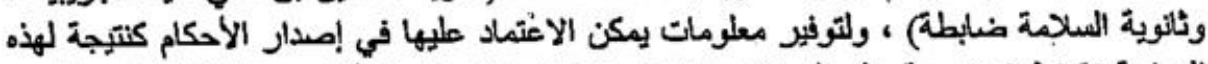

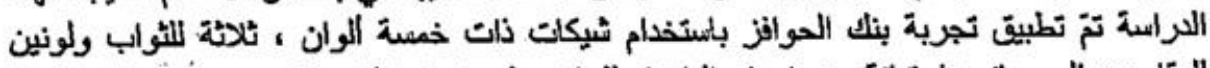

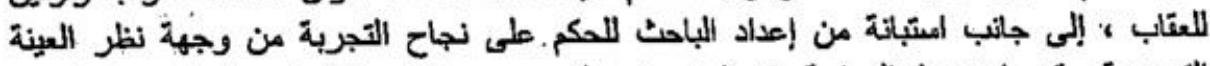

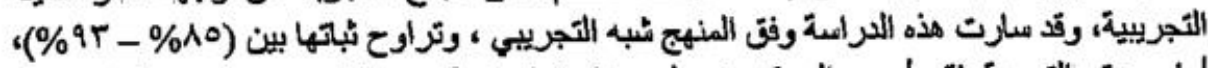

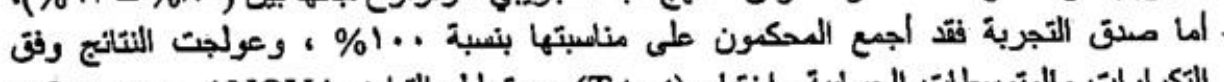

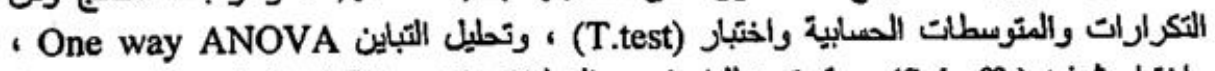

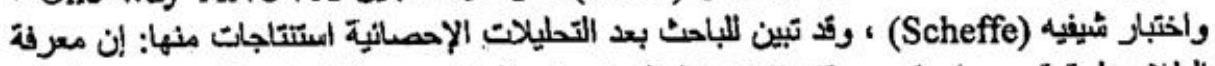

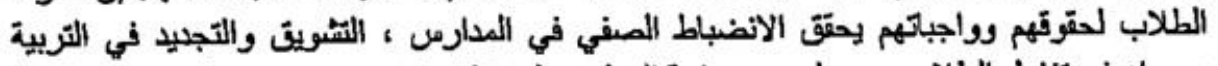

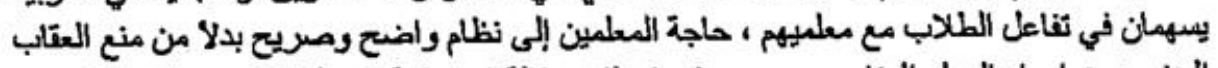

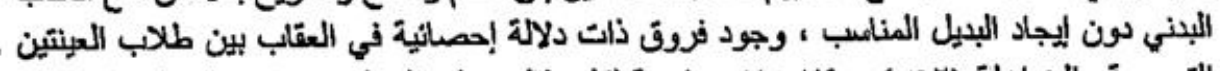

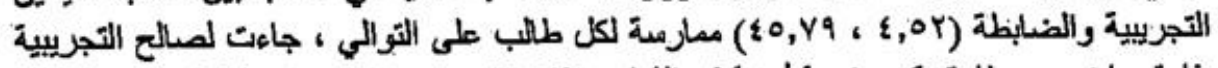

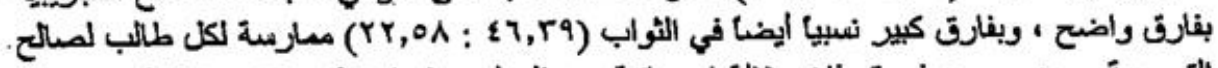

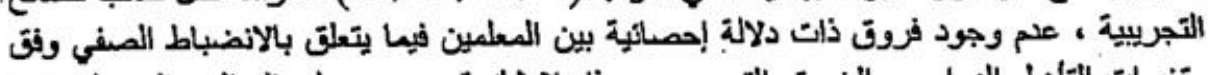

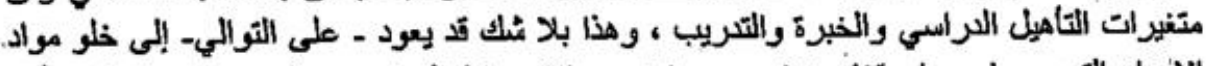

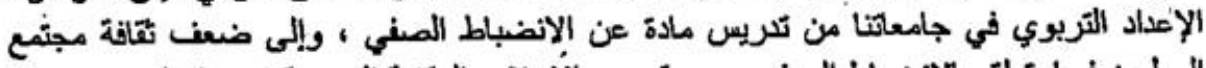

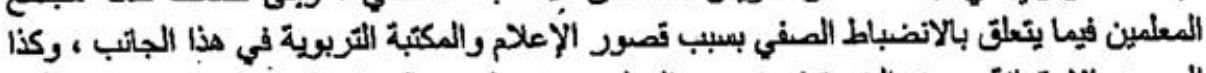

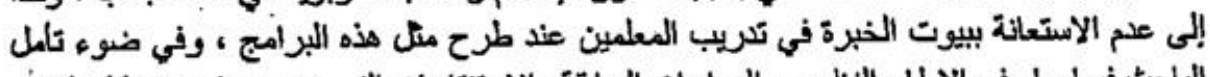

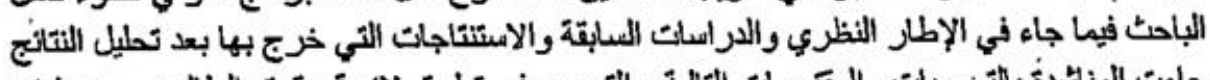

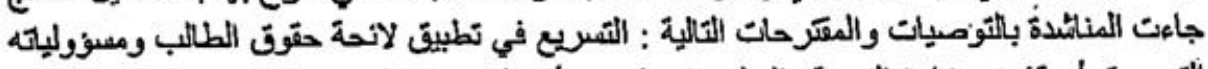

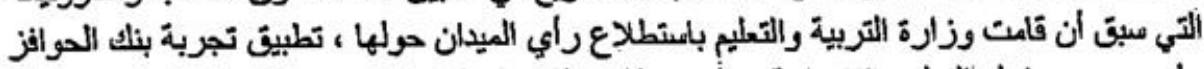

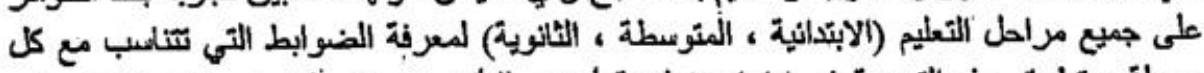

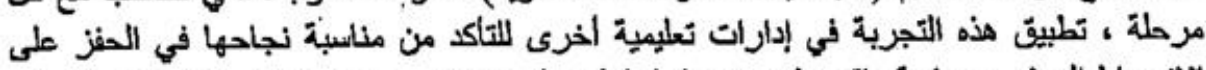

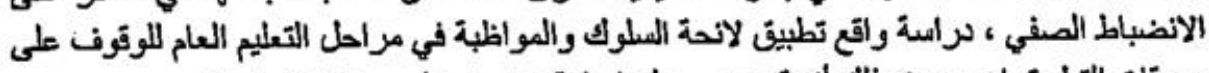

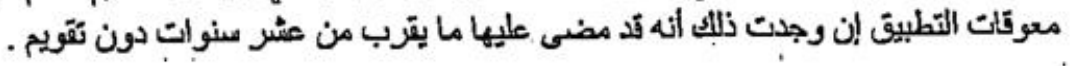




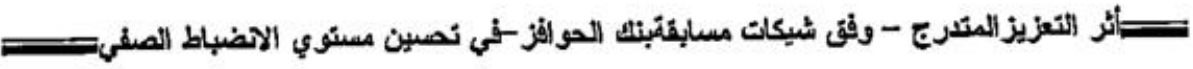
أتر التعزيز المتذرج - وفق شيكات مسابقة بنك الحوافز ـ في تحسين مستوى

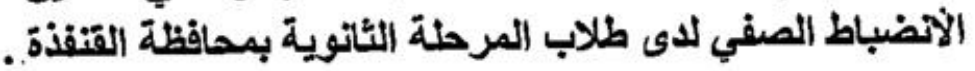

\section{(دراسة شبه تجريبية)}

د / ملي احمد الشيخي

|المقدمة :

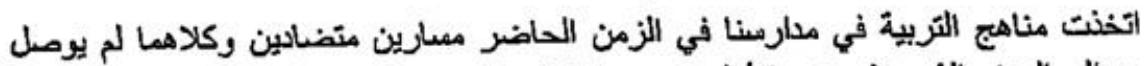

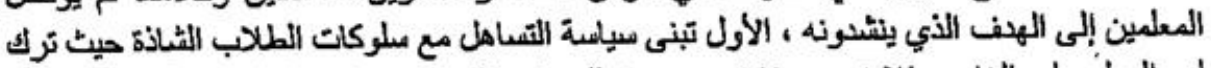

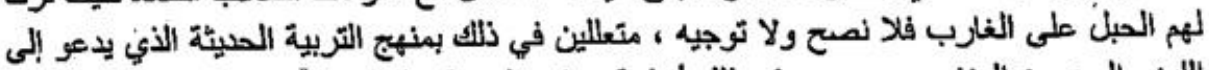

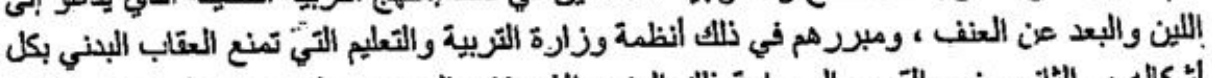

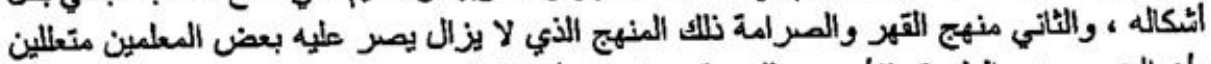

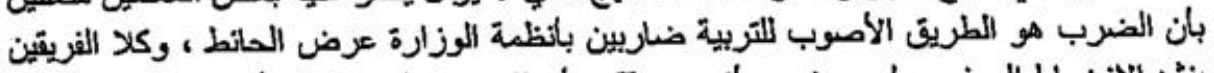

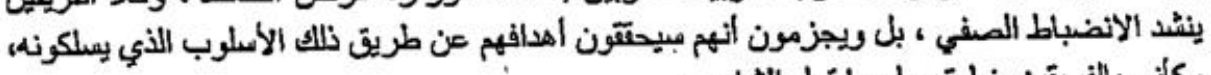

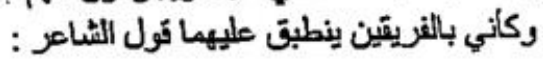

\section{وكل يدعي وصلاك بليلى وليلى لا تقز لهم بذاكا}

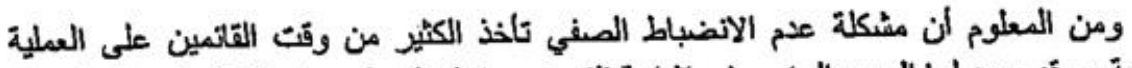

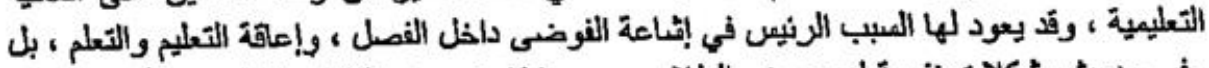

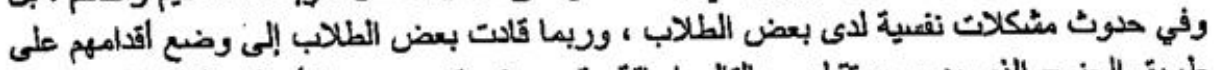

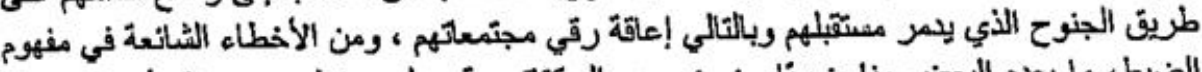

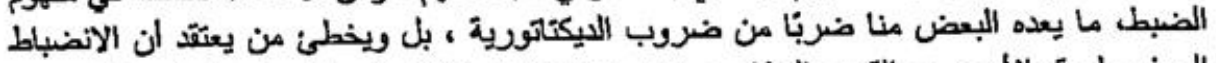

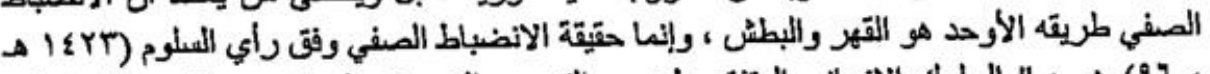

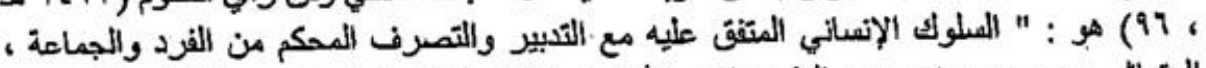

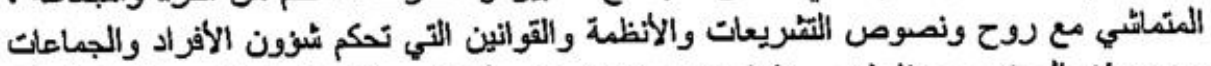

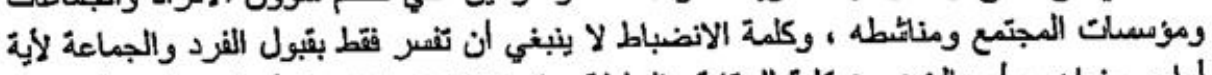

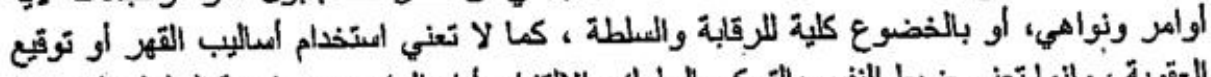

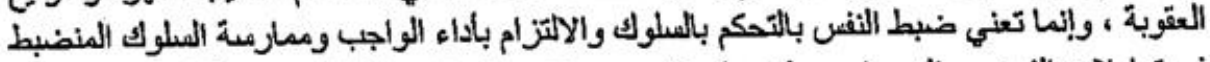

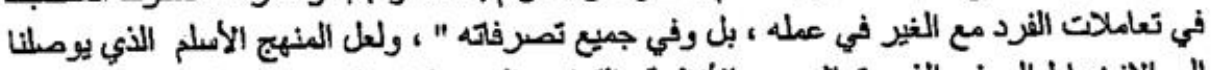

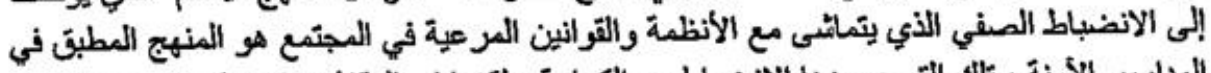

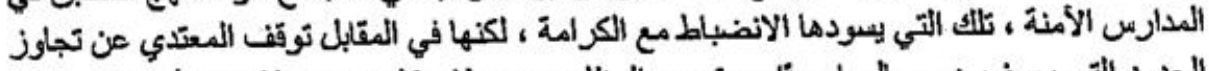

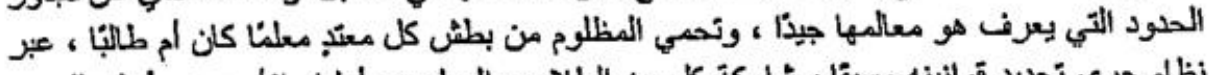

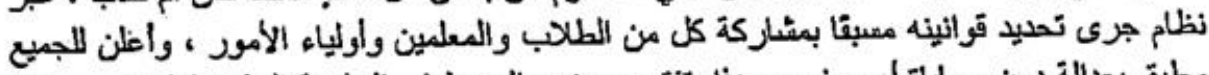

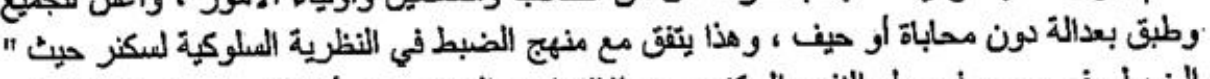

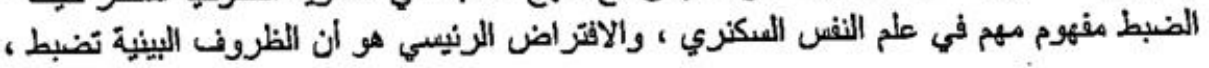

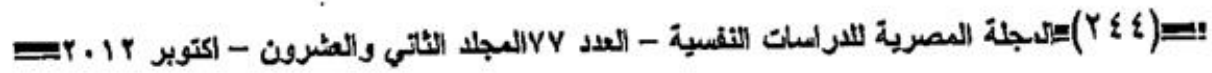




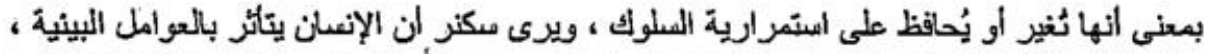

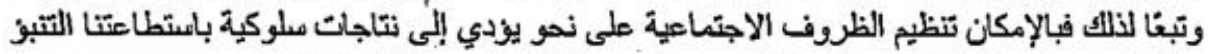

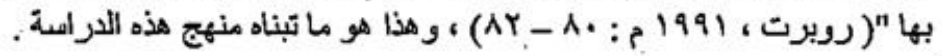

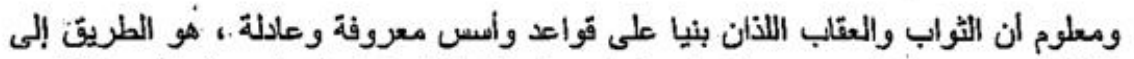

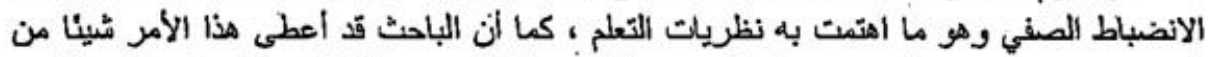

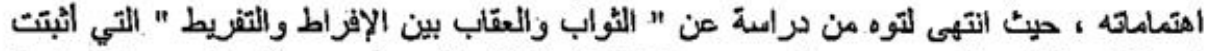

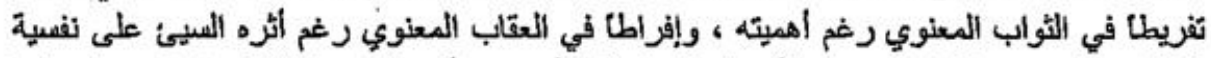

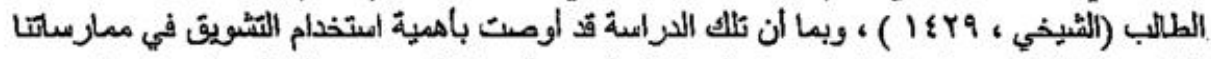

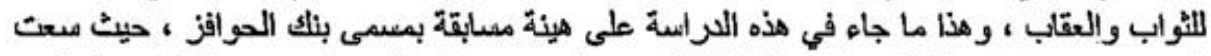

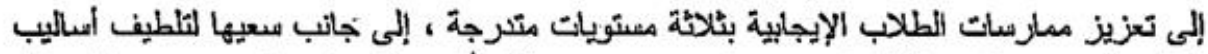

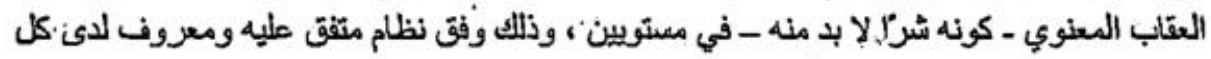

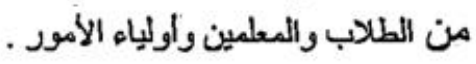

\section{مشكلة الار اسة وتساولاتها :}

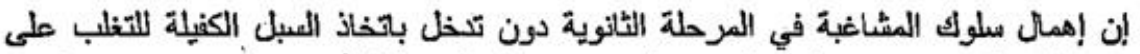

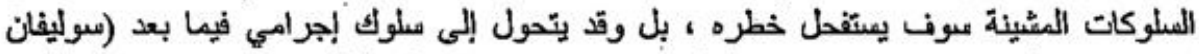

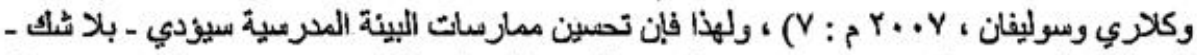

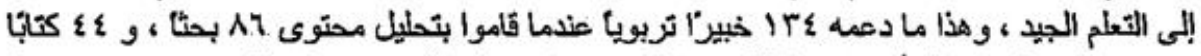

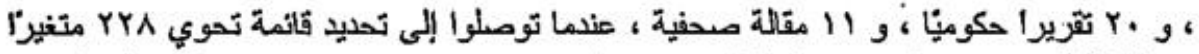

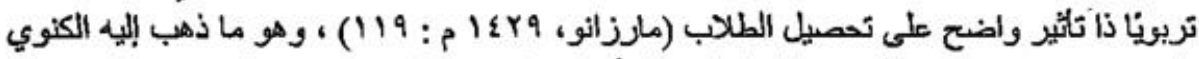

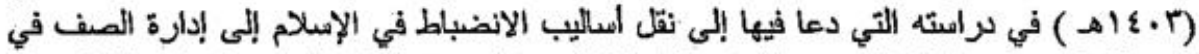

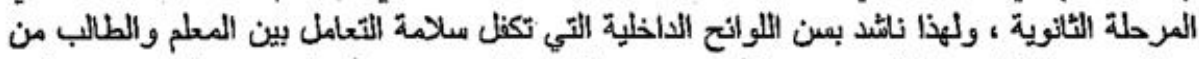

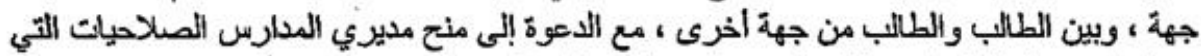

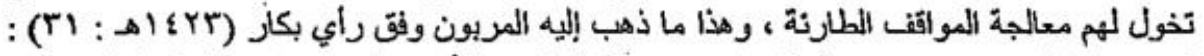

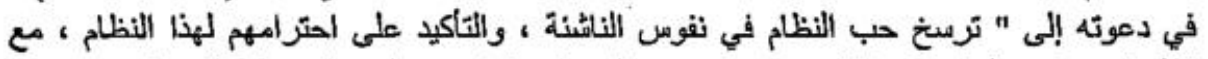

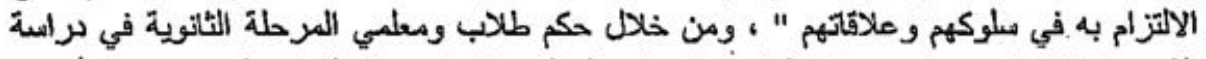

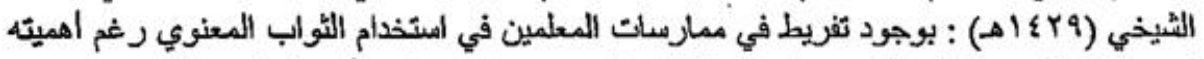

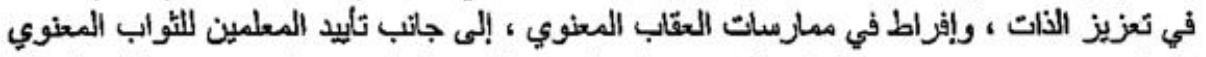

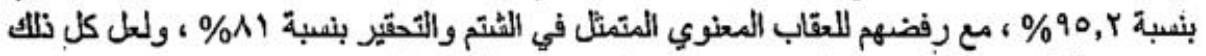

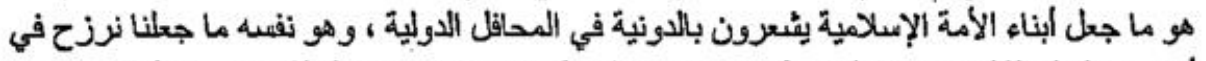

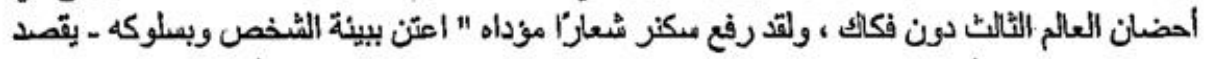

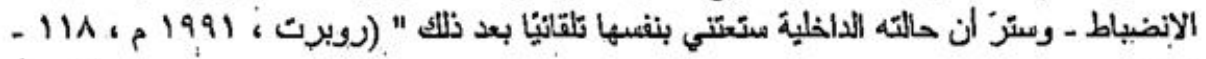

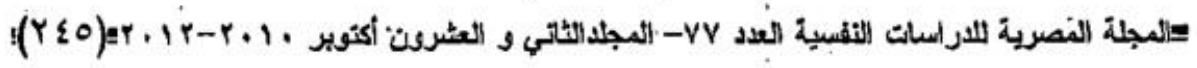




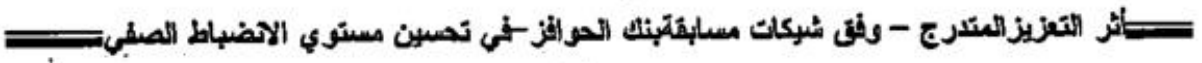

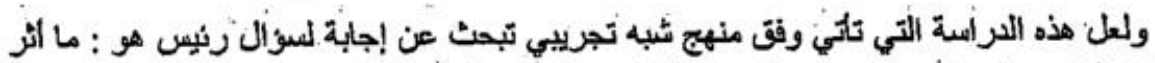

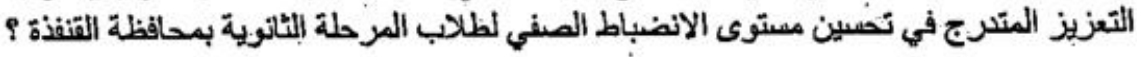

\section{والأي تنبثق منه التسباؤلات التالية :}

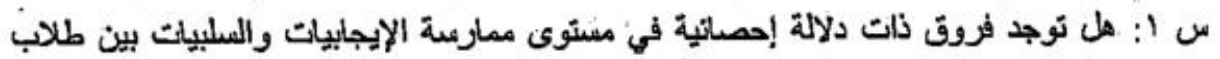

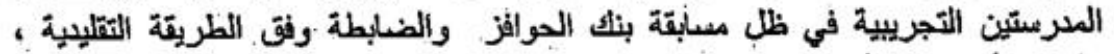

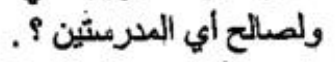

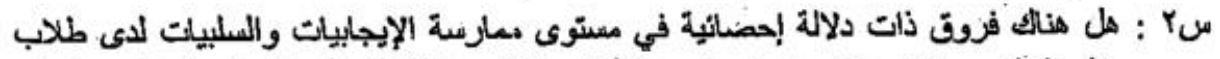

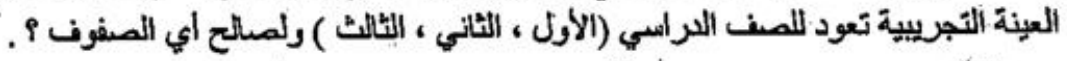

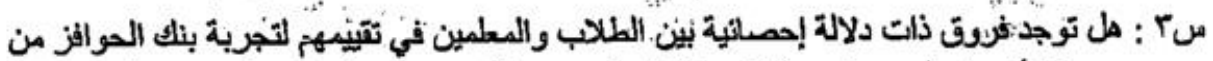

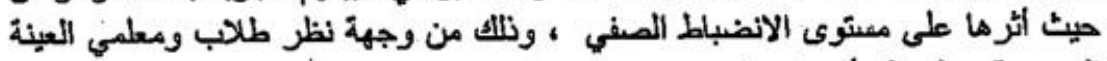

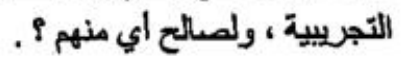

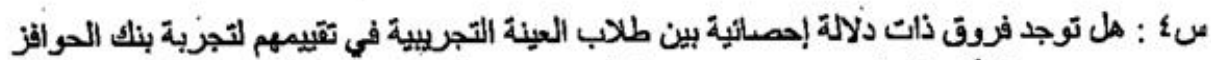

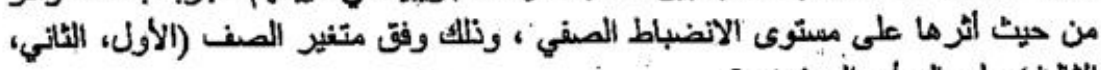

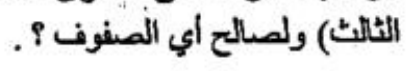

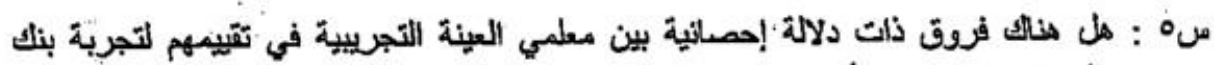

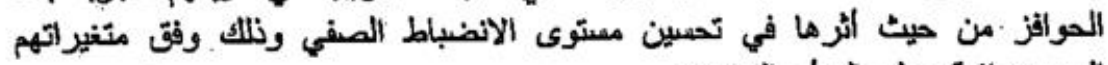

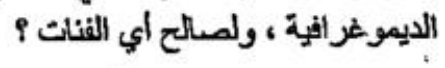

\section{أفدافت الدراسة :}

تهدف هذه إلثراسة إلى :

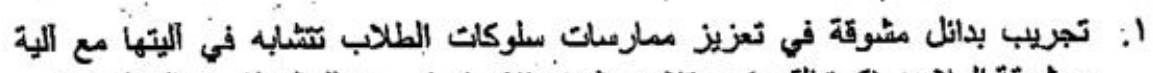

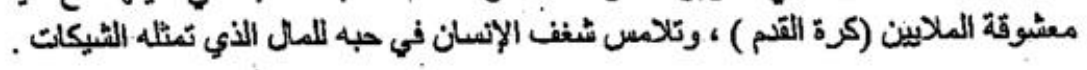
r. تحفيز الطلاب تحفيزا منتظما ومتواصلا حتى يصنمرو! في ضبط ملوكاتهم وفق التقاليد

$$
\text { المرعية. }
$$

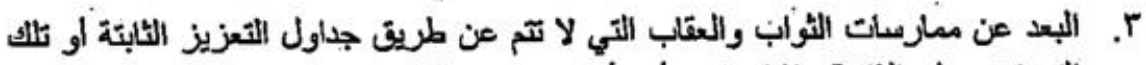

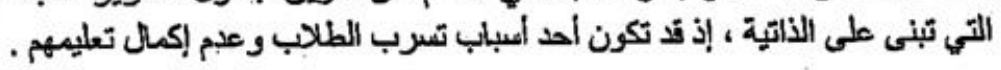

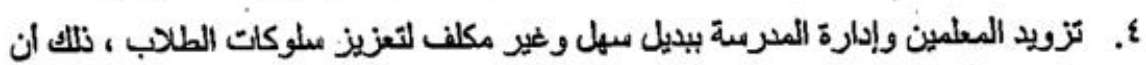

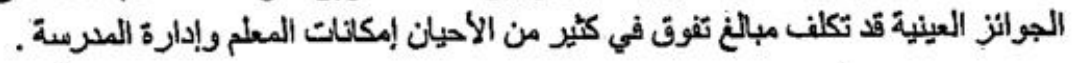

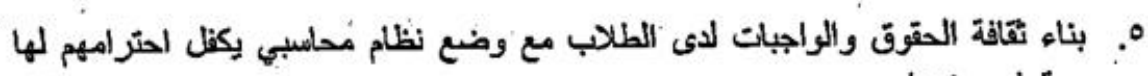
ووقوفهم عندها.

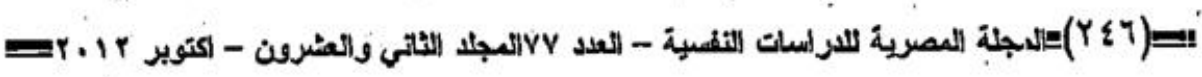


|

أهمية الدراسة :

تثبع أهمبة الارامة في كونها :

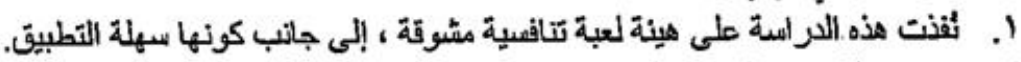

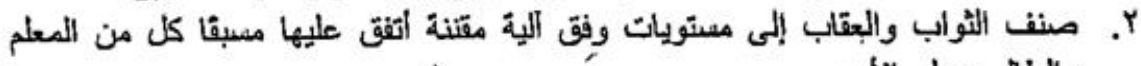

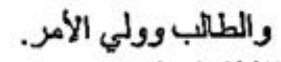

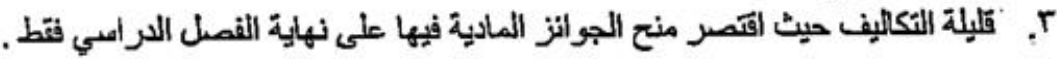

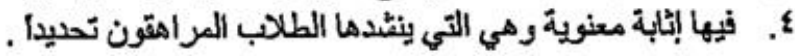

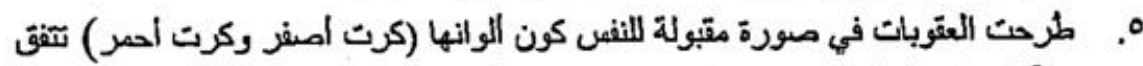

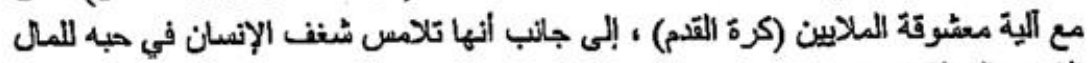

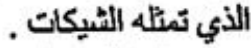

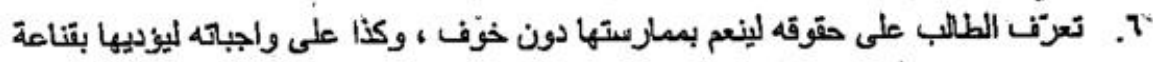

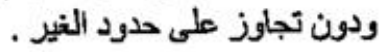

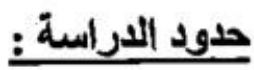

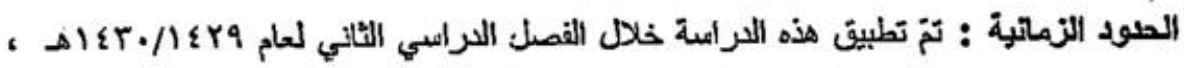

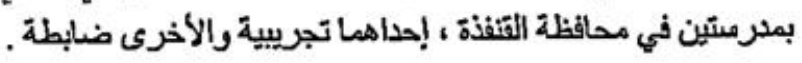

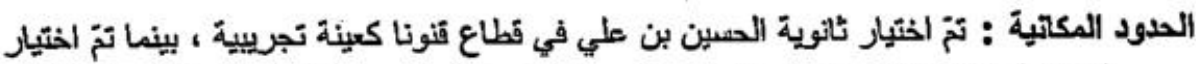

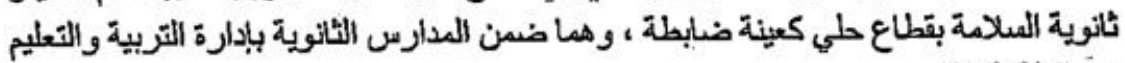
بمحافظة التففذة . الحدود الموضوعية : التصرت هذه الدراسة على قياس الثر التعزيز المترج (الثواب والعقاب)

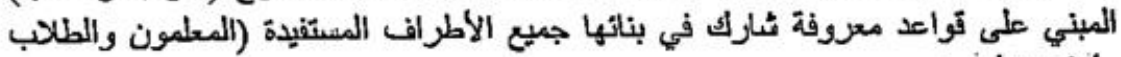
والولياء الأمور) .

\section{مصطلحات الإراسة:}

التعزيز المتلرج : ونعني به ما جاء في هذه العراسة من تصنيف للأواب إلى ثلاثلة مستويات عاله

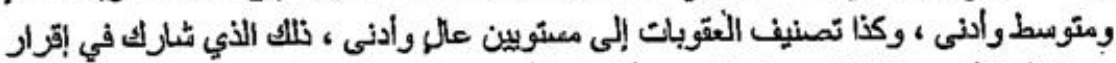

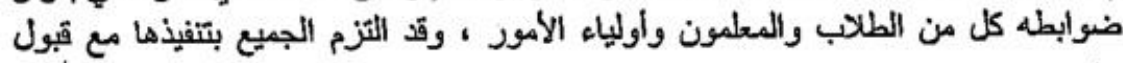

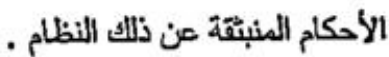

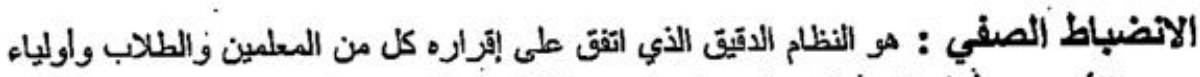

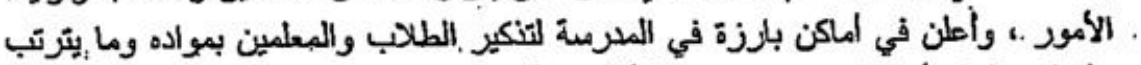

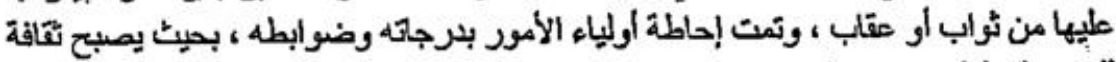

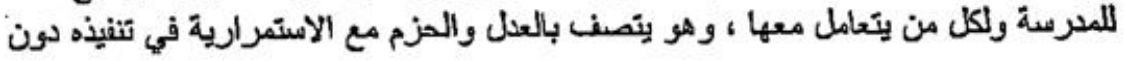

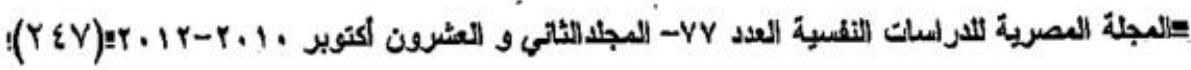




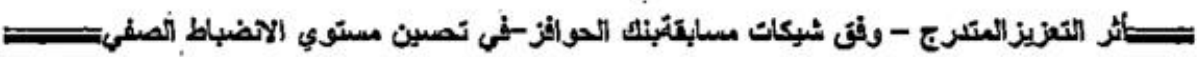

تراخ أو مجاملة أو جور ، ويقصد به الباحث : ان يكون متوسط ممارسات المبلوكات الإيجابية

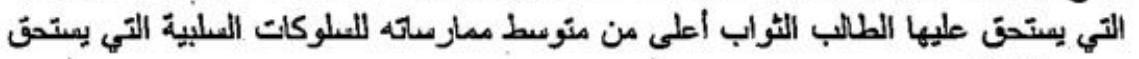
بموجبها العقاب .

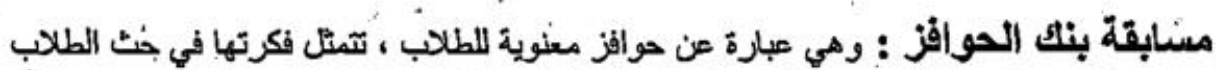

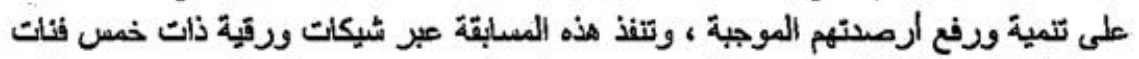

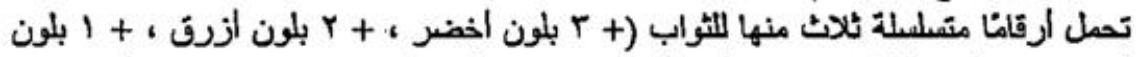

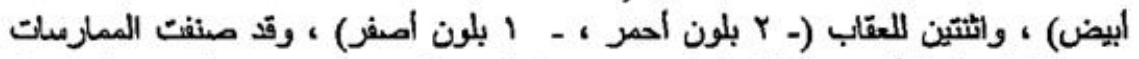

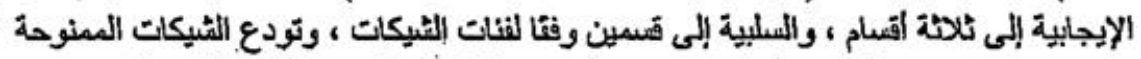

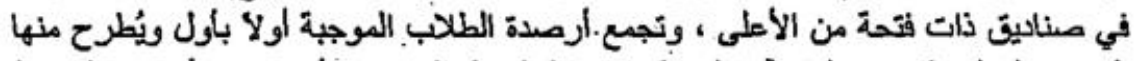

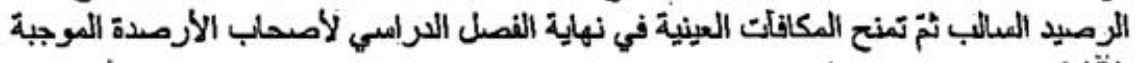
الغتالية.

\section{: الإطلار التطري}

يحمن بنا أن نفف عند بعض المصطلحات التي تفضي أو ذات العلاقة بالانضباط الجفي ، وذلك كما يلي :

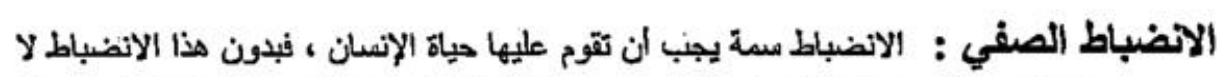

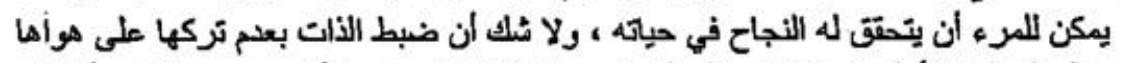

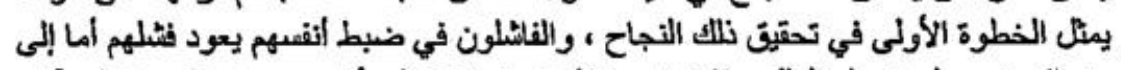

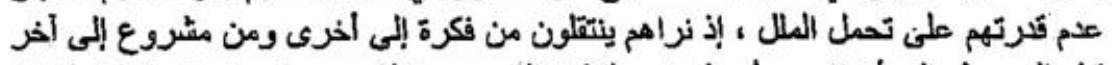

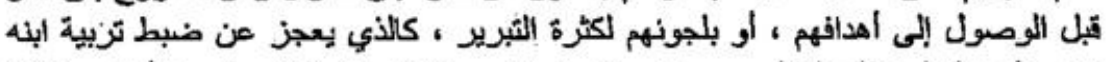

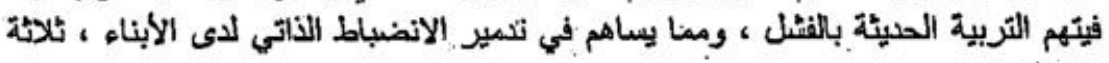

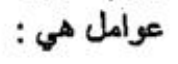

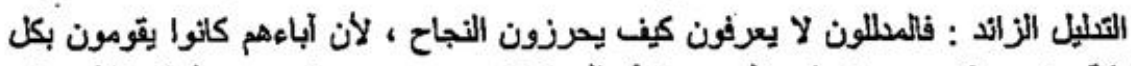

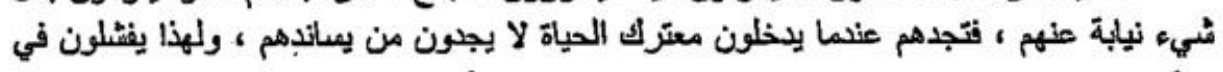
حياتهم.

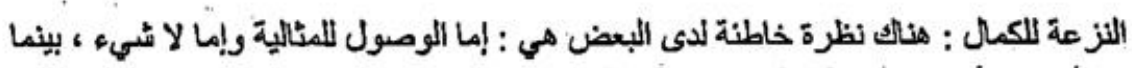

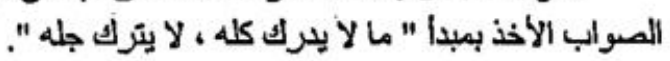

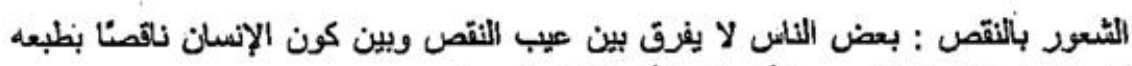

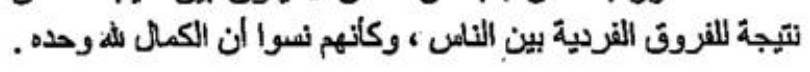

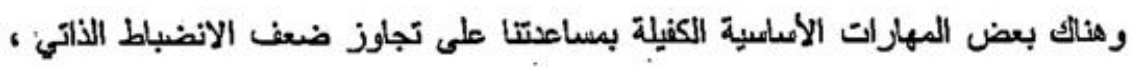
وهي: تحديد الهدف ، معرفة الالم والمتعة ، التعود على مواجهة المشاكل ، مراجعة القيم و المبادى ،

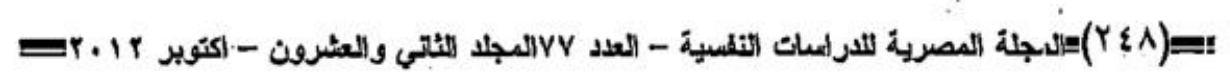


.د/ علي أحد صن الشيخي/|=

التخلص من العادات السلبية ، التعرف على نواحي القوة والضعف في الأات ، التعلم من الأخطاء .

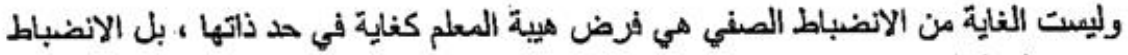

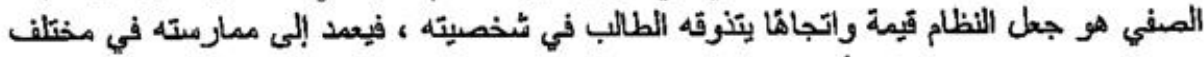

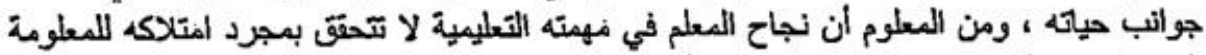

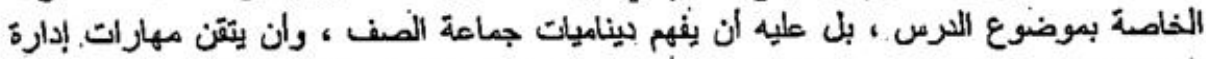

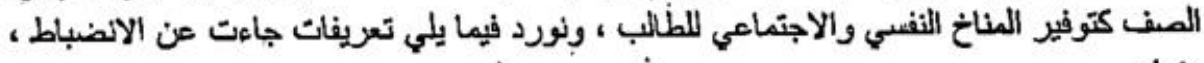
منها:

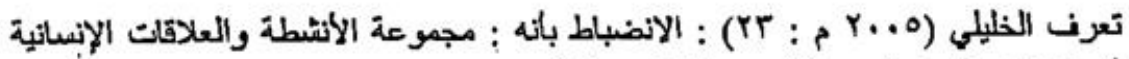

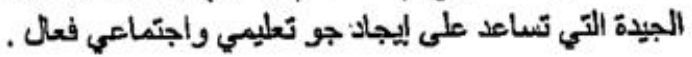

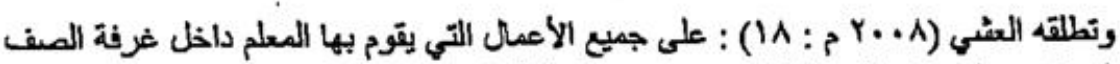

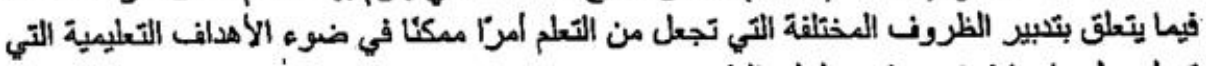

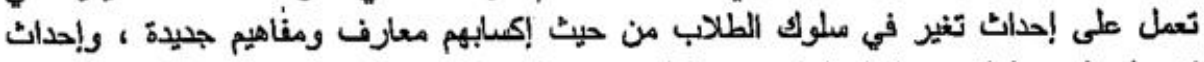
تنييرات في مهاراتهم ويناء اتجاهات إيجابية لديهم وتنمية ميولهم .

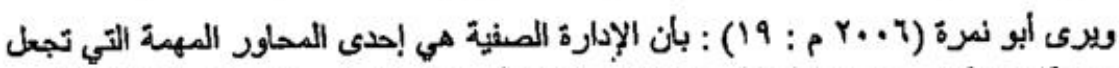

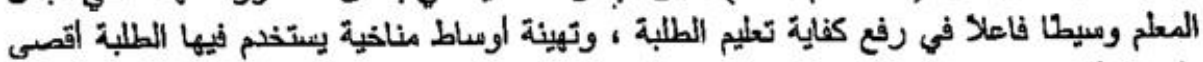

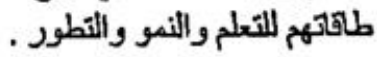

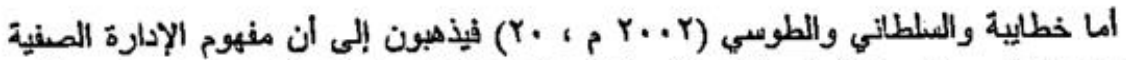

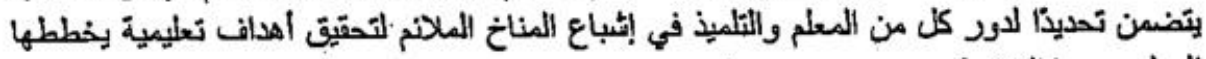
المعلم ويعيها المتلاميذ .

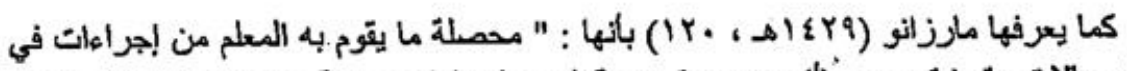

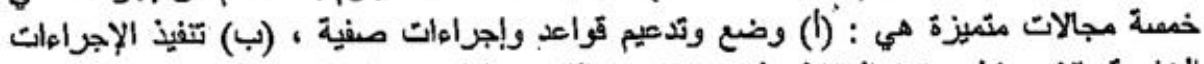

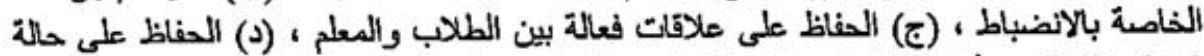

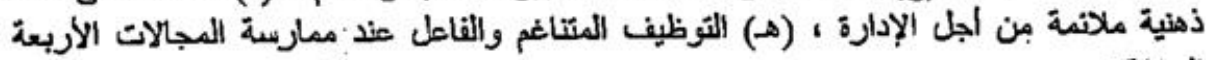
السبقة".

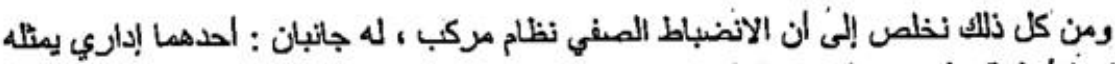

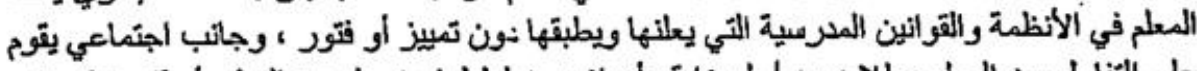

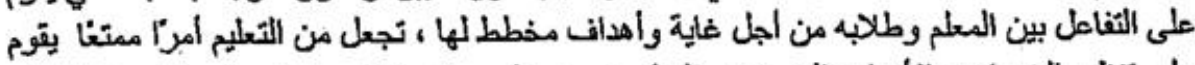

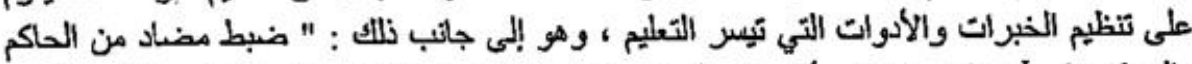

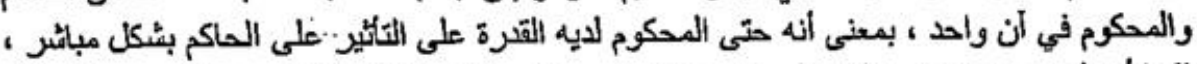

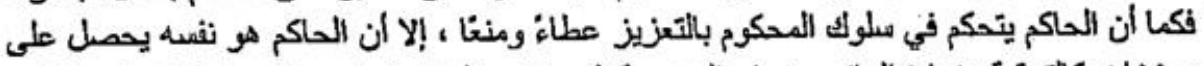

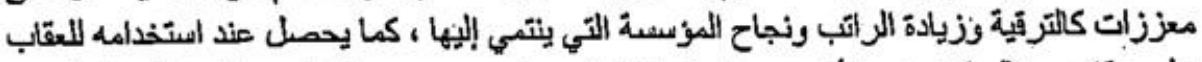

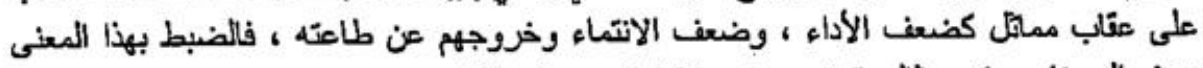

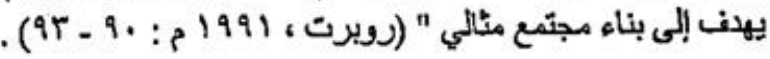

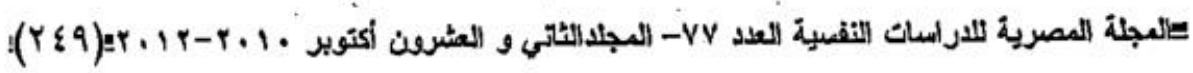




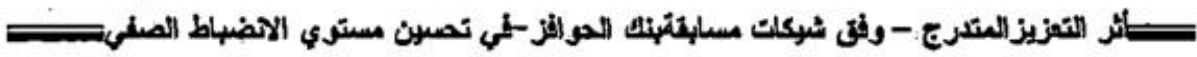

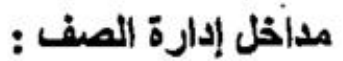

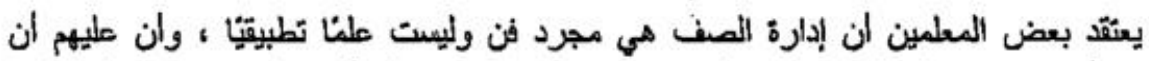

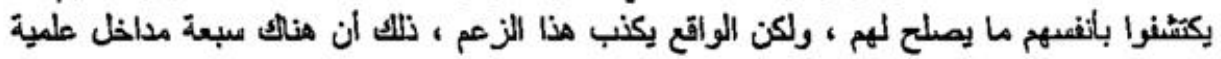

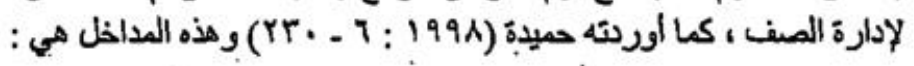

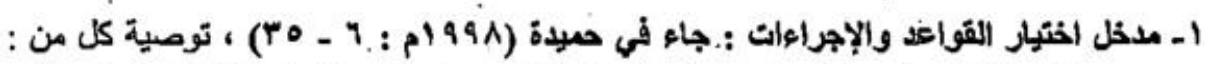

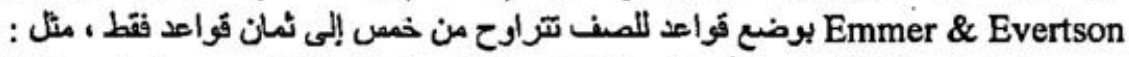

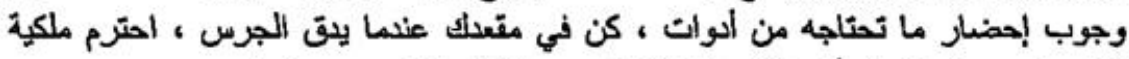

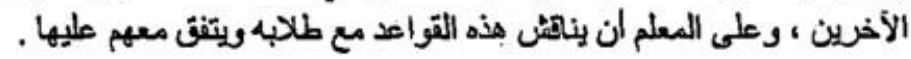

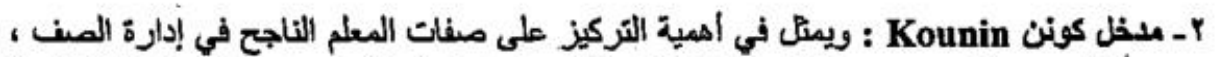

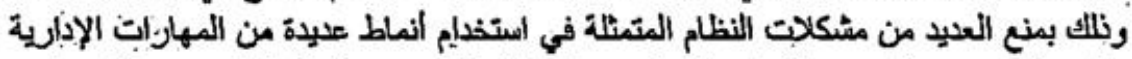

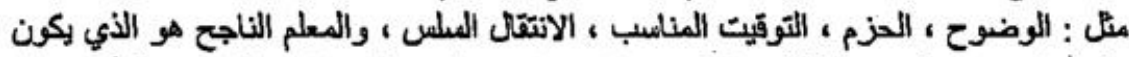

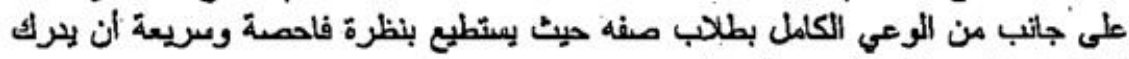

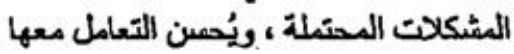

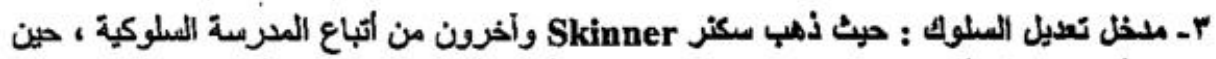

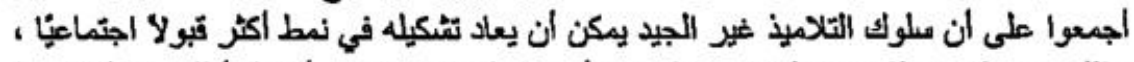

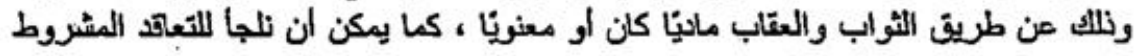

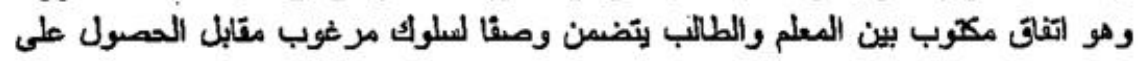

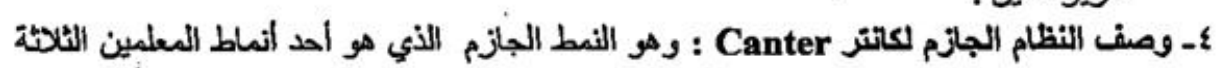

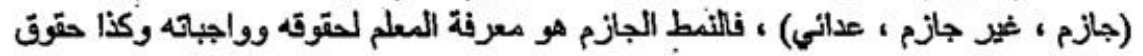

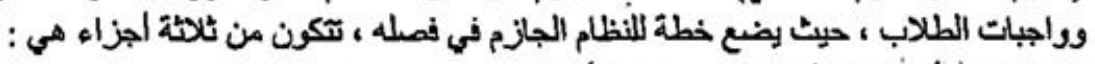

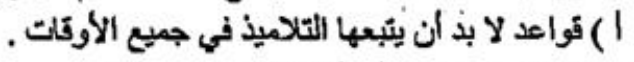

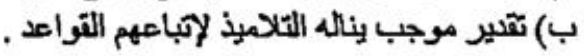

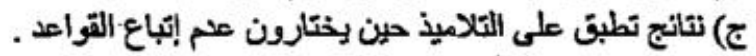

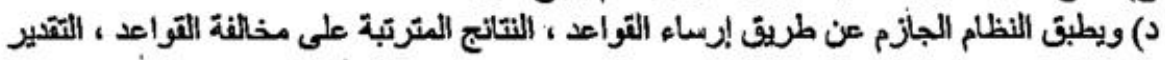

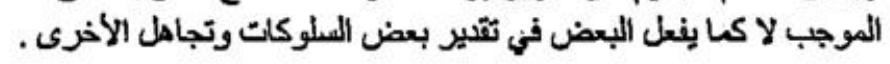

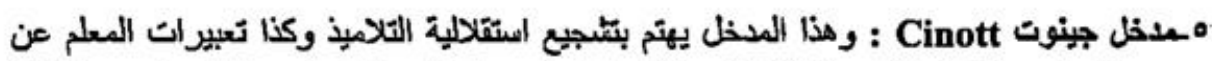

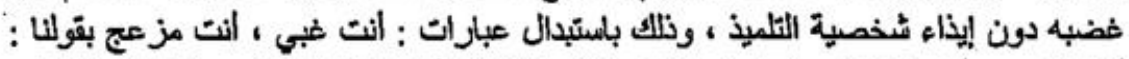

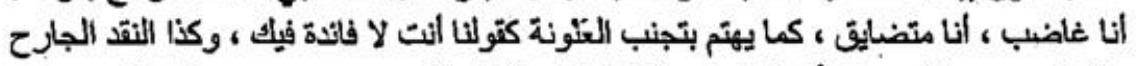

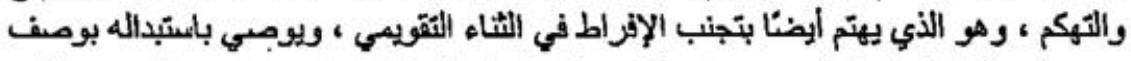

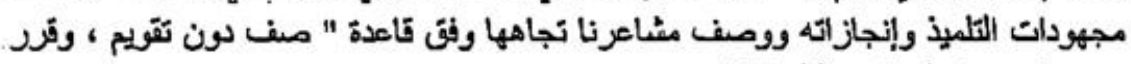
دون حكم ، واترك تقويم الثلميذ لنفسه

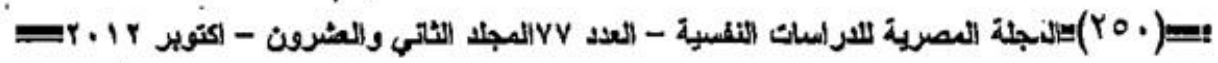


T- مدلل بودلف Rudolf : ويتمثل هذا المدلل في مساعدة التلاميذ على تغيير اهدافهم الخاطنة

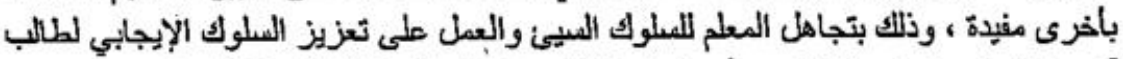

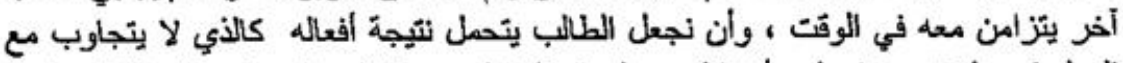

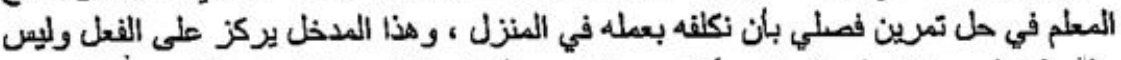

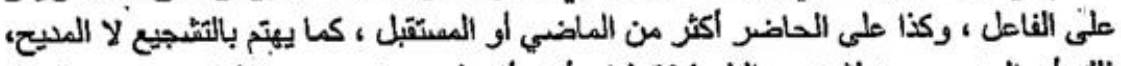

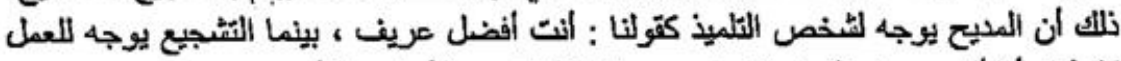

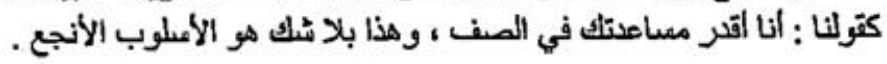

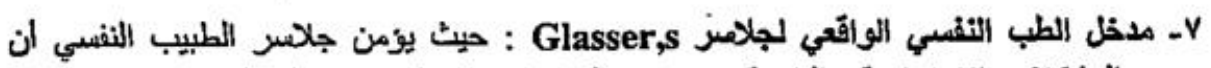

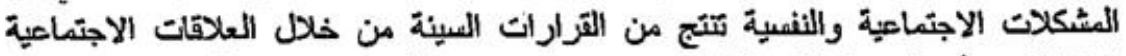

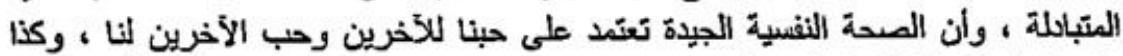

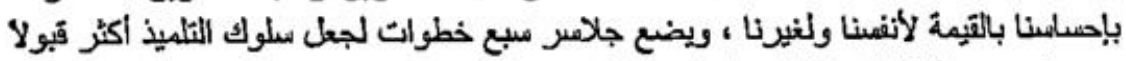

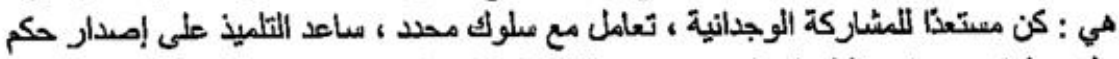

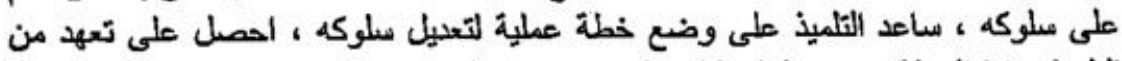

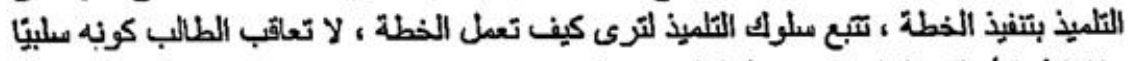

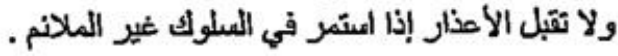

الثواب والعقاب من منظور نظريات علم النفس :

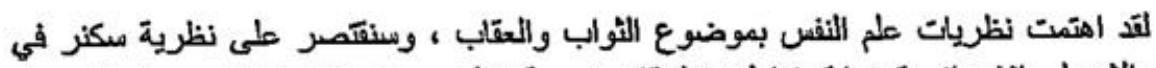

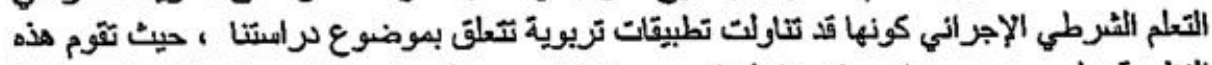

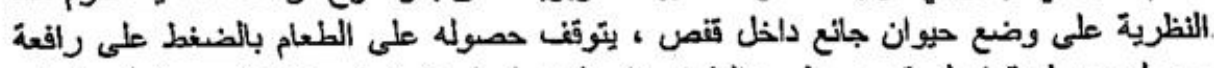

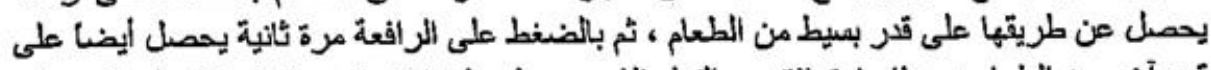

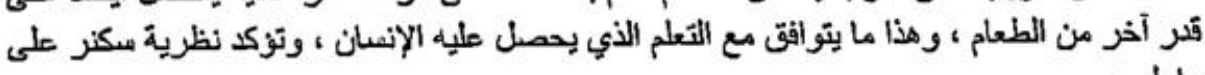
ما يلبي : • ثقل الاستجابة صندما تثل حاجة المفحوص اللتعزيز (حيوان جانع وأخر شبعان) .

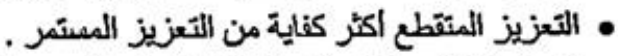

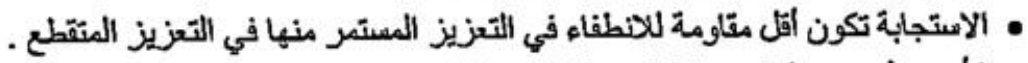

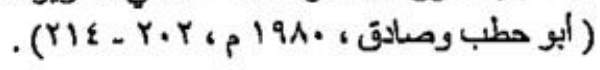

جذاول التعزيز :

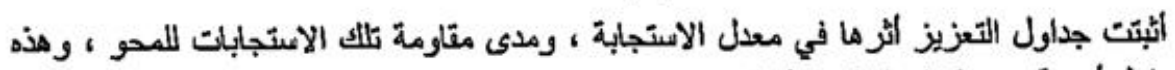

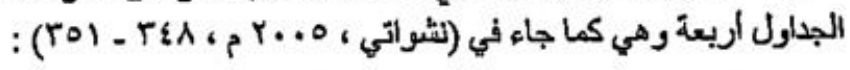

الم جدل التعزيز النسبي الثابت : حيث يتم التعزيز بعد عدد ثابت ، كتزيز الإجابة الثماثة

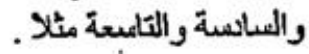

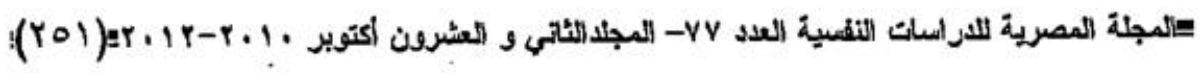




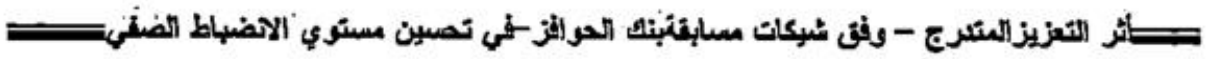

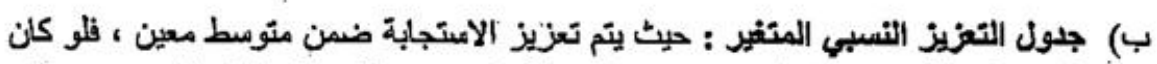

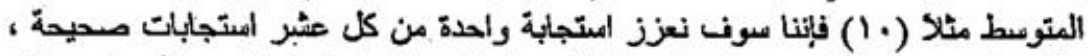

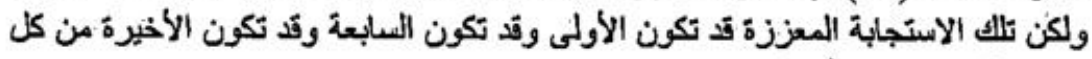

$$
\text { مجموعة مناك. }
$$

ج) جول التمزيز الزمنه الثابت : يتم التعزيز في هذا الجلول خسب فترات زمنية ثابتة ، كساعة او أعبوع أو ثهر .... ، مثلا .

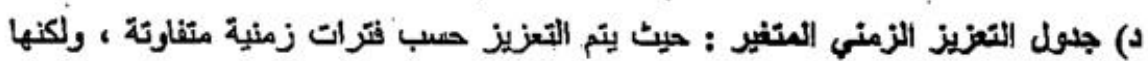

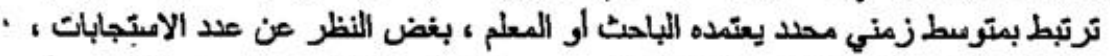

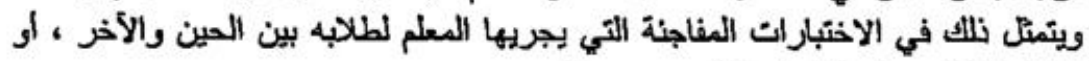

$$
\text { . - اختيار الطالب بطريقة عشبوانية . }
$$

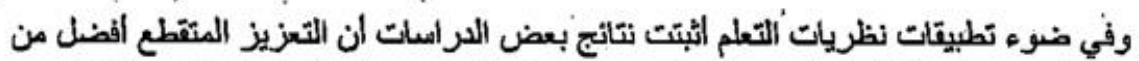

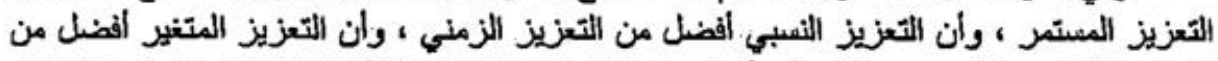

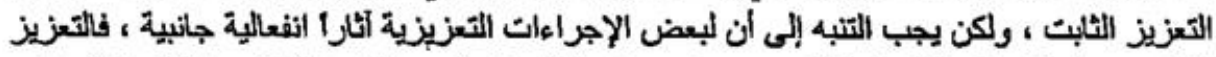

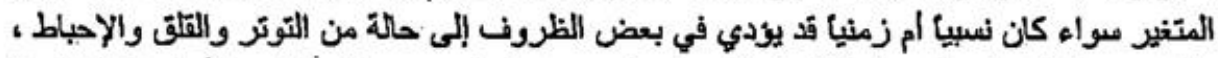

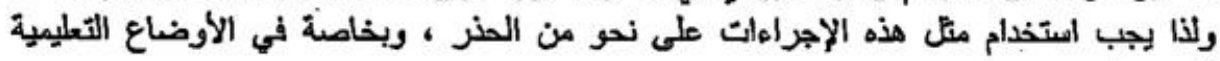
المدربية.

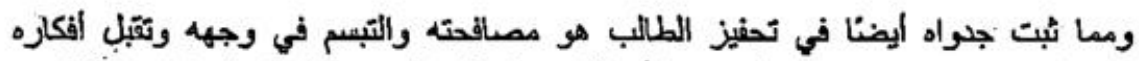

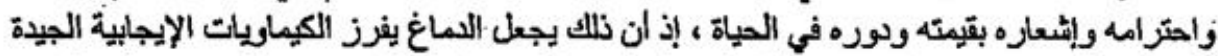

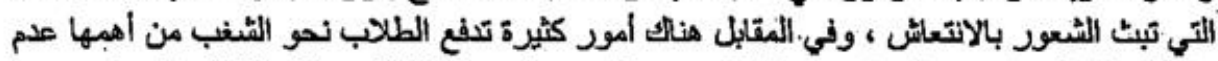

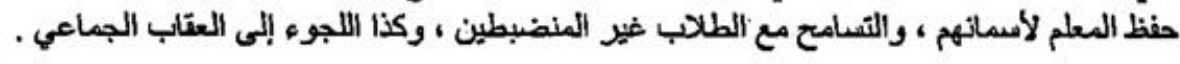

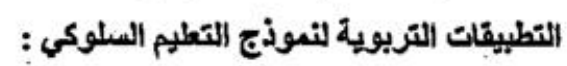

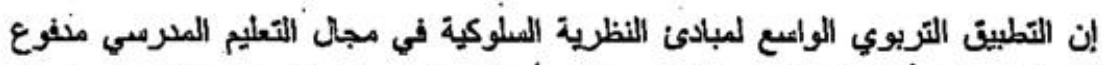

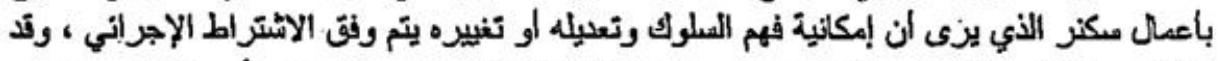

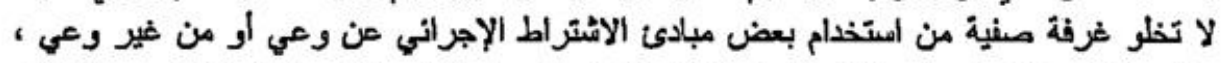

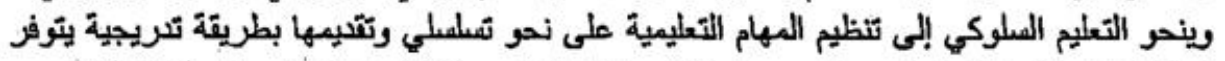

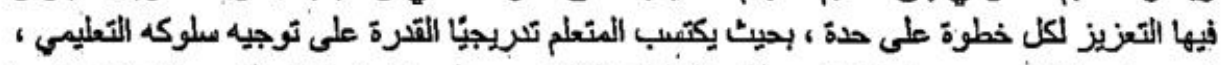

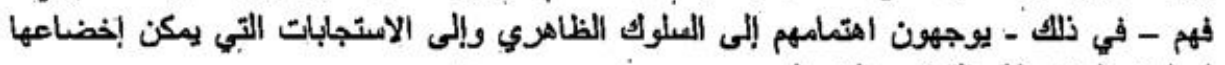
لعمليات الملاحظة والقياس و الضبط.

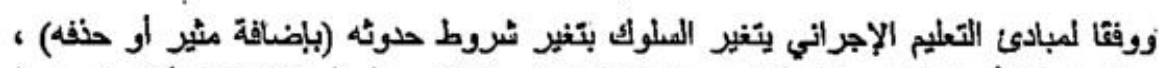

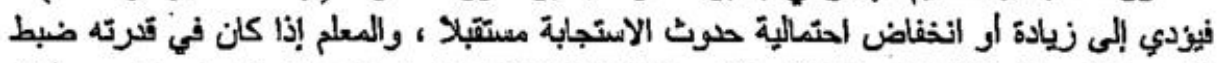

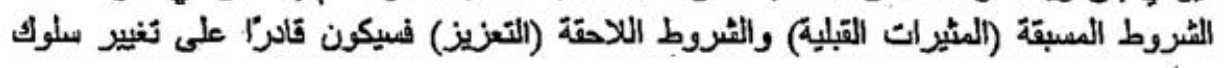

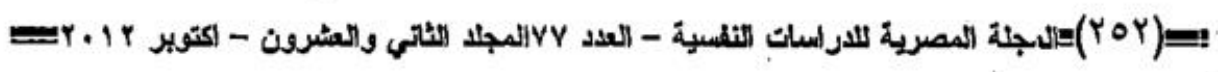


1.

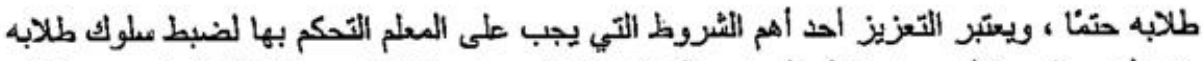

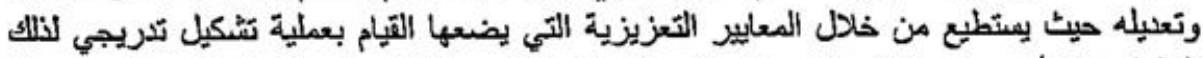

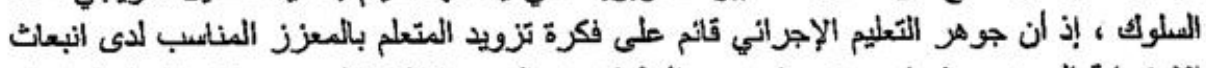

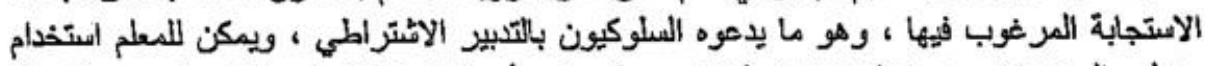

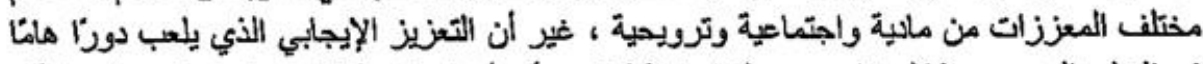

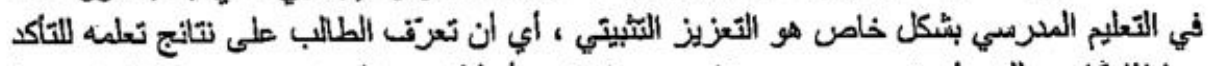

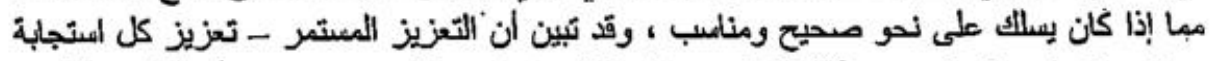

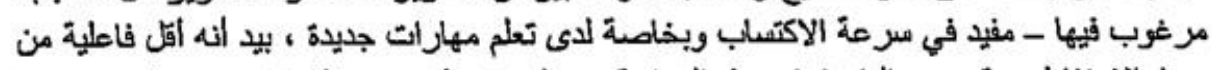

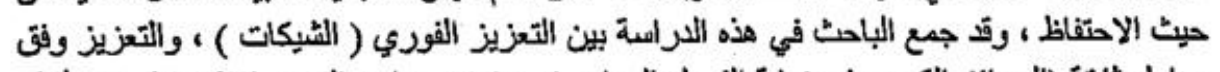

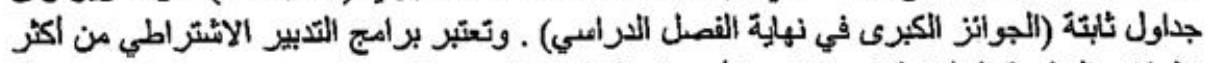

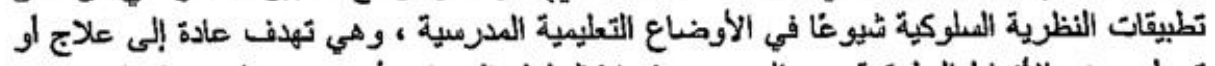

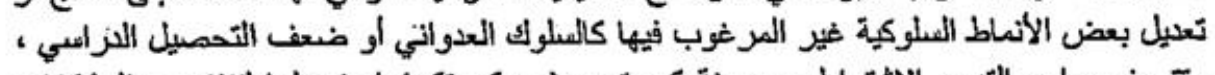

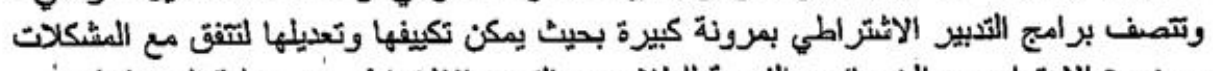

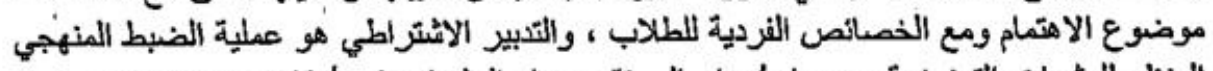

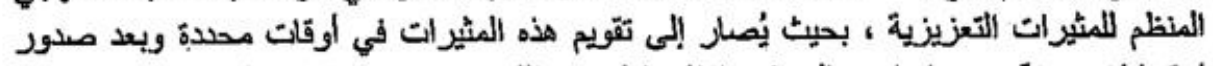

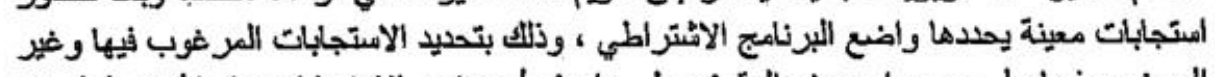

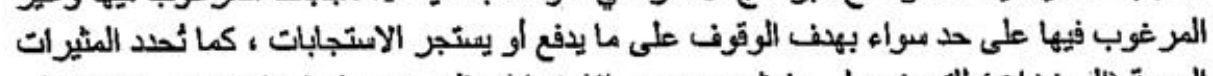

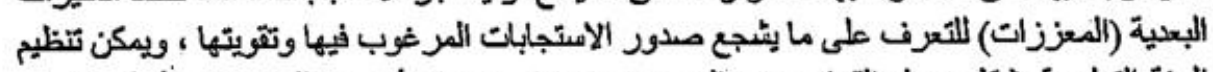

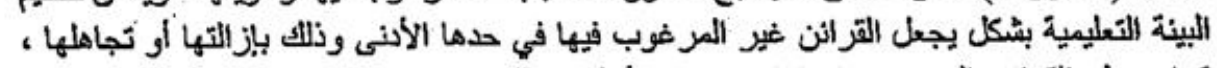

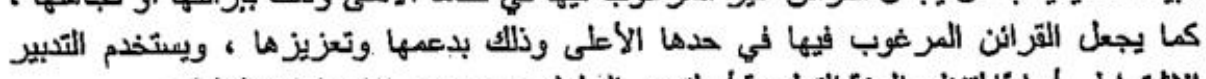

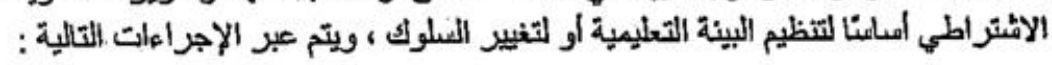

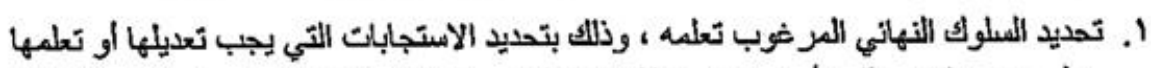

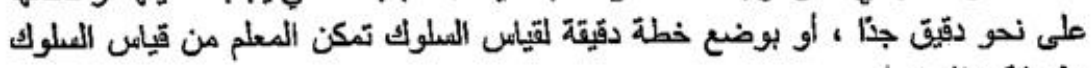

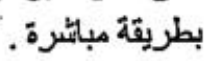

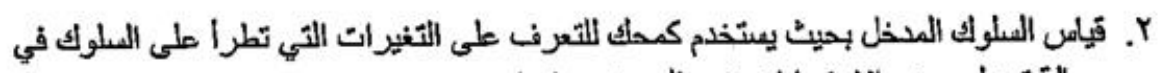

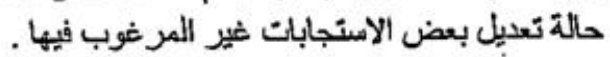

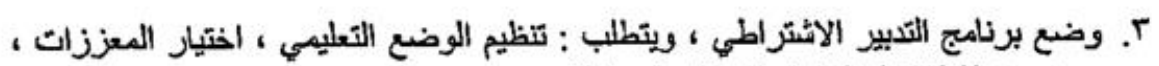

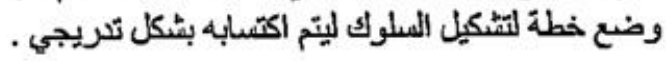

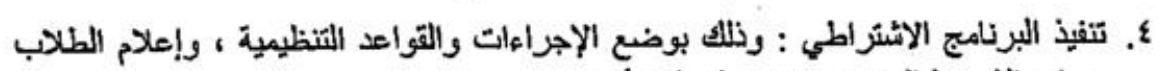

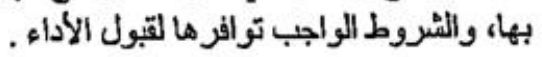

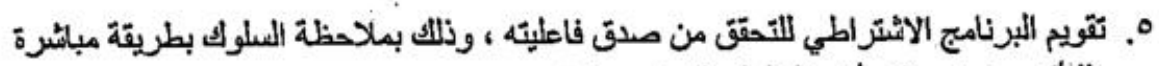

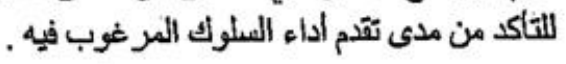

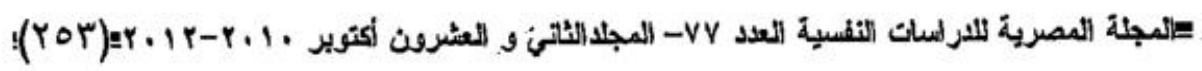




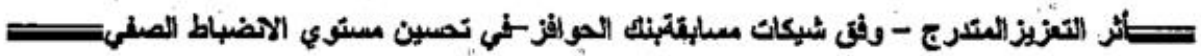

ويعتبر التعليم المبرمج من أكثر التطبيقات التربوية امتخذامًا لمبادئ نظرية بنكثر في التعلم

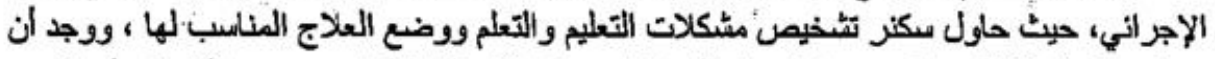

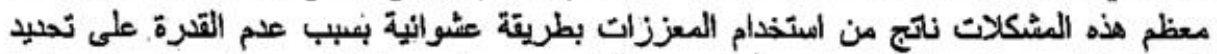

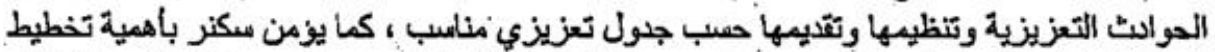

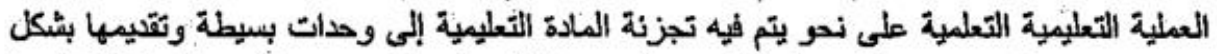

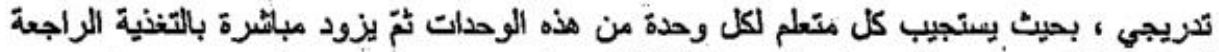

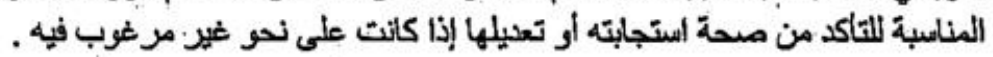

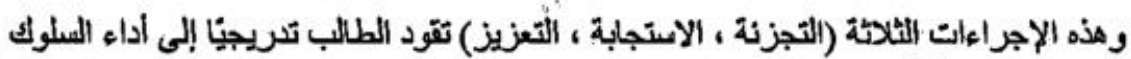

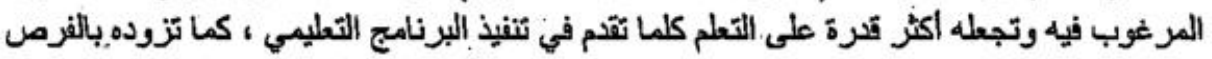

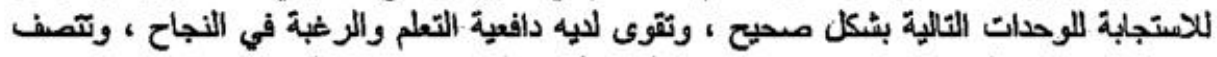

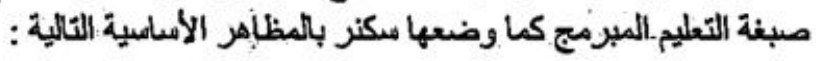
1 أجزنة المادة إلى وحدات بسيطة ، وترتينها وتقيمها على نحو متسلمل .

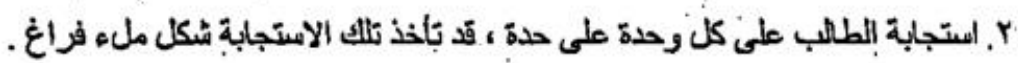

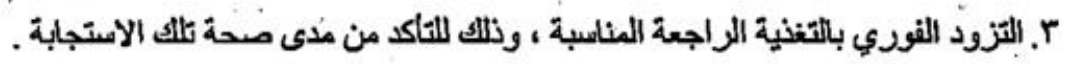

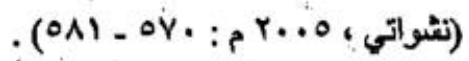

\section{تجارب تربوية في الانضباط الصفى :}

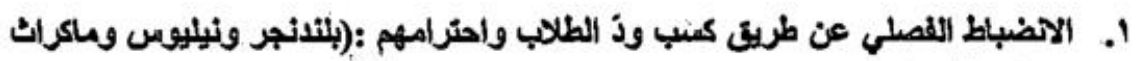

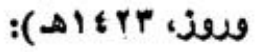

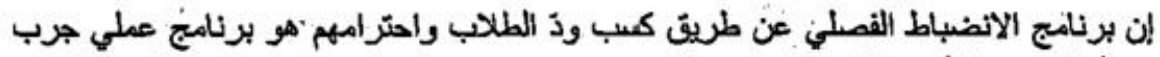

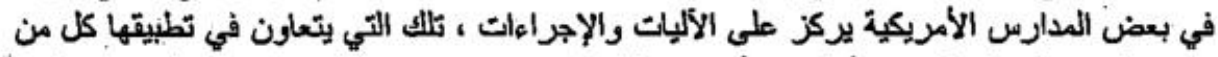

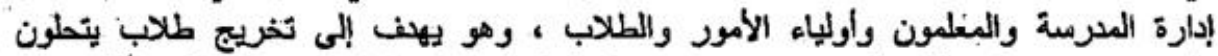

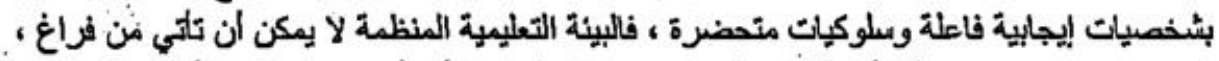

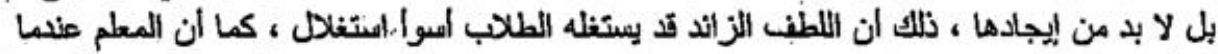

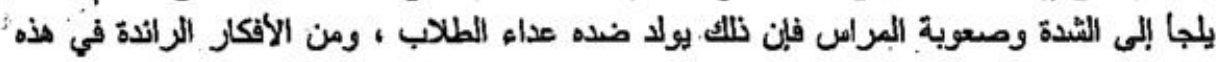

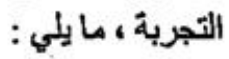

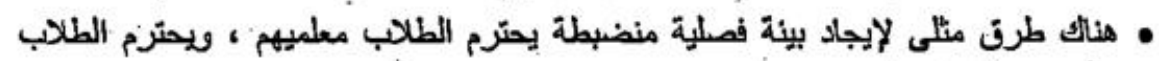
بعضهم البعض .

• إن الانضباط الفصلي لا يقتمر على ما يفعله معلم واحد في فصل بعينه ، وإنما الأمر يمتد.

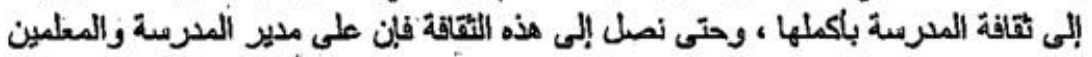

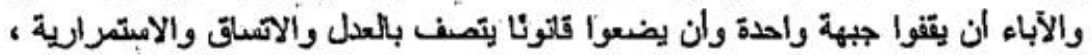

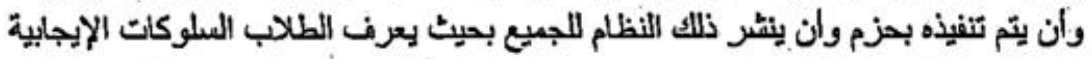

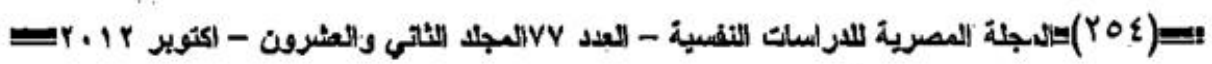


=

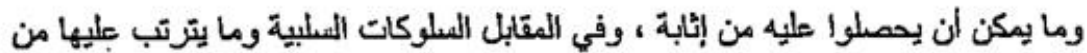

عقوبات عند مخالتتها .

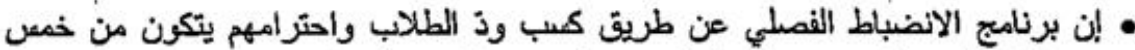

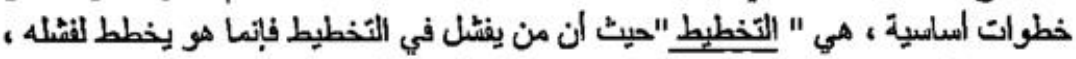

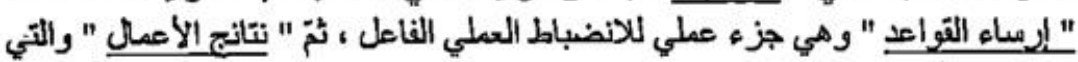

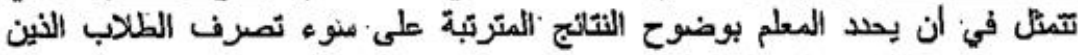

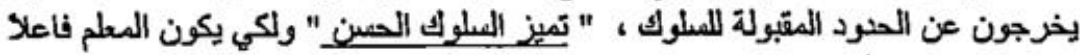

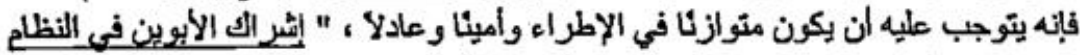

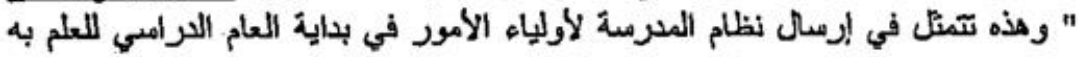

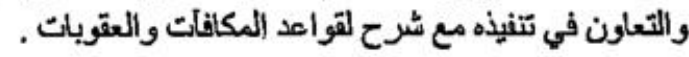

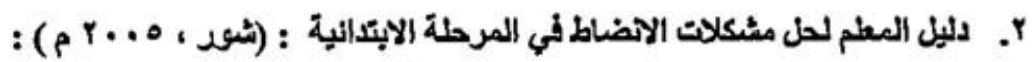

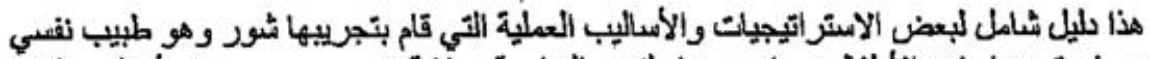

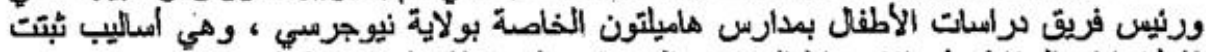

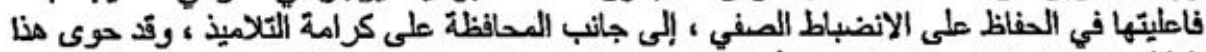

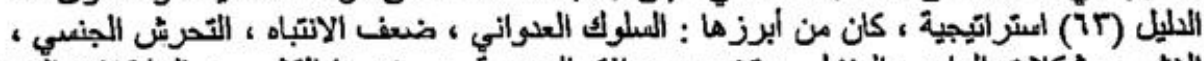

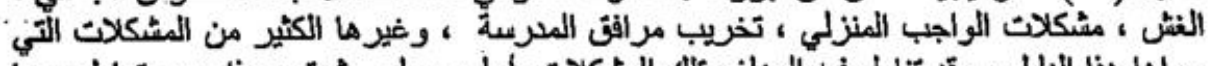

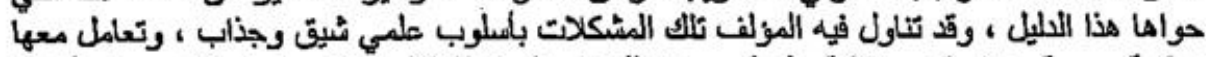

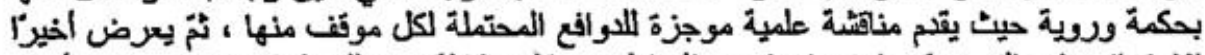

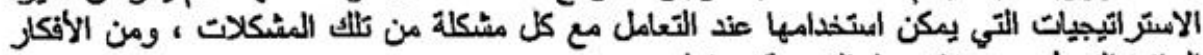

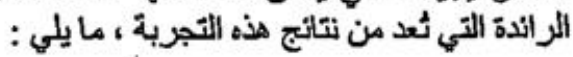

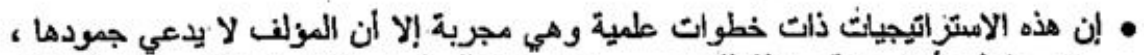

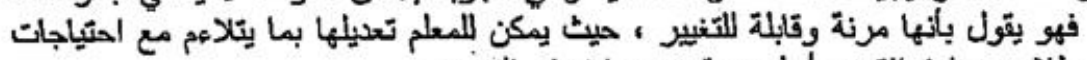

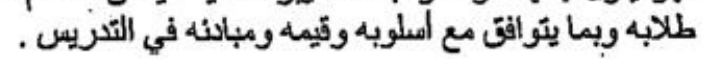

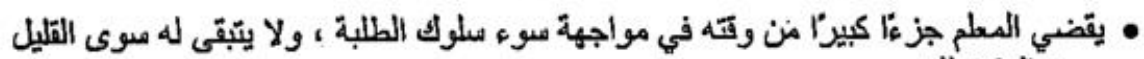
من الوقت للتسريس. • رغم اهمبة الانضباط الصفي إلا أنه يتم تجاهله بند إعداد المعلم في كليات التربية ، وكنا عند تنتئيم البرامج التدريبية . • • عند اختيار الأسلوب المناسب لمواجهة إحدى المثكالات يجب توخي الاعتدال في معالجتها ،

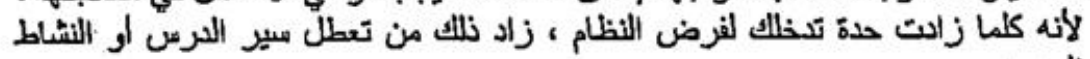
المعرشي. • ليس النظلام لفظا مرادفا للعقاب بالضرورة ، لأنه من خلال الانضباط المدرسي يتم تعلم

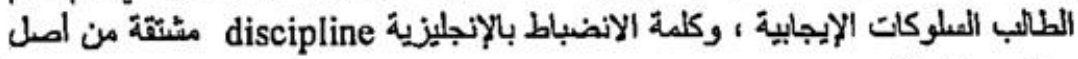
يوناني معناه التكريس .

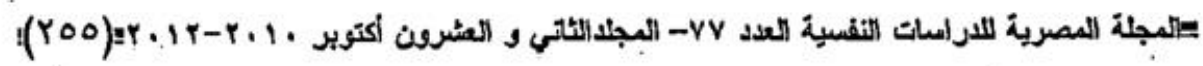




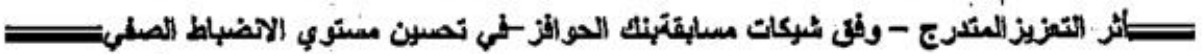

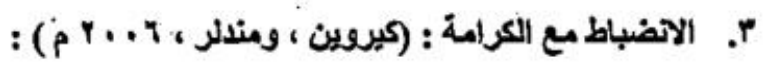

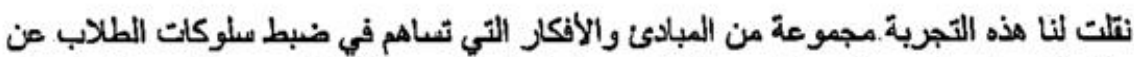

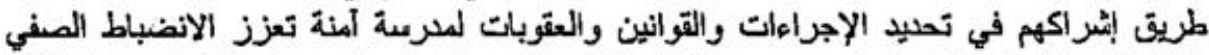

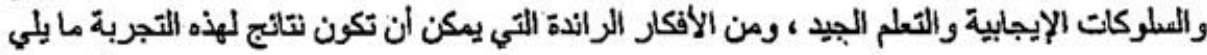

• يجب ان تكون لدينا مدارس آمنة تعزز الكرامة لجميع الطلاب دون استطناء.

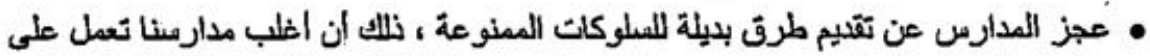

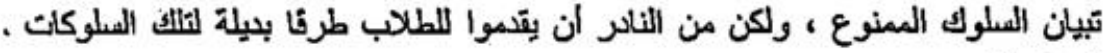

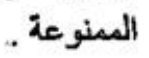

• برنامج الضبط يجب ان يُتمل على الأهداف والمبادى والقوانين وإجراءات التطبيق

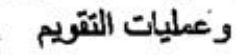

$$
\text { • عملية الانضبلط الصفي لها ثلاثية أبعاد هي : الوقاية ، الإجراءات ، القرار . }
$$

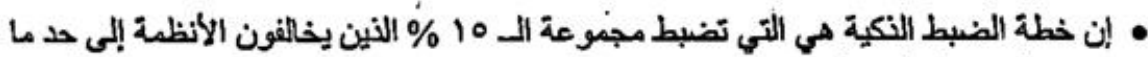

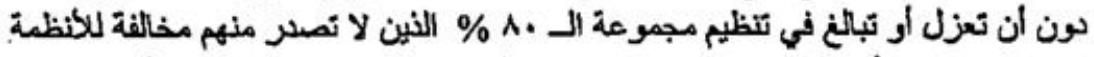

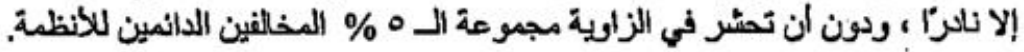

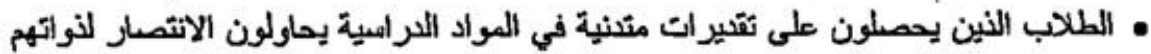

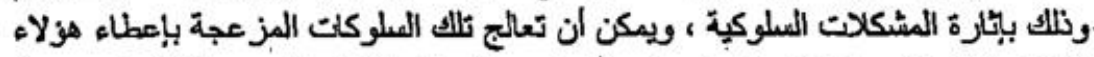

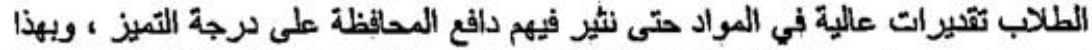

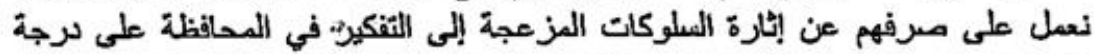

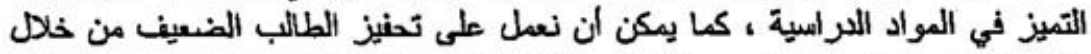

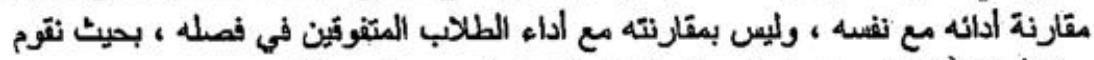

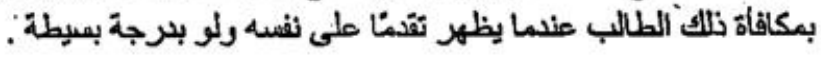

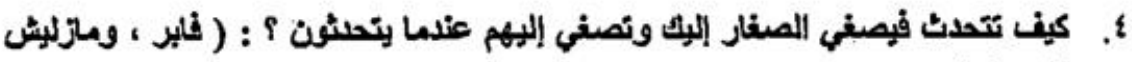

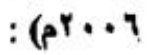

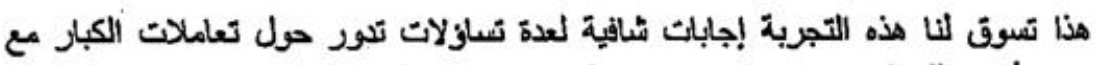

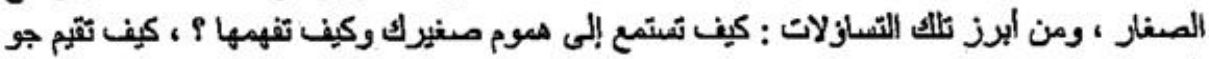

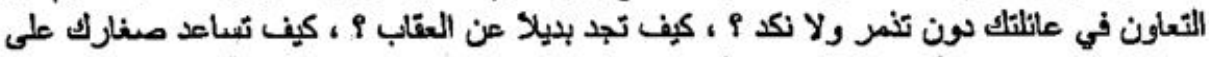

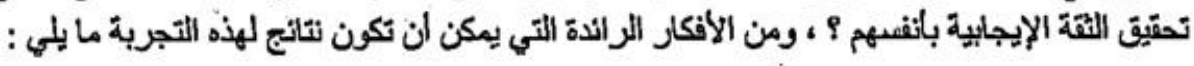

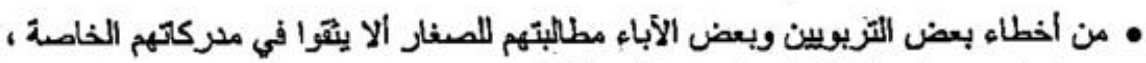
وإنما يجب عليهم الاعتماد على مدركات الكبار . . • ما يحتاجه الناس في جميع الأعمار في لمظة الضيق ليس موافقة الأخرين او مخالفته ، بل

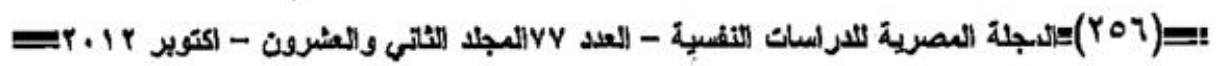




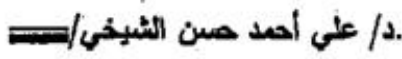

$$
\text { يحتاجون إلى من يعترن بما يعانون . }
$$

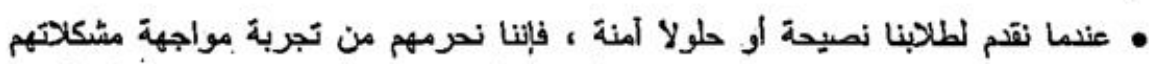

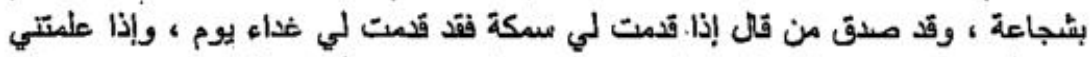

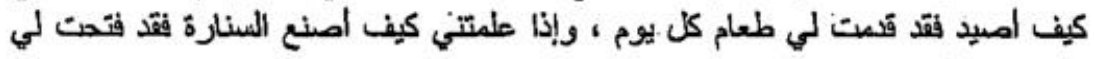
طريقا إلى الثراء.

• افتح سلة لأماني الطفل ومجل بها كل أمانيه ، فهذا سيخديا من روزعه في حالة هيجانه.

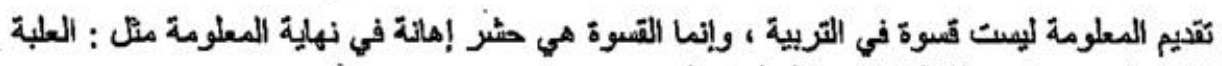
الفار غة توضع في سلة النفايات ، إنكا لن تتعلم . • لكي تكسب استجابة الصغار اعطورصفا : مازال الثور في الحمام منارًا ، أو إعط معلومات :

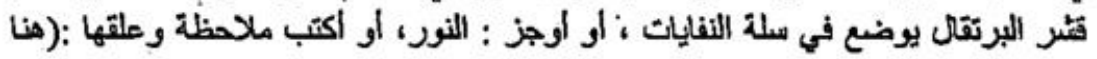
توضع المخلفات )

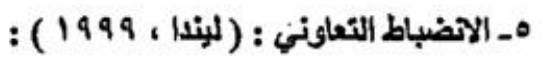

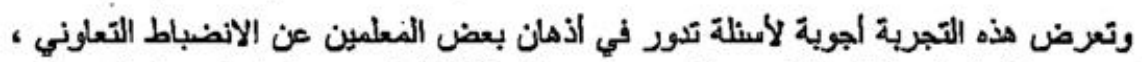

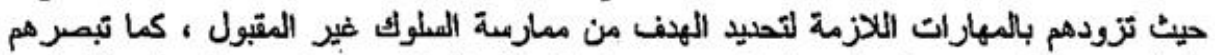

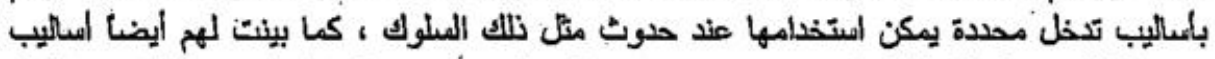

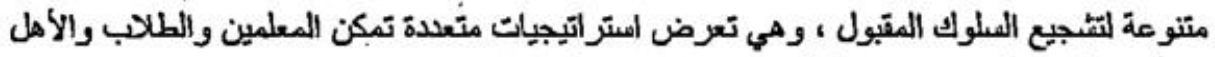

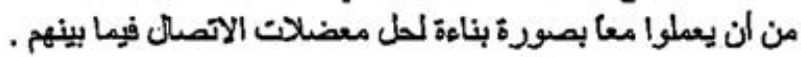
دراسات سابقة : من انسورة

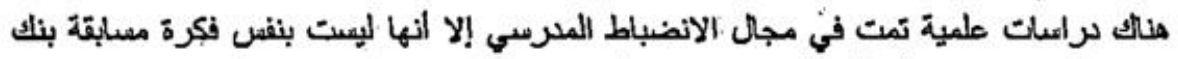

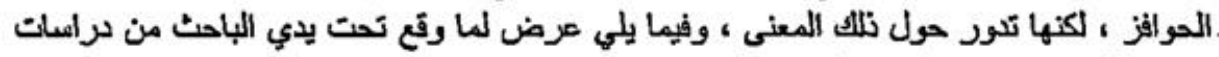

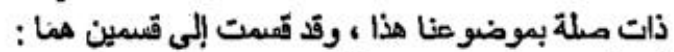

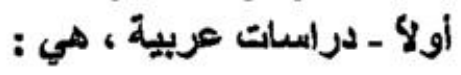

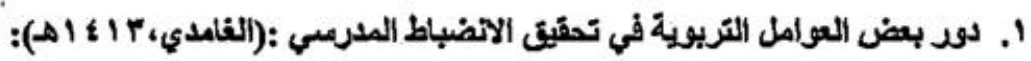

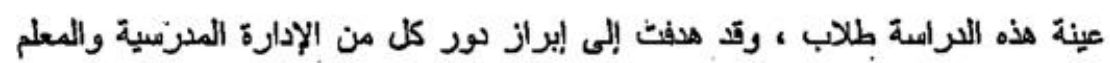

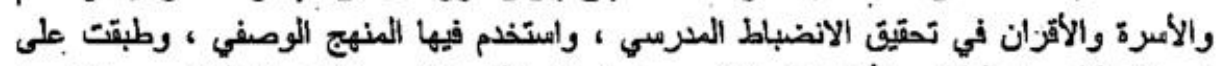

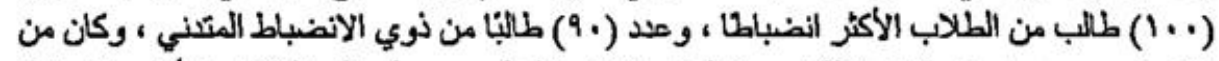

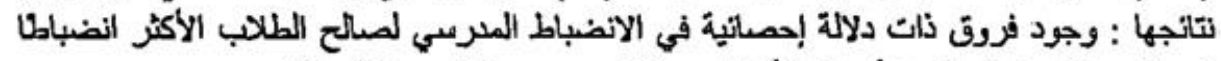

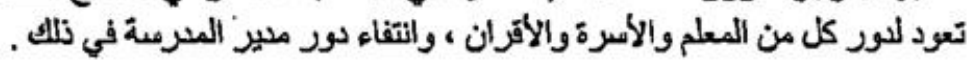

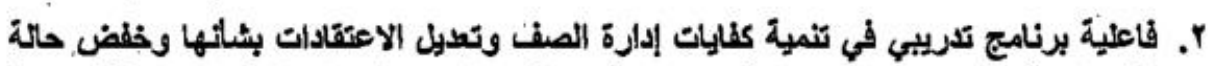

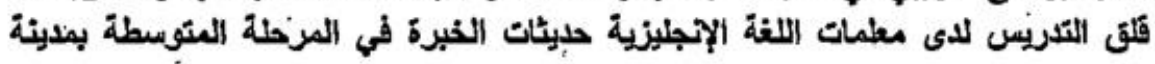

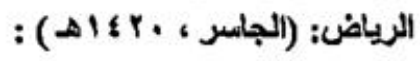

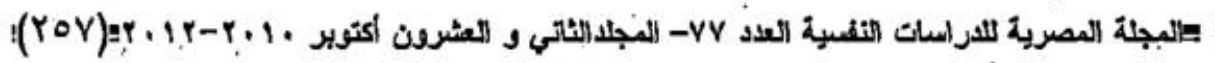




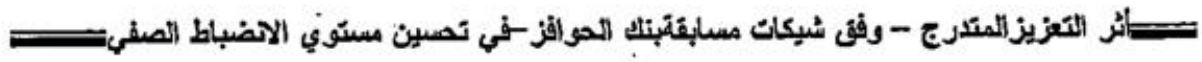

عينة هذه الدراسة معلمات ، وهدت إلى استقصاء فاعلية برنامج تدريبي في تنمية كفايات

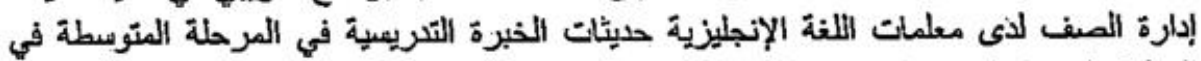

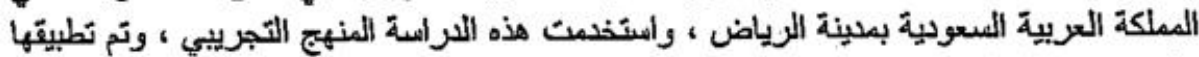

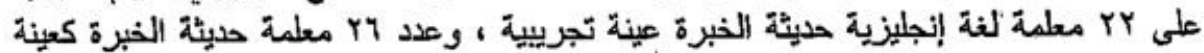
ضابطة ، وقد توصلت الدراسة إلى نتائج منها : وجود فروق دالة إحصانيّا في منغيز كفايات إدارة

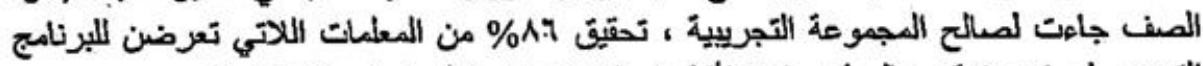
التريبي لمستوى تمكن عالم بلغ •^^\% فاكثر في كفايات إدارة الصف في الاختبار البعدي . r. درجة ممارسة مهارات إلدارة الصف كما تكركها معلمات التربية الأسرية في المرحلتين

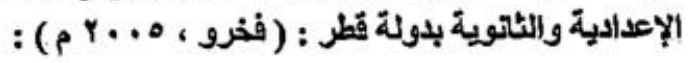

عينة هذه اللرامة معلمات ، ومن اهدافها التعرف على درجة مملرمة مهارات إدارة الصف لدى الصى

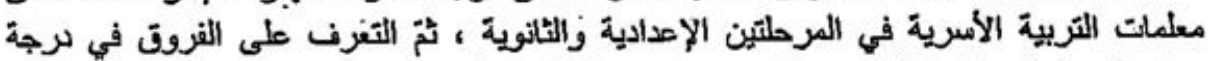

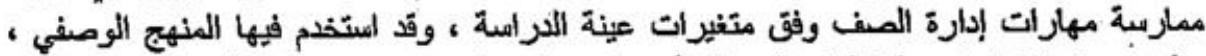

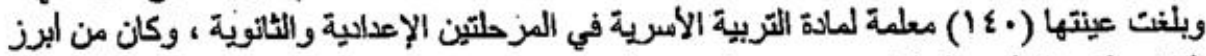

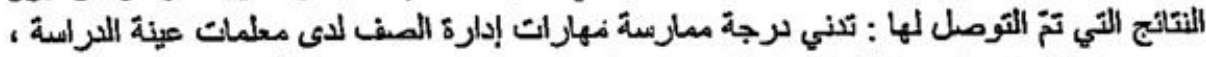

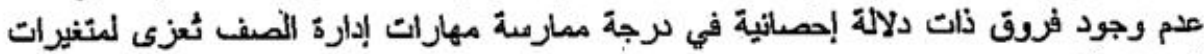
الخبرة و الثخريب ودود

؛. الثر استخدام برامج إدارة الصف الحاسوبية على تحصيل طلاب المرحلة الثانوية: (الصيف ،

$:(\$ 1 \leq Y \mathrm{~V}$

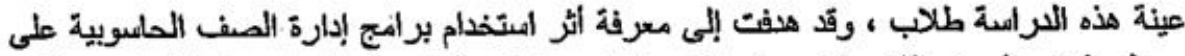

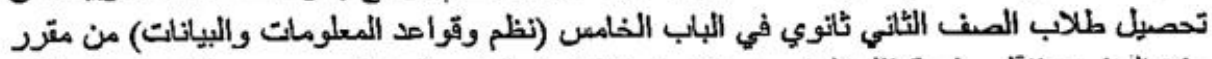

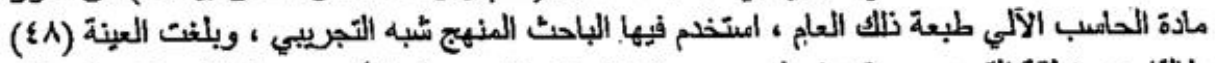

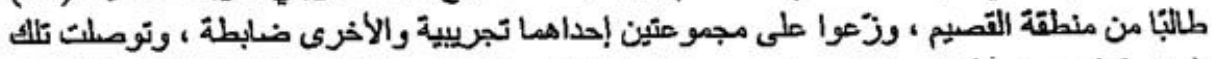

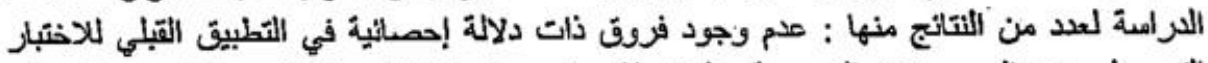

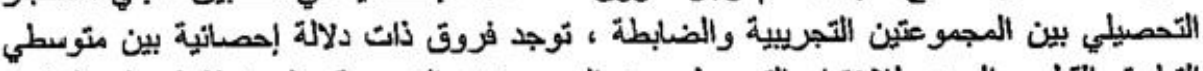

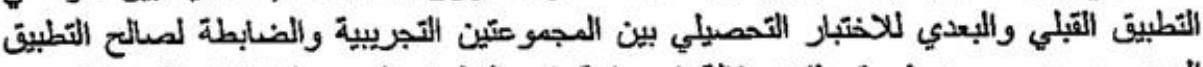
البعدي ، عدم وجود فروق ذات دلالة إحصاتينة في التطبين البعدي للاختبلر التحصيلي بين

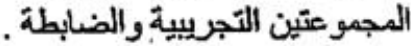

\section{ثانيًا ـ دراسات أجنية}

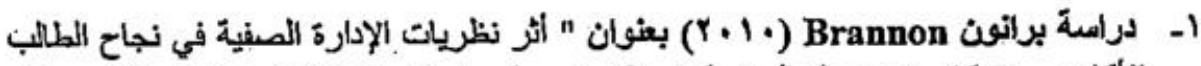

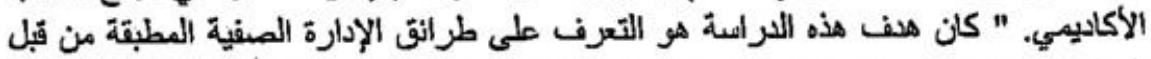

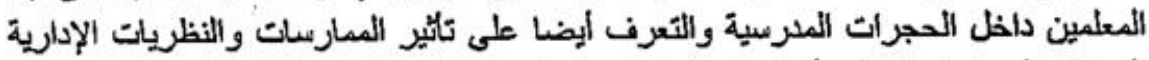

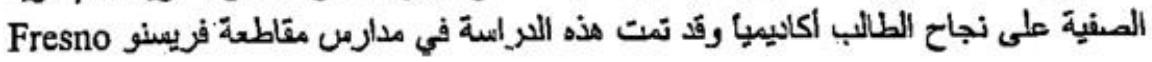

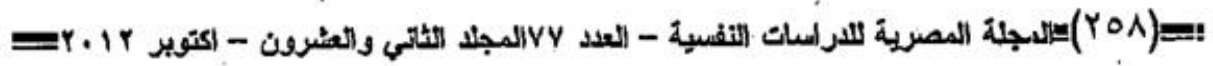




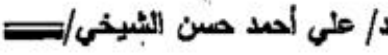

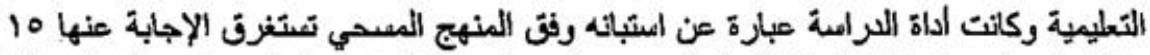

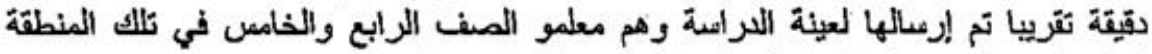

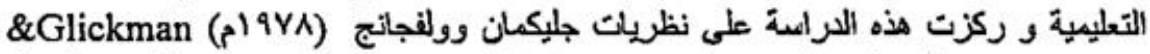

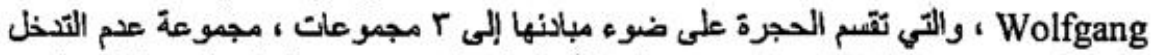

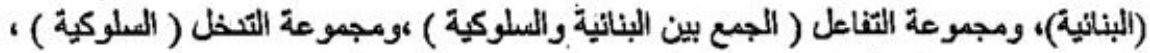

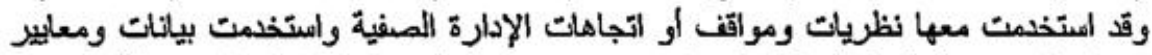
ولاية كاليفورنيا التعليمية ،لتحليل العلاقة بين مبادى الإدارة المفية المطبقة والنجاح الاكاديمي.

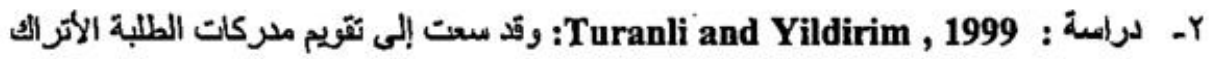

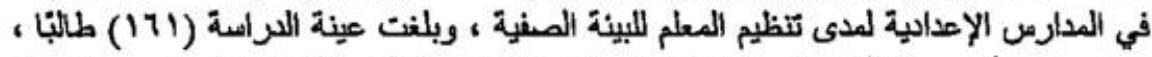

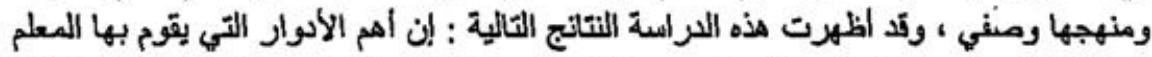

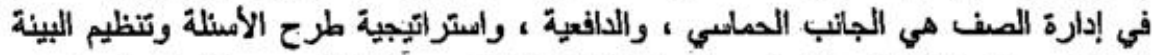

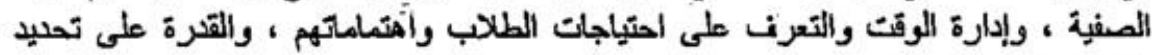
الأهداف التعليمية بوضوح.

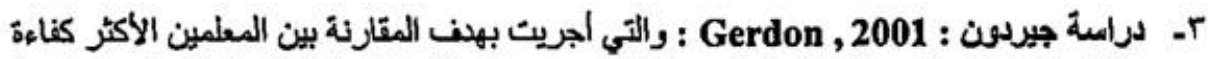

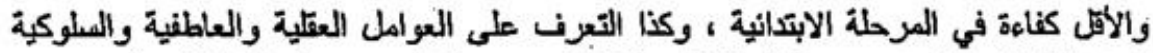

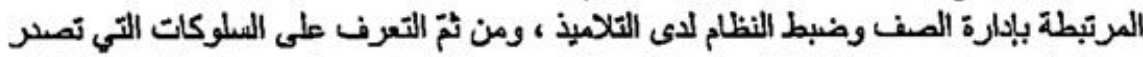

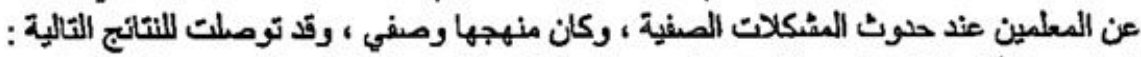

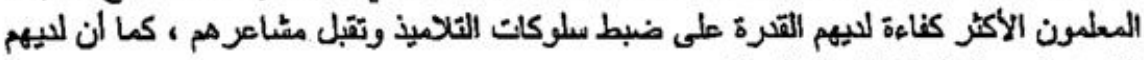

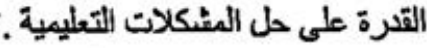

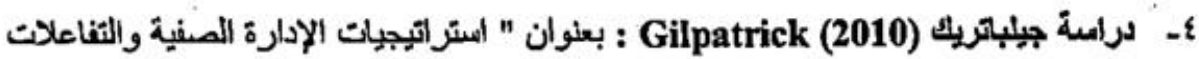

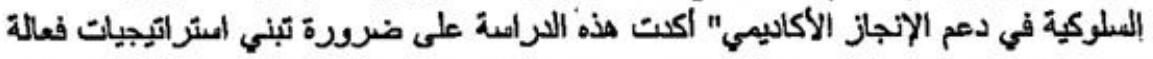

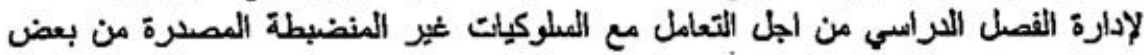

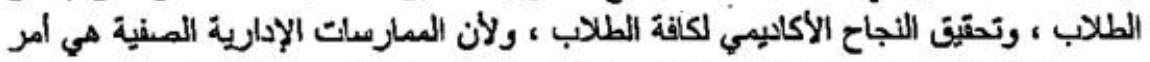

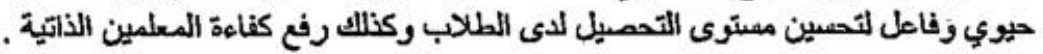
وفي إطار النظرية البنائية يجب إعداد كافة المعلمين وتلبية الحتيلجاتهم المهنية حتى يتم تنريس

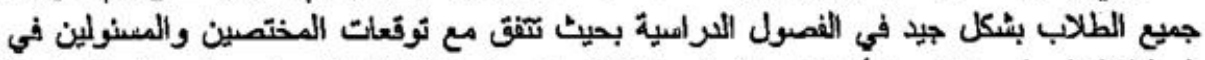

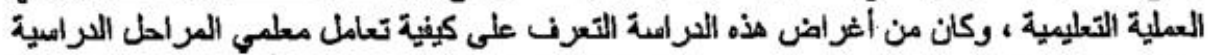

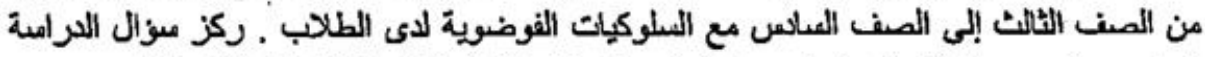

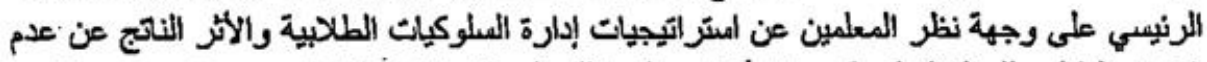

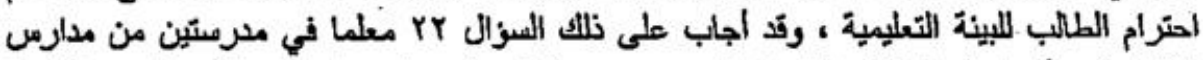

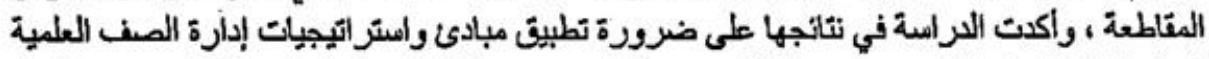

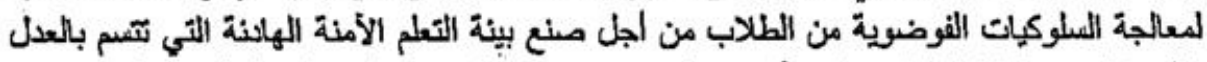

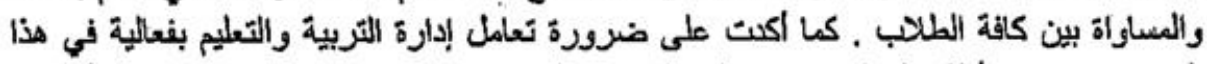

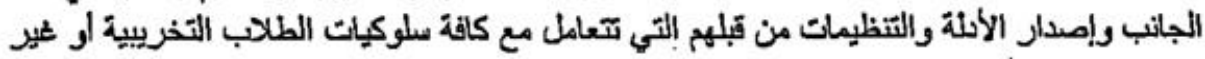

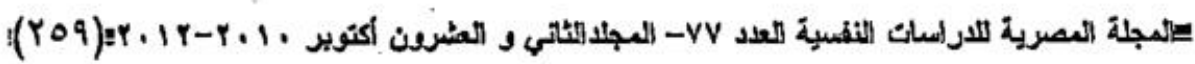




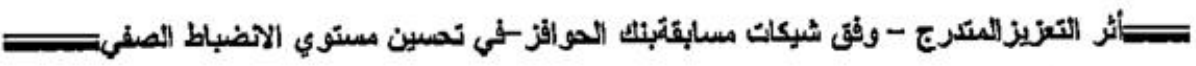

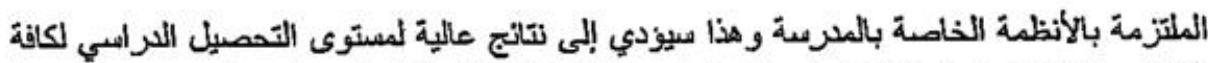

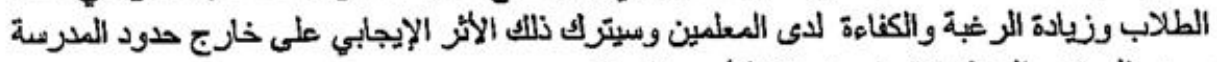

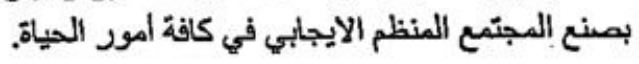

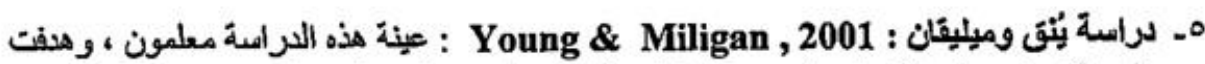

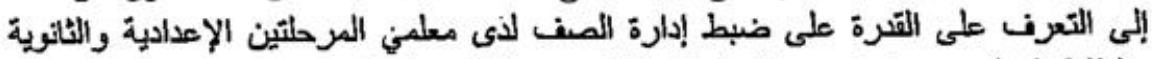

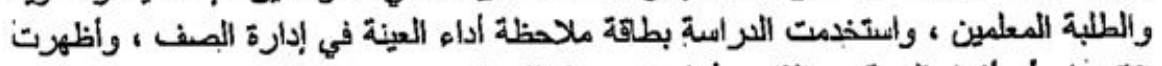

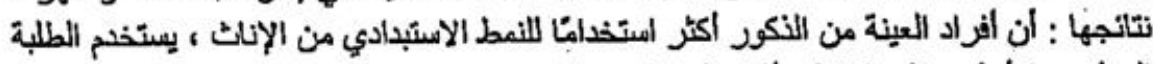

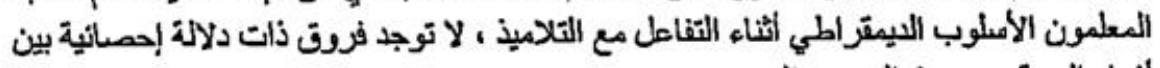

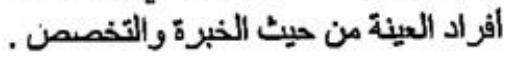

4- دراسة وايت وبارن : Wait \& Warrn , 2001 : والتي هدفت إلى المقارنة بين المعلمين

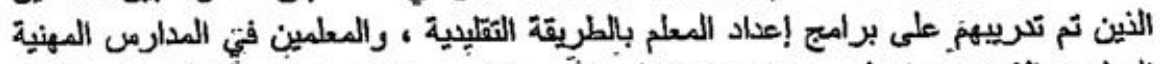

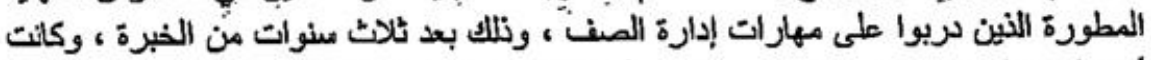

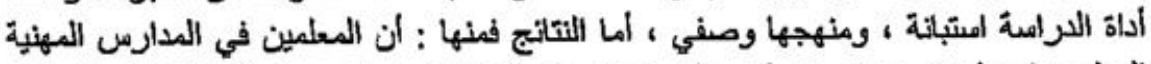

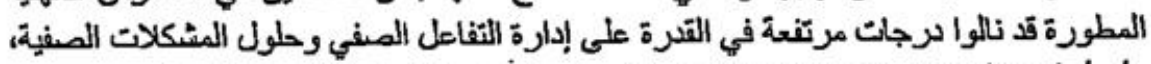

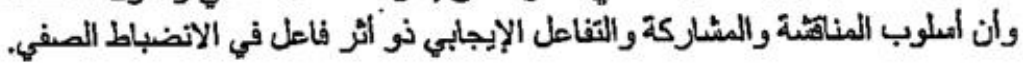

\section{تعقيب عام على الدراسات السابقة :}

1 ـ قلة الدراسات التي تتاولت الثلواب والعقاب معا رغم اهميتهما ، مقارنة مع موضوعات تثل عنهما اهمية . الهرات ب ـ العراسات التي جاءت في هذا الباب ، تناولت العقوبات المدرمية اكثر من تلك التي تناولت ج - الثراسات التي تناولت الفكر التربوي الإسلامي ، غلب مليها المنهج التاريخي.

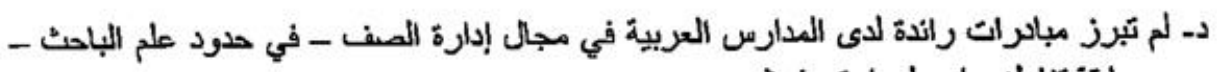

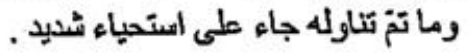

هـ - الدراسات الأجنبية في الإدارة الصفية جاءت أكثر عمقاك من تلاك الدراسات العربية في هذا الباب .

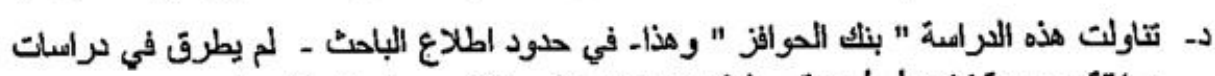

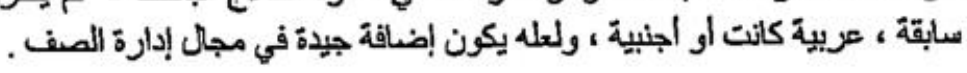

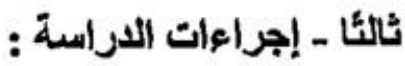 منهج الاراسة : مأنأ}

منهج هذه المرامة ثُبه تجريبي ، ومن المعلوم ان المنهج التجريبي يعالج المتغيرات المستطلة ،

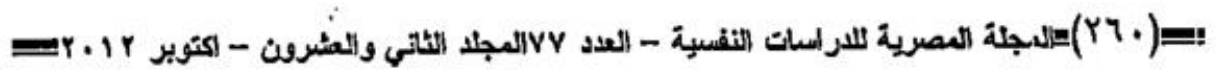


.

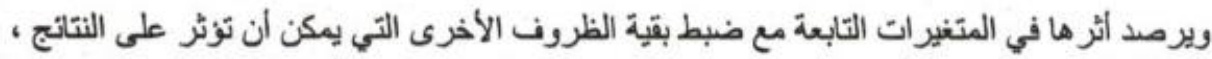

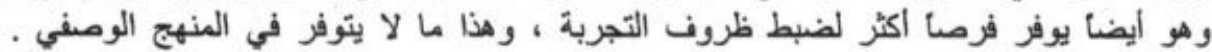

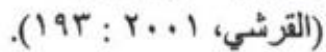

والدراسة التجريبية تجرى بغرض تاكيد بعض المفاهيم النظرية والتحقى منها في إطار الالتزام

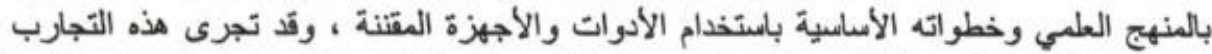

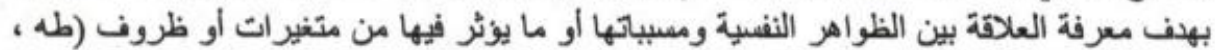
.(1) : Y..r

\section{مجنمع وعينة الدراسة :}

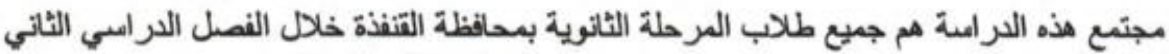

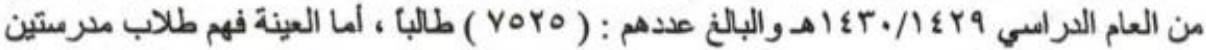

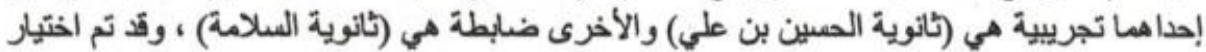

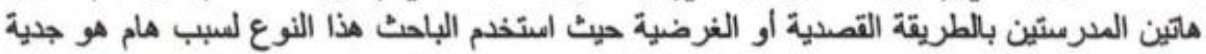

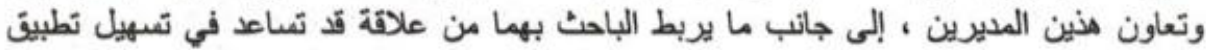

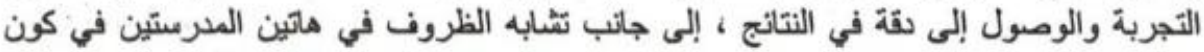

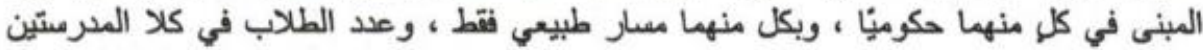

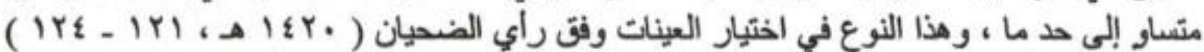

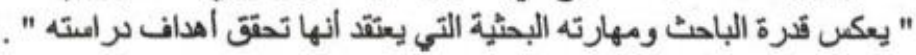

جدول (1) العينة التجريبية والضابطة " عينة بنك الحوافز ".

\begin{tabular}{|c|c|c|c|c|c|c|c|c|}
\hline indill & السجبوع & अजा & (it) & उुाI & हाप्तो & غ & المقربسة & p \\
\hline rq & IAV & $\varepsilon$. & ov & 9. & تكونا & تجريبية & ثاتوية الحصين بن & $T$ \\
\hline$r$. & 109 & $\varepsilon \varepsilon$ & of & $\pi$ & حلى & ضايطة & ثاتوية السلافة & T \\
\hline
\end{tabular}

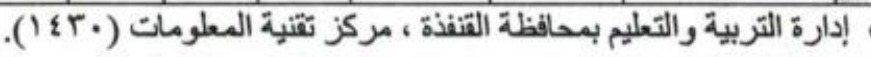




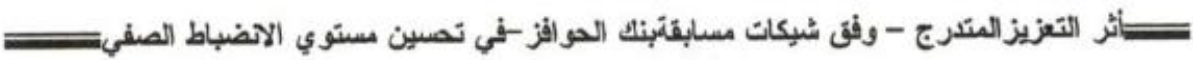

* جول (r) عينة الدراسة التجريبية التي طبقت عليها الاستبانة.

\begin{tabular}{|c|c|c|c|c|}
\hline \multicolumn{4}{|c|}{ الصغفر } & \multirow[b]{2}{*}{ الطلدب } \\
\hline المجسوع & الثلن ثاتوي طبيعي & الثاتي ناثوي طبيغي & الاول الثلوي & \\
\hline irs & rv & 41 & $\infty$ & \\
\hline المجموع & براeست & بكالوريون تربوي & بلونوسن ثير نربوي & \\
\hline ra & $=$ & ra & 1. & العودل العلىه \\
\hline & 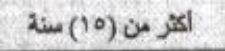 & من & أل لمن (0) منروات & \\
\hline ra & . & ra & $\circ$ & 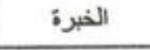 \\
\hline العجموع & 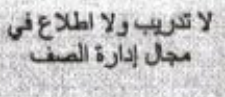 & الطلاع فن مجن تهري إدارة & تريب على إدارة الصف & الثليب \\
\hline ra & $r$ & rr & 18 & \\
\hline
\end{tabular}

• إدارة التربية والتعليم بمحافظة القنفذة ، مركز تقنية المعلومات (•rع ( ).

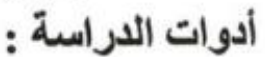

استخدم البلحث في دراسته الأدوات التالية :

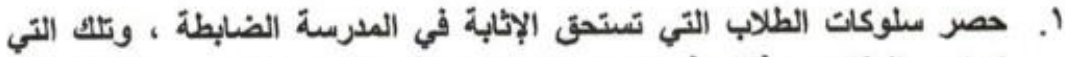

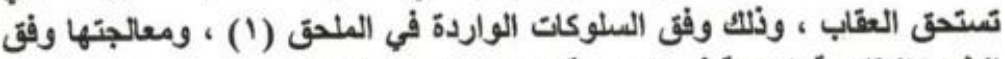

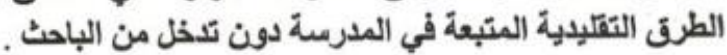

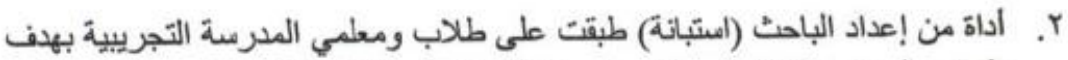

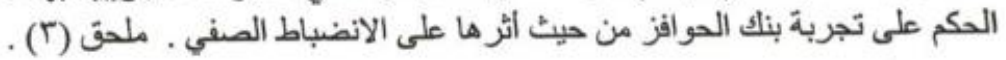

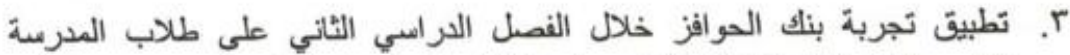

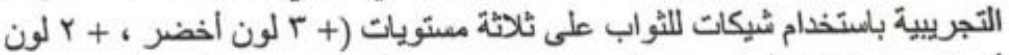

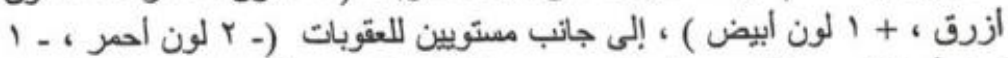

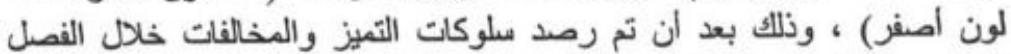

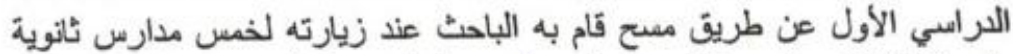

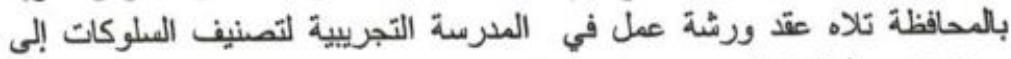

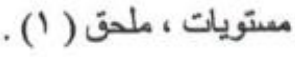

\section{الخصانص السيكومترية لأداة الدراسة :}

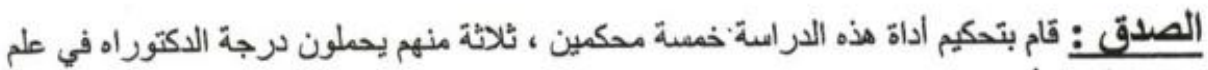

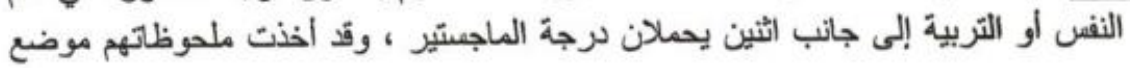

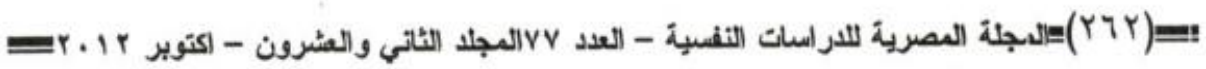




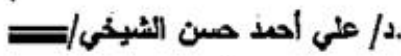

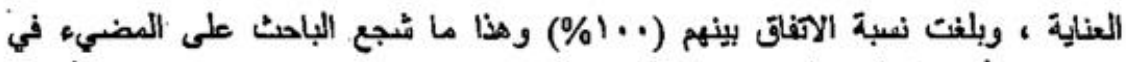

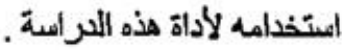

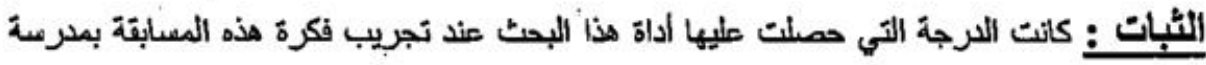

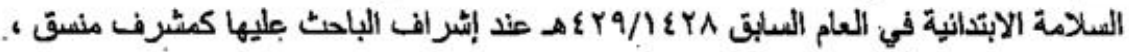

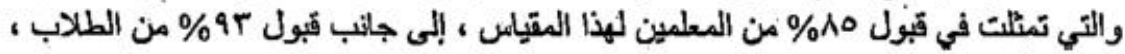

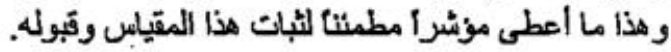

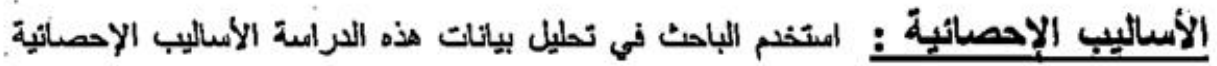

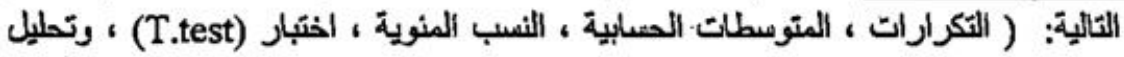

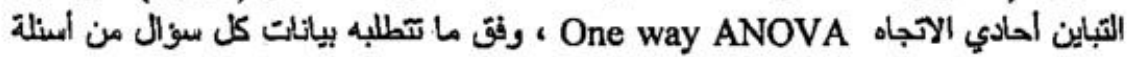

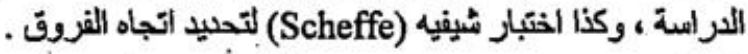

الاجزاع|ت الأنة

تمّ خلال الثهل الاراسي الأول العمل بالفطوات التالبة:

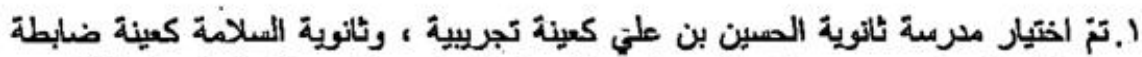

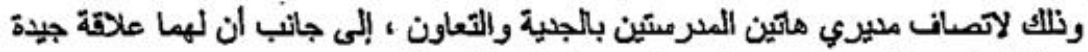

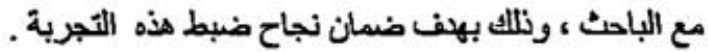

Y. تيام الباحث بمفح لخمس مدارس ثانوية لاستطلاع آراء المعلمين حول السلوكات الإيجابية

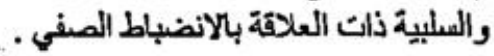

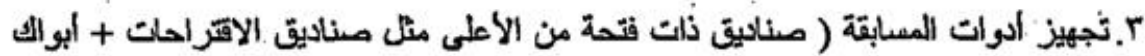

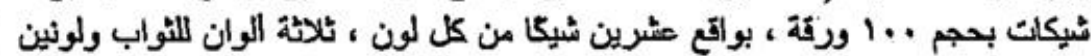
اللعقاب ) وجميعها مرقمة تصلمبليًا. ؛. حصر المواقف وتصنيفها إلى معتويات (ثلاثنة مستويات للثواب ، ومستويين للعقاب) ، وتم نلاك من خلال ورش عل تم عقدها في مدرنية العينة التجريبية.

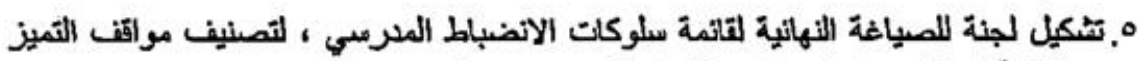

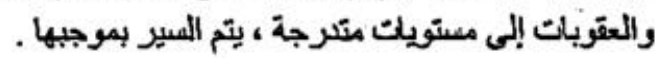

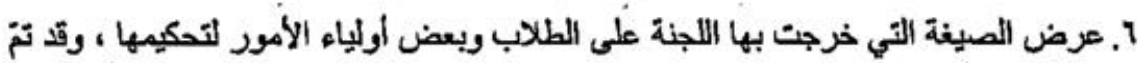
الأخذ ببا جاء عنهم من ملحوظات مفيدة .

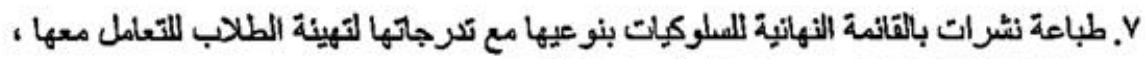
وتبليغها لأولياء الأمور بهنف التعاون في تتفيذها .

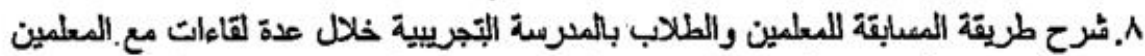

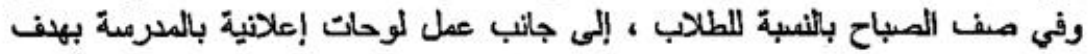

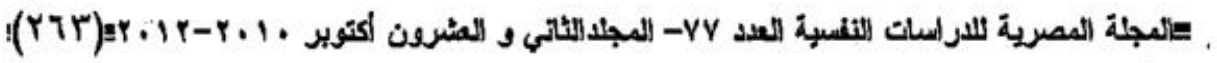




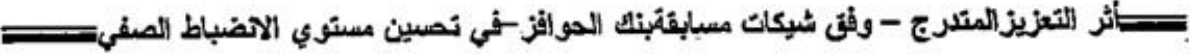

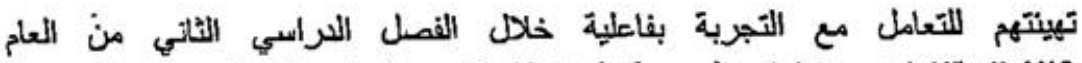

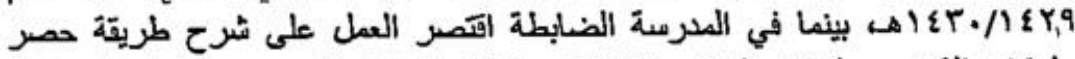

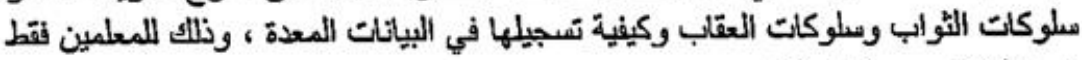

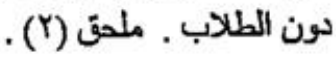

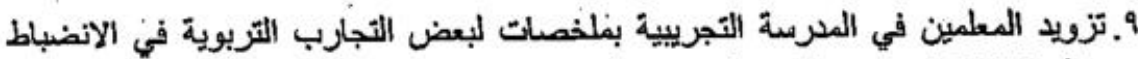

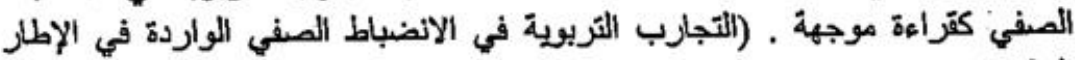

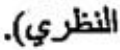
• 1. ترزيب معلمي المدرسة التجريبية على الية معابقة بنك الدوافز ، وحثهم على الدقة في ،

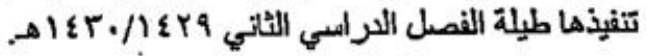

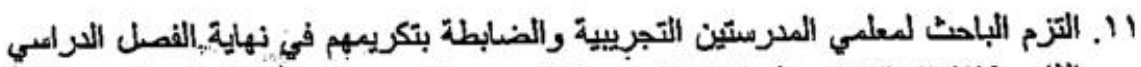

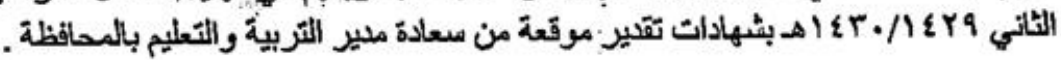

أما خطوات العمل خلال الفصل الثراسي الثاتي فهي المدربسة التجريبية ، فكاتت كالتلالي : 1 البدء في تطبيت المسابقة بامتخدام شيكات اللثواب والعقاب المترجة .

r. متابعة تطبيق المصابقة اولا باول وحث الزملاء على التعاون في رصد جميع الممارعات .

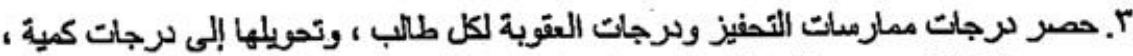
ومن ثتّ إعلان رصيد كل طالب أسبو عيّا وشهريًا نم اخيرا فصليًا . ع.تكريم المعلمين بُّهادات تقدير موقعة من سعادة مدير التربية والتعليم بالمحافظة ، ونلك

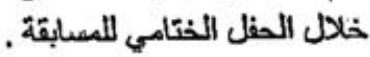

\section{آلية تنقيذ المسابقة :}

تمت الامستعانة في تتفيذ هذه المعابقة بالآلية التتالية : 1.رعت بذه الممابقة إعلاميًا لجنة المتمية الاجتماعية بعجلان حيث تكفلت بنفقات الإعلانات والثطرات التوعوية. r. صناديق صغيرة من الالمنيوم ذات فتحة من الأعلى تشبهه صنالايق الاهتراحات ، تودع بداخلها

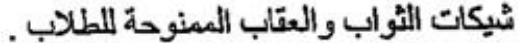

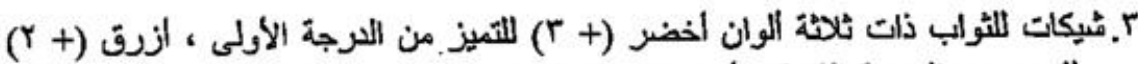

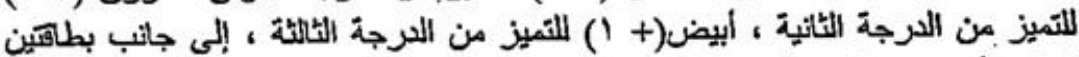

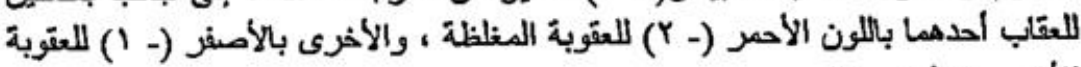
الأنى . (ملحق ع).

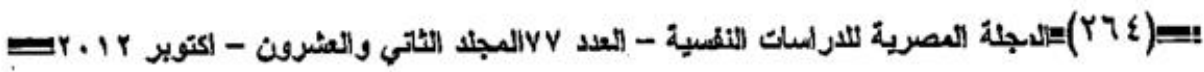




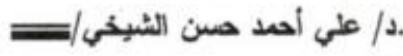

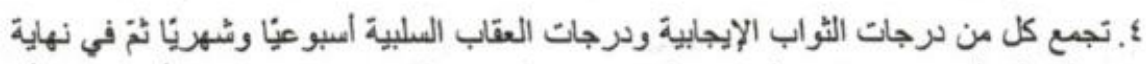

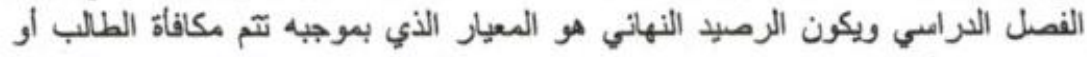

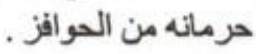

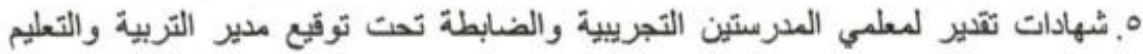

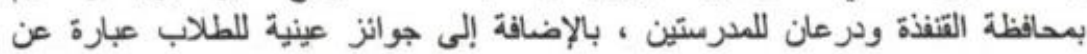

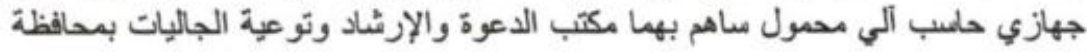

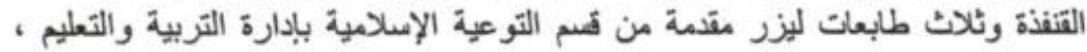

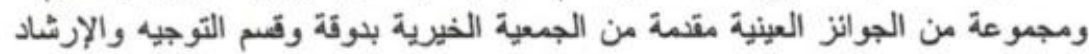
الطلابي بالمحافظة ، وكذا لجنة التنمية الاجنماعية بعجلان إعلامئًا.

\section{الأوزان المستخدمة في تفسير نتانج الدراسة :}

تمّ تفسير نتانج هذه الدر اسة وفق الاوزان التالية :

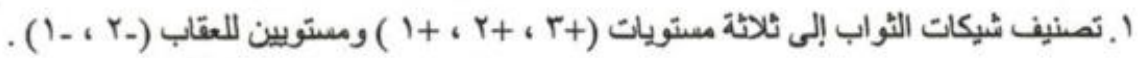

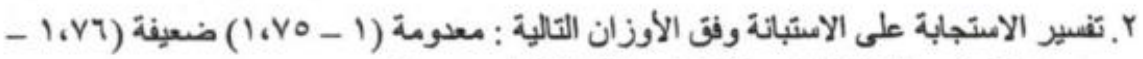

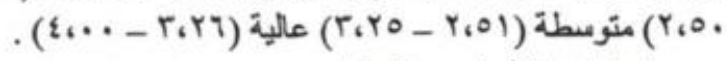

\section{آليةة حصر سلوكات الثواب والعقاب :}

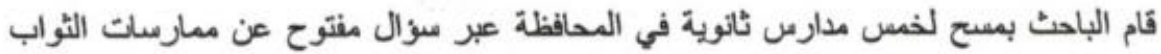

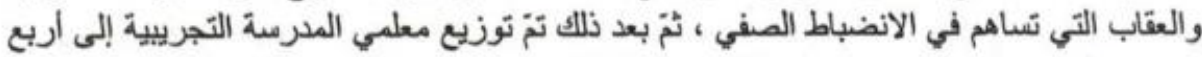

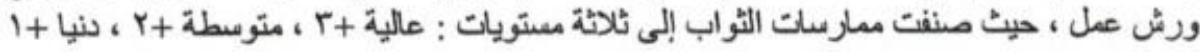

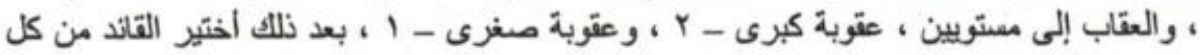

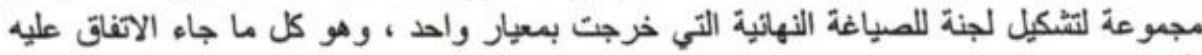

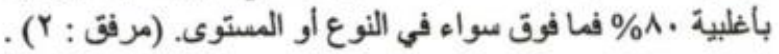

\begin{tabular}{|c|c|c|c|c|c|}
\hline & | & $a s$ & injul & 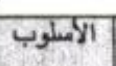 & A \\
\hline 25 & $r$ & 1 & & & \\
\hline & & $\sqrt{ }$ & الاتنظام فى أداء الواجبات & \multirow{3}{*}{ 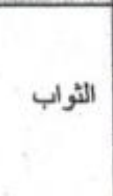 } & 1 \\
\hline & $\sqrt{ }$ & & المثاركة الفاطة فى الدرس & & Y \\
\hline$\sqrt{ }$ & & & الصلع بين زميلين متخاصسين & & $r$ \\
\hline$=$ & & $\sqrt{1}$ & التحر الصباحي & \multirow{2}{*}{ العقاب } & 1 \\
\hline$=$ & $\sqrt{ }$ & & الغياب يلون عزر & & r \\
\hline
\end{tabular}

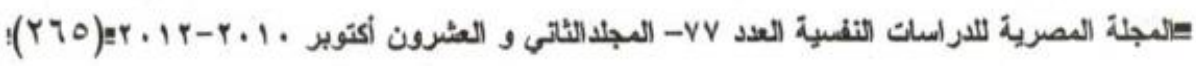




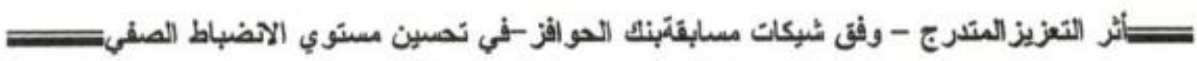

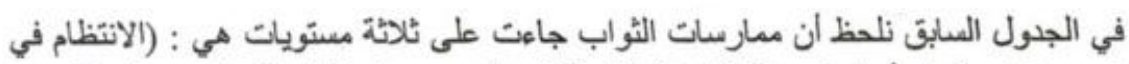

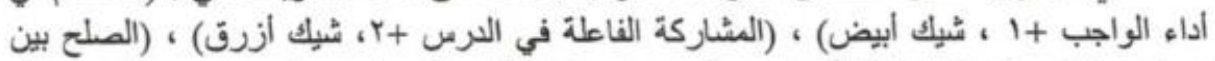

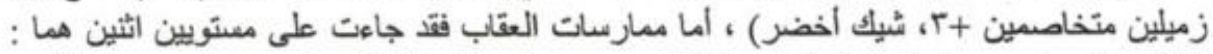

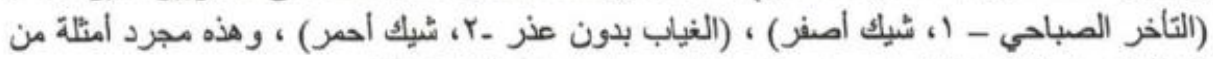

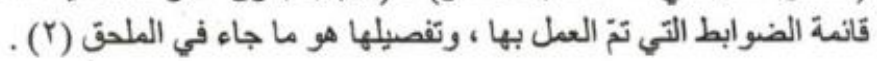

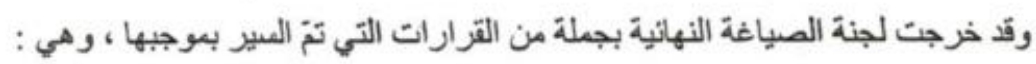

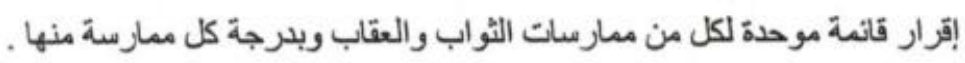

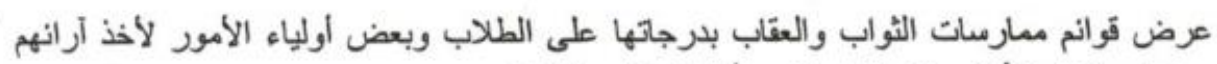

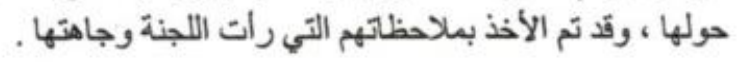

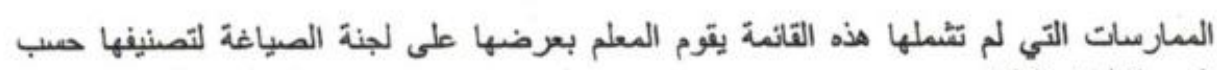

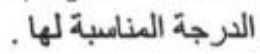

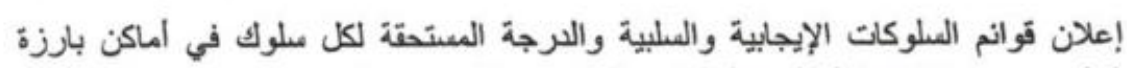

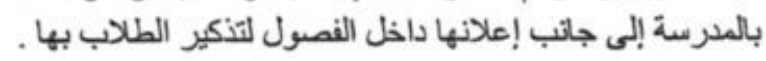

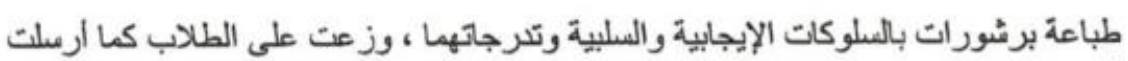

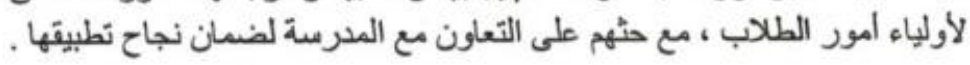

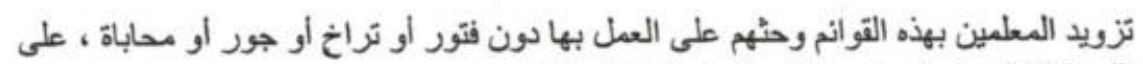

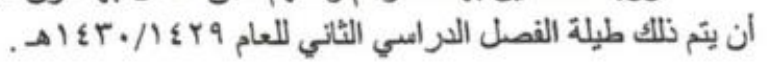

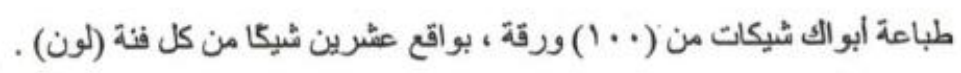

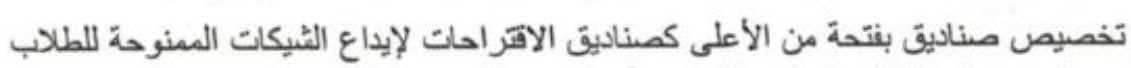

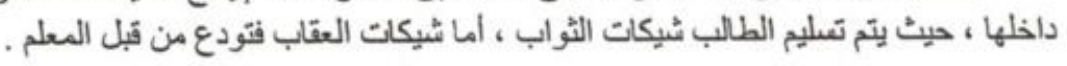

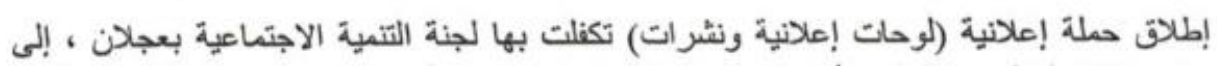

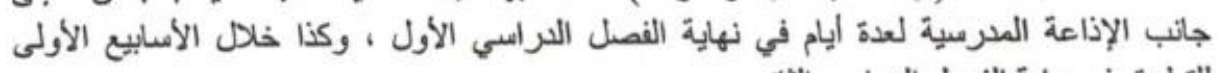
اللتطبيق في بداية الفصل الدراسي الثاني .

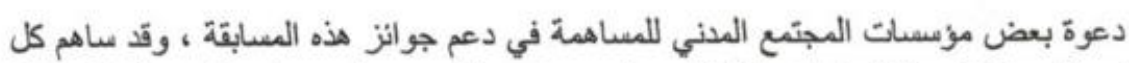

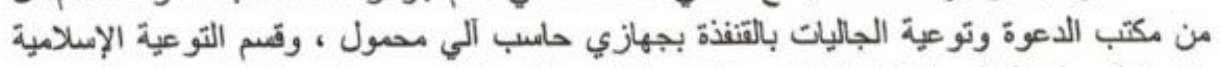

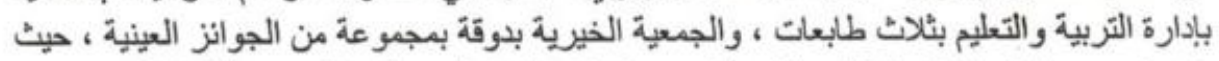

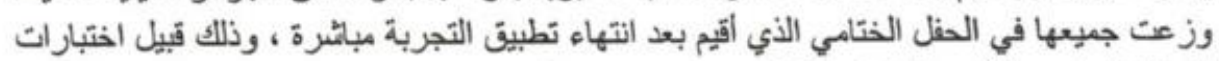

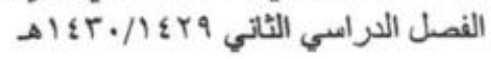

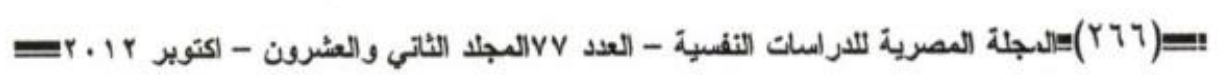


=

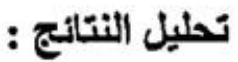

السوال الأول : ل تل توجد فروق ذات دلالة إحمانية في ممتوى ممارسة الإيجابيات والملبيات بين

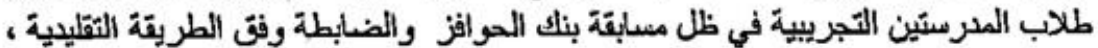

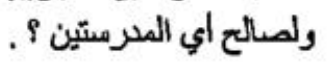

للاجبابة على هذا السوال تمّ استخدام اختبار (T . test) ونلاك لمعرفة الفروق بين المجبوعتين،

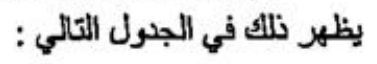

$$
\text { جدول (\&) الفروق في ممتوى دلالة ممارسة الإيجابيات }
$$

\begin{tabular}{|c|c|c|c|c|c|c|c|c|}
\hline sig & Df & $\mathrm{T}$ & $\mathrm{F}$ & المعيازيات & المبّرمسط & المثلد & العيئة & اللمارية \\
\hline \multirow[t]{2}{*}{$\cdot, \cdots$} & \multirow{2}{*}{$1 \wedge 7, \varepsilon\} \varepsilon$} & \multirow[t]{2}{*}{$1, \mathrm{AIV}$} & \multirow[t]{2}{*}{$Y, 8,9$} & $\cdot, r \cdots v$ & $\left\{7, r^{9}\right.$ & IAY & التجريبية & \multirow[t]{2}{*}{ الايجابية } \\
\hline & & & & $\cdot, 9$ \& & $Y Y, O A$ & 109 & المضابطة & \\
\hline \multirow[t]{2}{*}{$\because \cdots$} & \multirow{2}{*}{ rit, Yot } & \multirow[t]{2}{*}{ rov, ov $\varepsilon$} & \multirow[t]{2}{*}{$\because, \cdots \wedge$} & $1, \cdot 1$ & $\varepsilon, 0 Y$ & IAY & التجريبية. & \multirow[t]{2}{*}{ المطبية } \\
\hline & & & & $1, .7$ & $\{0, Y q$ & 109 & الفنابطة & \\
\hline
\end{tabular}

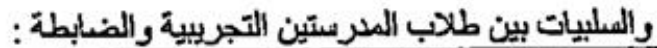

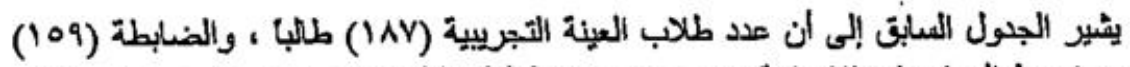

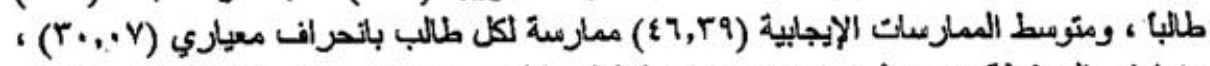

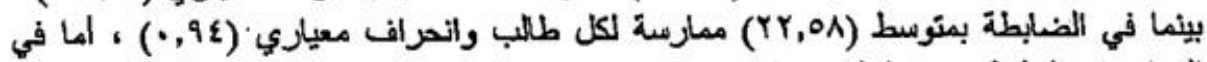

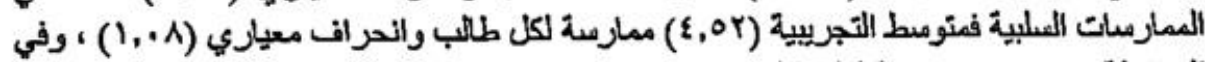

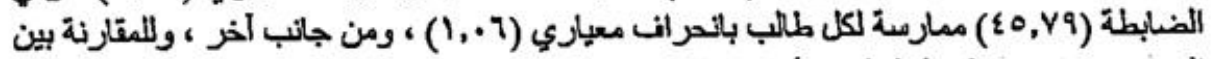

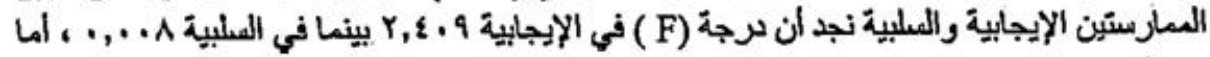

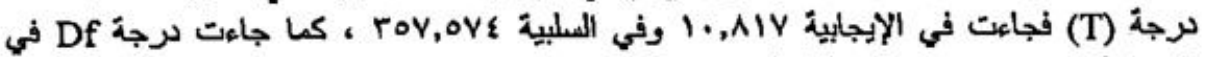

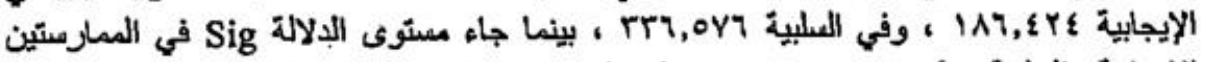

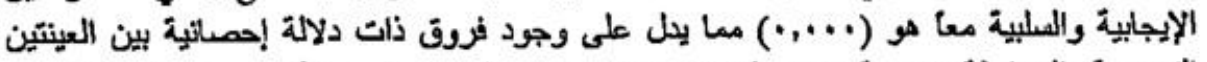

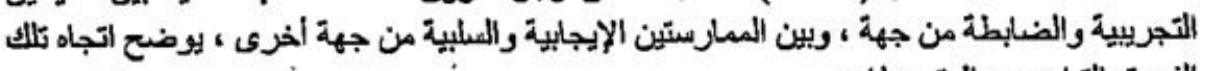

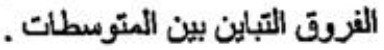
كما تشير الأرقام في الجذول اعلاه إلى المؤشرات التالثة :

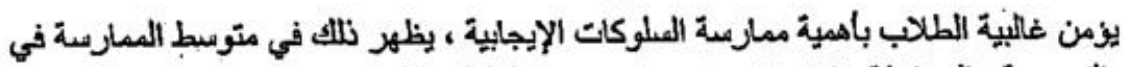

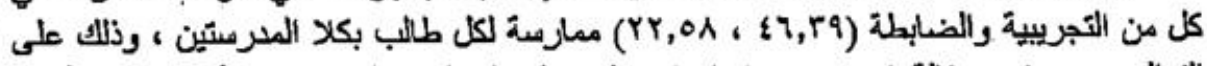

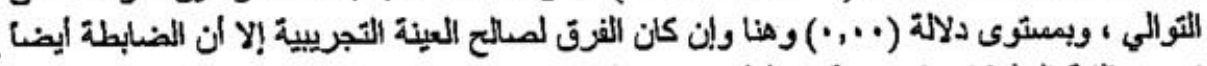

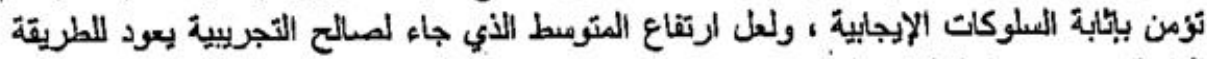

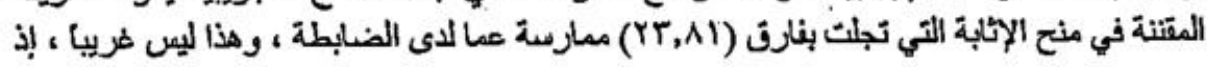
Elle 


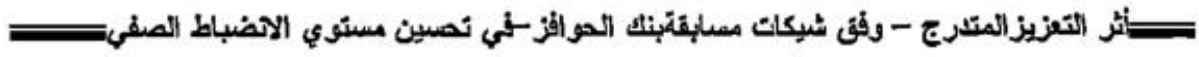
ان التخطيط وتقنين العمل يولد الوضوح ويبعد الشخص عن العشوائية والذاتِِة. بروز فروق واضدة وجلية بين المجوعتين التجريبية والضابطة في متوسط العقوبات في

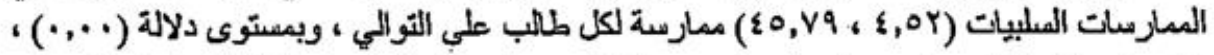

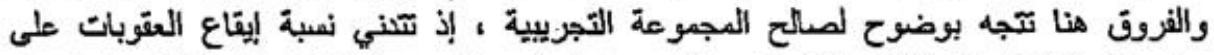

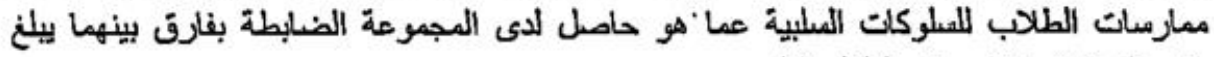

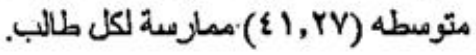

ومن خلال تالك المقارنات نقف على قناعة بنجاح معابقة بنك الموافز في تحتق الانضباط المباط

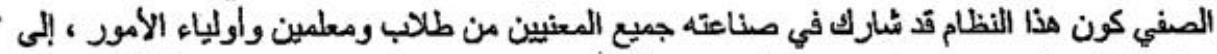

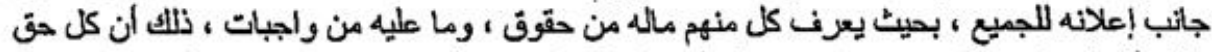

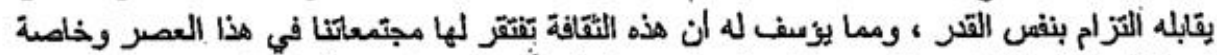

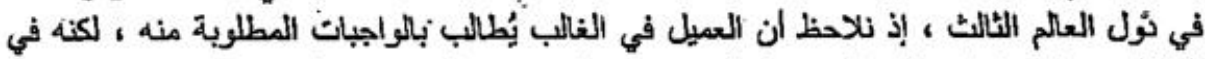

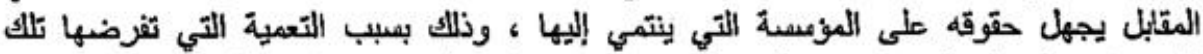

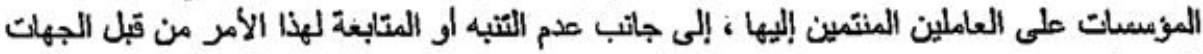

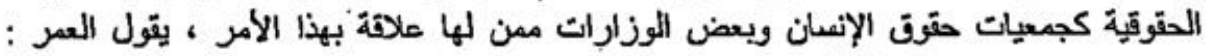

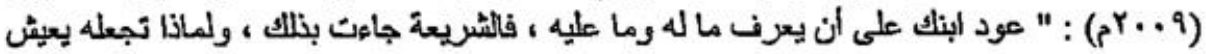

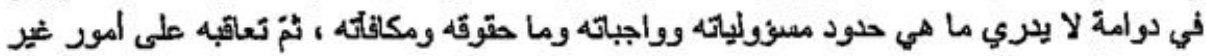

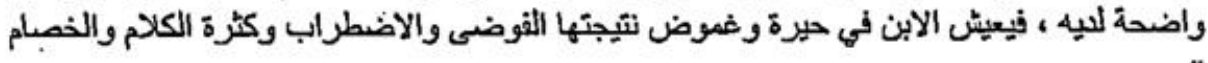

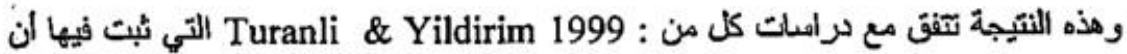

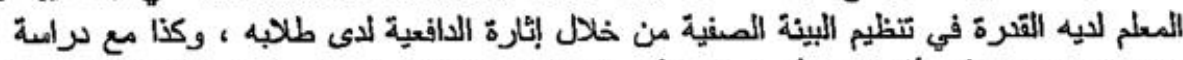
Gerdon 2001

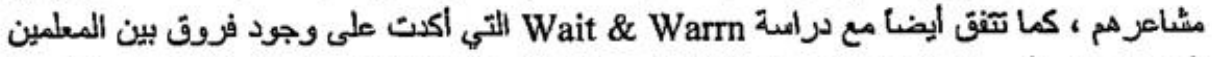

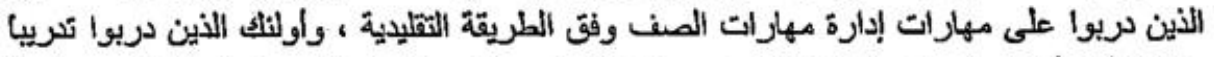

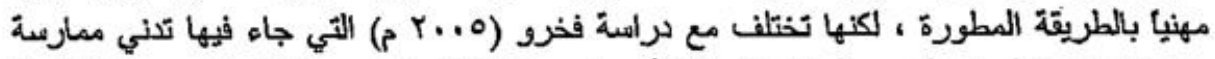

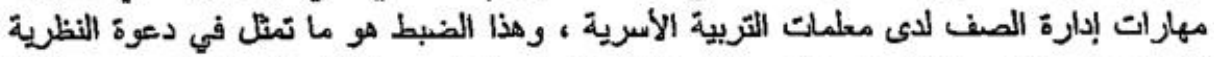

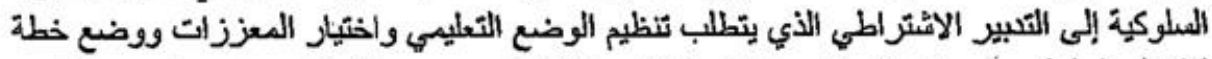

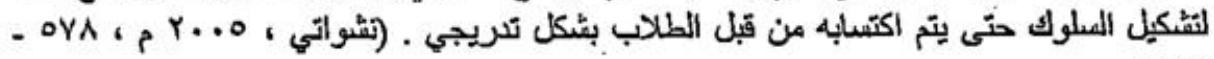
. (ov9

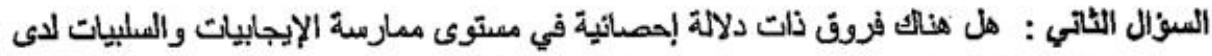

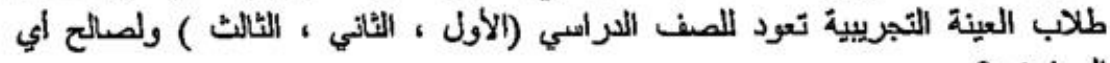

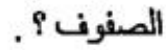

لمعرفة معتوى مملرسة السلوكات الايجابية والملبية بين المصفوف الثلاثة في العينة

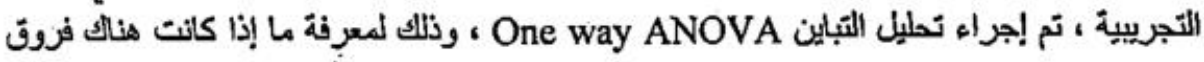

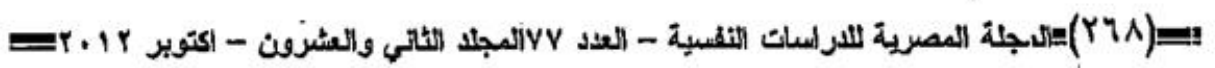




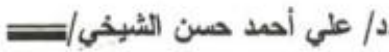

بين المتغيرات الثلائة ، يظهر ذلك في الجدولين التاليين :

جدول (0) : يبين الاحصاء الوصفي لطلاب العينتين التجريبية والضابطة :

\begin{tabular}{|c|c|c|c|}
\hline الآتمر الق العهلزي & لالشوسل & العد & الصف \\
\hline$\cdot, \mathrm{Vq}$ & YT & 9. & الأول \\
\hline$\cdot, \mathrm{VV}$ & 17,0 & or & الثاني \\
\hline$\cdot, \mathrm{V} \varepsilon$ & 11,7 & $\varepsilon$. & الثآل \\
\hline
\end{tabular}

جدول (1) الفروف في ممتوى ممارسة الإيجابيات والملبيات باستخدام بنك الحو افز بين طلاب العينة

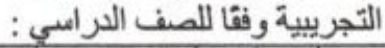

\begin{tabular}{|c|c|c|c|c|c|c|c|c|}
\hline 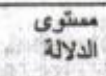 & (F) $)^{20}$ & 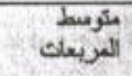 & مجلمرع & القرجة & التبلين & العدد & इसा & الستضير \\
\hline \multirow[t]{3}{*}{.,ort } & \multirow[t]{3}{*}{ זrר, • } & ovr,rry & $\begin{array}{r}11: 4,7 y \\
y\end{array}$ & r & العجمبو علت & 9. & الأول & \multirow[t]{3}{*}{ الإيجابية } \\
\hline & & Q.V,Aro & $\begin{array}{r}178.81, \\
7.9\end{array}$ & $11 t$ & النجلو عك & ov & الثائى & \\
\hline & & $=$ & $\begin{array}{r}\text { IXANA, } \\
\text { YVA }\end{array}$ & $1 \mathrm{AT}$ & اللجهوع & t. & الثلاث & \\
\hline \multirow[t]{3}{*}{$*,, \cdots$} & \multirow[t]{3}{*}{$r \varepsilon, 1 \leqslant Y$} & ra,riA & $0 \Lambda, 7 F V$ & T & الينيو عت & 9. & الأول & \multirow[t]{3}{*}{ المطليية } \\
\hline & & $\cdot, \wedge \circ 9$ & $101, \ldots 0$ & 114 & البجعو عات & ov & الثلاني & \\
\hline & & $=$ & $r i v, 7 \in Y$ & $1 \mathrm{AT}$ & العجموع & f. & الثالث & \\
\hline
\end{tabular}

* توجد فروق ذات دلالة إحصانية عند معتوى دلالة (1 + *, ).

تشير قراعة الجدولين المابقين للدلانل التالية :

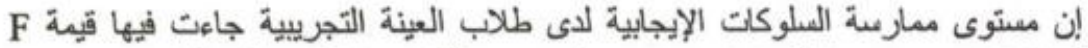

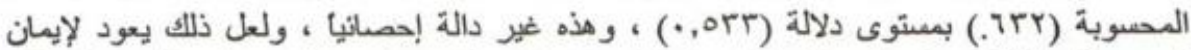

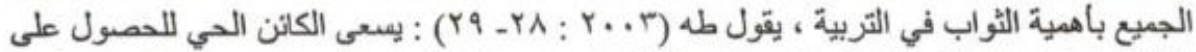

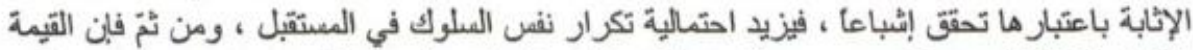

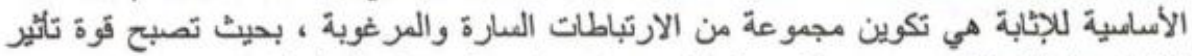

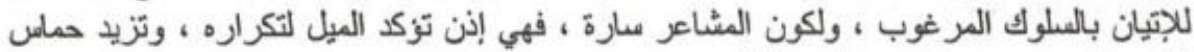

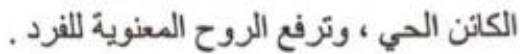

إن مصتوى ممارمة العلوكات السلبية لدى طلاب العينة التجريبية جاءت قيمة F المحسوبة

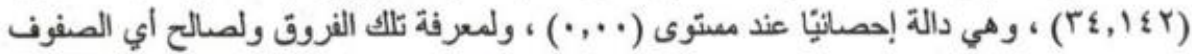
تثجه تطلب هذا الأمر من الباحث إجراء اختبار ميفيه (Scheffe) لتحديد وجهة التباين .

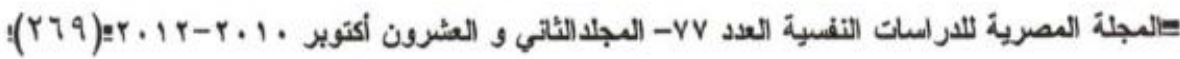




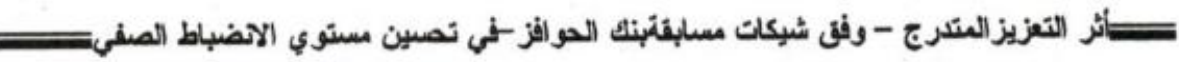

$$
\text { (V) جدول }
$$

يوضح اتجاه الفروق في مستوى ممارسة الإيجابيات والسلبيات باختلاف الصف الدراسي

\begin{tabular}{|c|c|c|c|}
\hline المبف & الصفا & الصف الورل & الممارية / الصنت \\
\hline 0,0 Yo & $\varepsilon, \varepsilon T T$ & $r, 970$ & السلبيكت \\
\hline
\end{tabular}

ومن خلال قراءتتا للجدول السابق فابن الأرقام تشير للحقانق التالية :

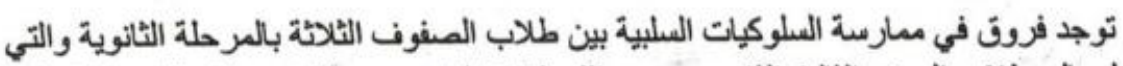

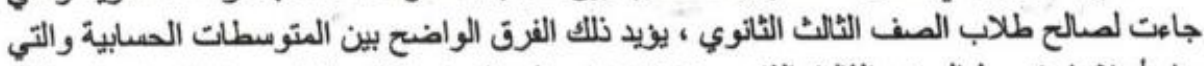

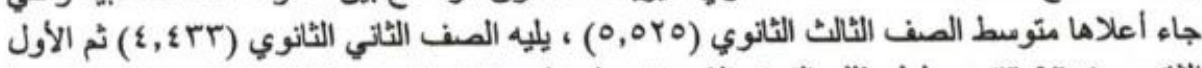

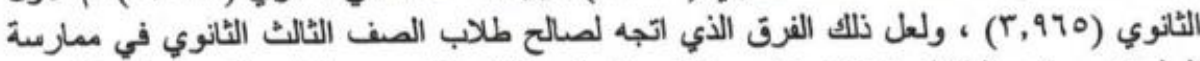

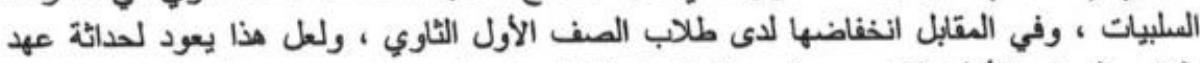

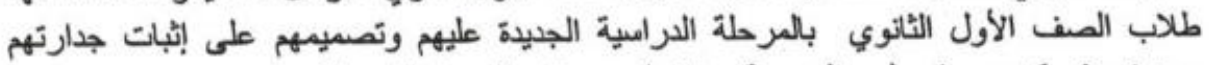

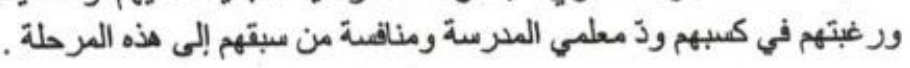

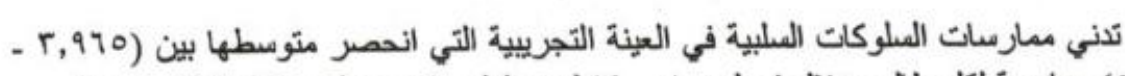

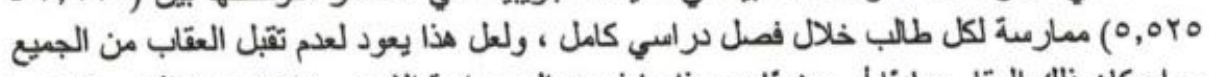

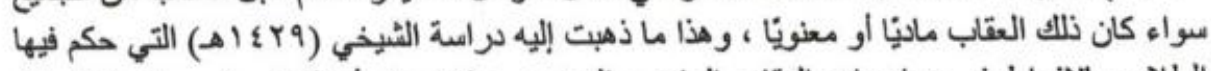

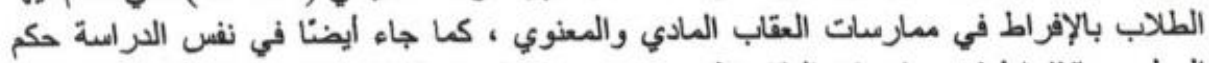

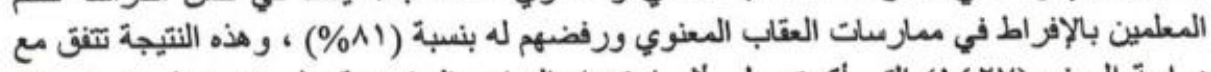

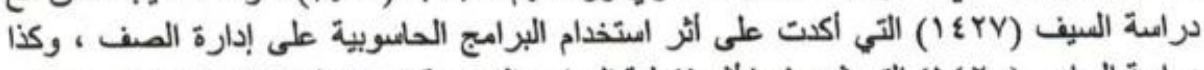

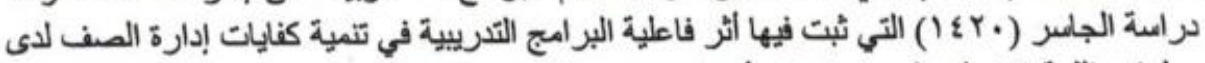

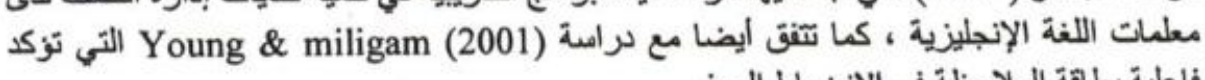

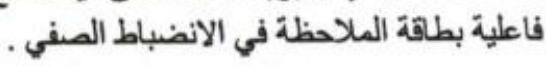

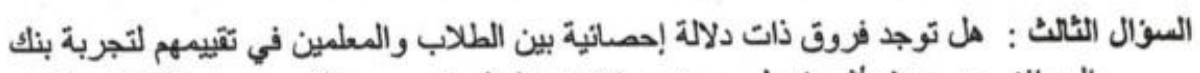

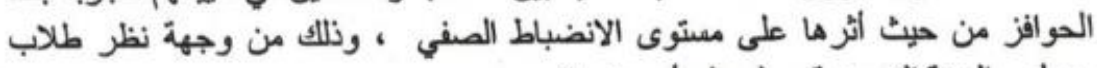

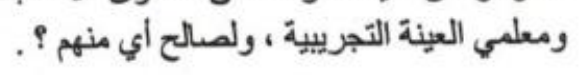

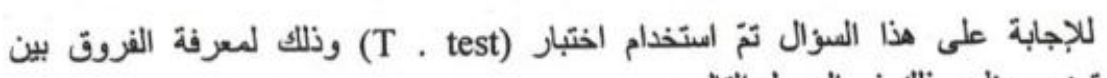

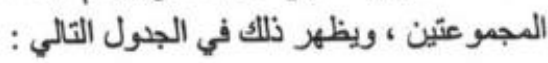

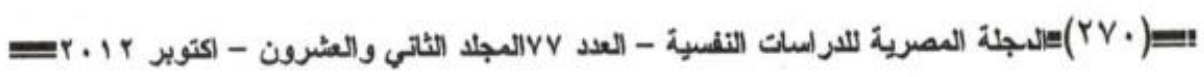




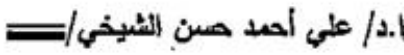

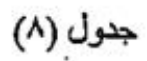

الفروق بين الطلالب والمعلمين في تقييمه

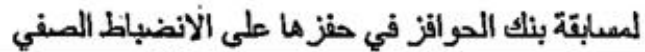

\begin{tabular}{|c|c|c|c|c|c|c|c|}
\hline Sig & - df & . $\mathrm{T}$ & $\mathrm{F}$ & الالانمرافي & العَوسط. & العدد & العهنة \\
\hline \multirow{2}{*}{ 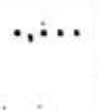 } & \multirow{2}{*}{ IrI,rri } & \multirow[t]{2}{*}{0,979} & \multirow[t]{2}{*}{ IT, } & אור,. & Y,qY£ & IYA & طلب \\
\hline & & & & $\therefore, T \leq \varepsilon$ & r,\&า. & rq & معلم \\
\hline
\end{tabular}

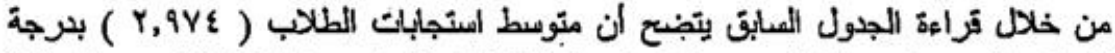

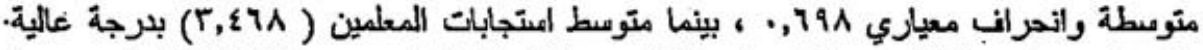

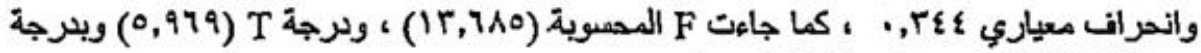

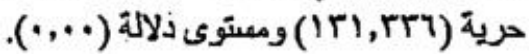

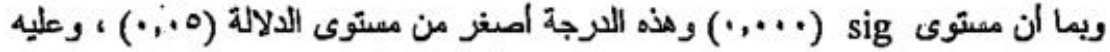

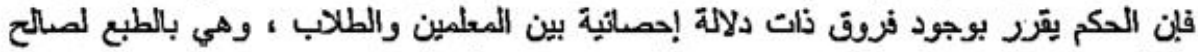

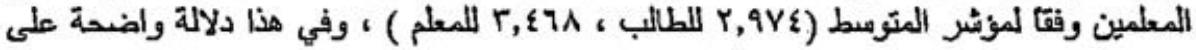

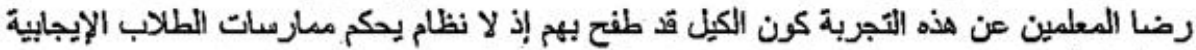

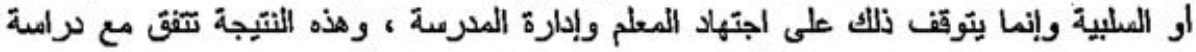

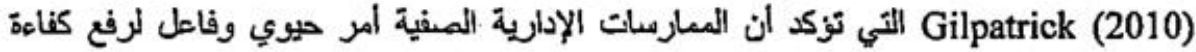

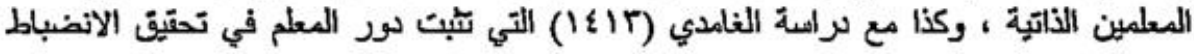

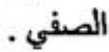

الفوال الرابع : هل هناك فروق ذات دلالة إحصاثية بين طلاب العينة التجريبية في ثقييهمه التجربة

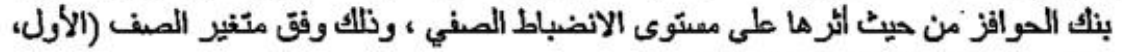

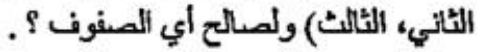
المعرفة أثر تجربة بلك الموافز على مستوى الاتضباط الصفي بين الصفونت الثلائة ، تم

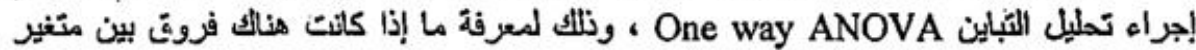
المبف ، يظهر نالك في الجدولين التأليين :

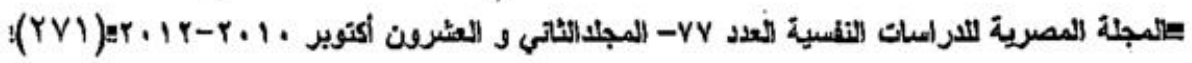




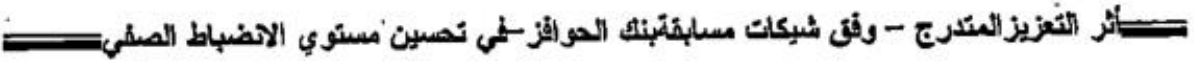

(9) جلول)

\begin{tabular}{|c|c|c|c|}
\hline \multicolumn{4}{|c|}{ يبين الإحصاء الوصفي لطلاب العينتين التجريبية والضنبطة : } \\
\hline الانحراتَ المعيازي & المتروسط & العدد & الصف \\
\hline$\cdot, \mathrm{VV}$ & $r Y, 9$ & 00 & J' \\
\hline$\cdot, 10$ & YY,O & 27 & آلثاتى \\
\hline$\cdot 7$ & 17,7 & YY & الثتلث \\
\hline
\end{tabular}

جلول (· (1) الفروق في تقيبم تجربة بنك الحوافز

\begin{tabular}{|c|c|c|c|c|c|}
\hline متوق اللالاس & $\begin{array}{l}-4 \\
F\end{array}$ & مدبطريع الهلن & مرهة الترية & مروع مريعك تشيل & i \\
\hline \multirow{3}{*}{ *,., } & \multirow{3}{*}{ t.rey } & $1,11$. & $r$ & r.ty & ائ المعرعبك \\
\hline & & ., & iro & ov,av. & نلمل المهيموعك \\
\hline & & - & inv & 11,Ats & مجسرع \\
\hline
\end{tabular}

* : توجد فروق ذات دلالة إحصائية عند مستوى دلالة (1 (...) .

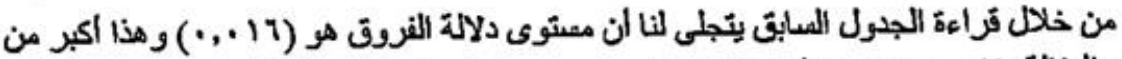

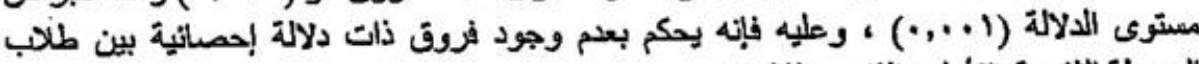

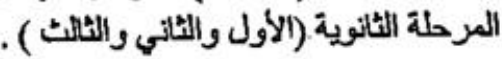

العو'ال الخامس : هل هناك فروق ذات دلالة إحصاثية بين معلمي العينة التجريبية في ثقيمهم لتجرية

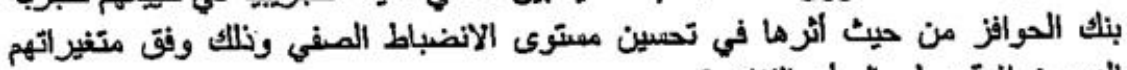

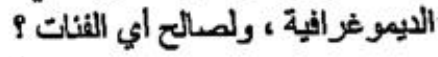
لمعرفة الفروت بين المعلمين وفقا لمتغيز الموهل المراسي ، وذلك من حيث ثقيمهنم على نجاح

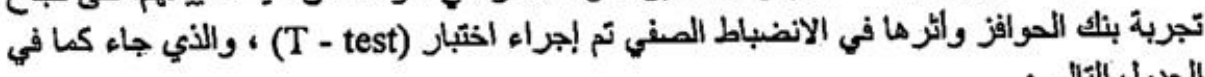

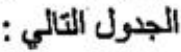
جذول (' ") يوفسح اتجاه الفروق بين المعلمين وفق متنغير المؤهل البزاسي من حيث ألثره على الانضباط المففي :

\begin{tabular}{|c|c|c|c|c|c|c|}
\hline sig & df & $\mathrm{T}$ & الاسترات العهزئ & كشوسط & 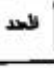 & "مر山ل \\
\hline \multirow[t]{2}{*}{., 090} & \multirow{2}{*}{ 19,rea } & \multirow[t]{2}{*}{,.$t 01$} & - rarta & T,trite & 1. & بكلورين يل تريعي \\
\hline & & & - rirrt & r.tATr & ra & يكلوريون تزيوه \\
\hline
\end{tabular}

من خلال أسقراء الجذول المبابق يتضح عدم وجود فروف ذات دلالة إحصاثية بين المعلمين

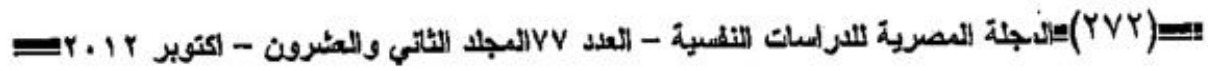




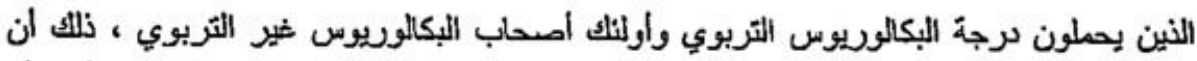

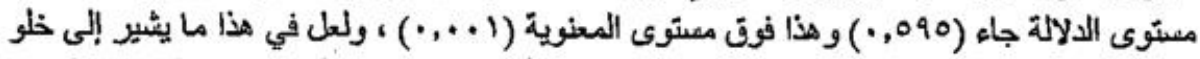

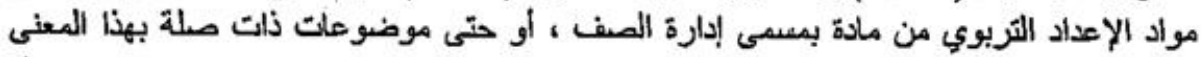

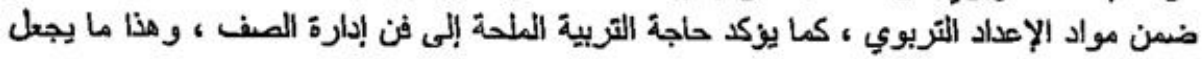

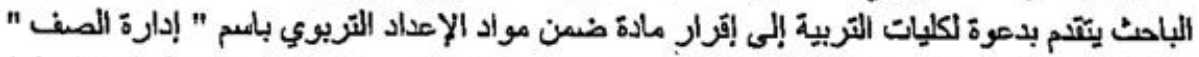

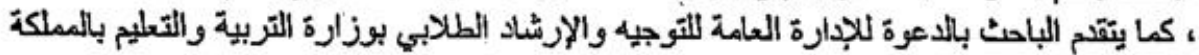

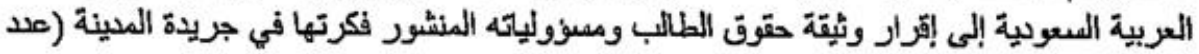

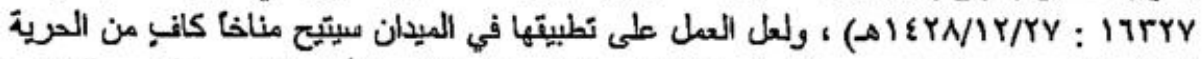

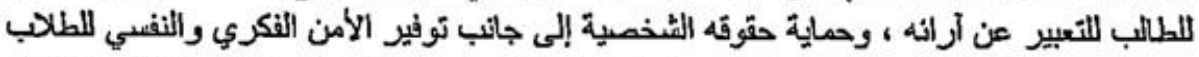

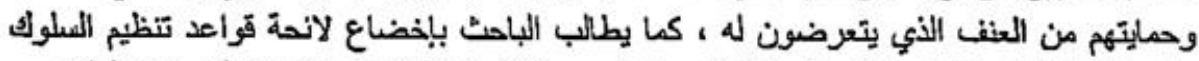

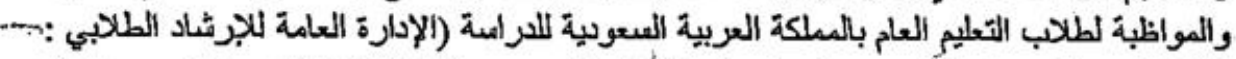

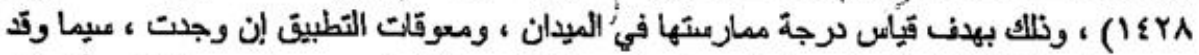

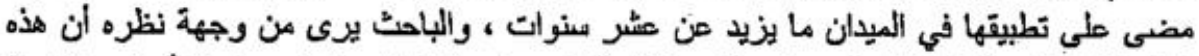

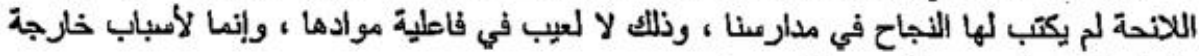

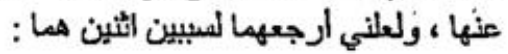

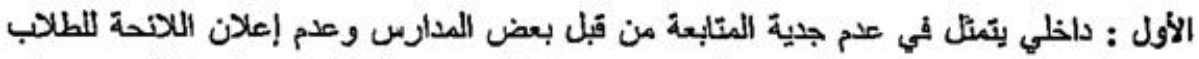

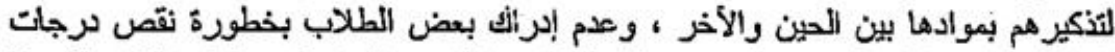

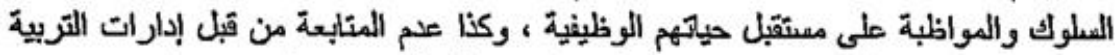

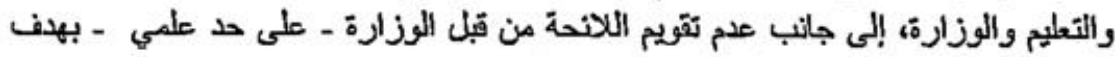

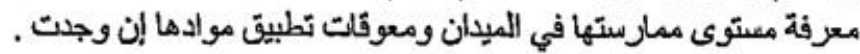

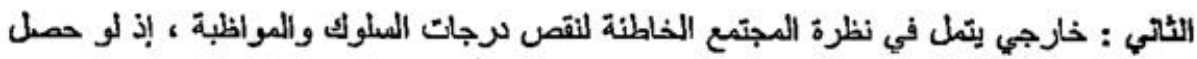

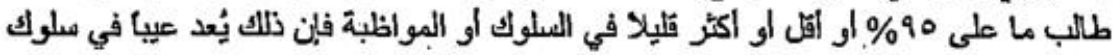

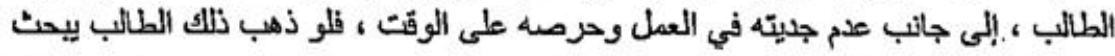

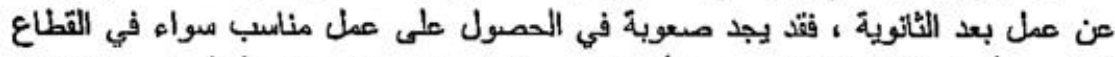

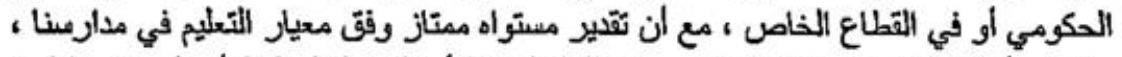

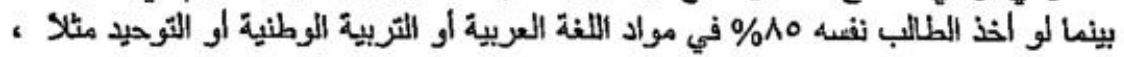

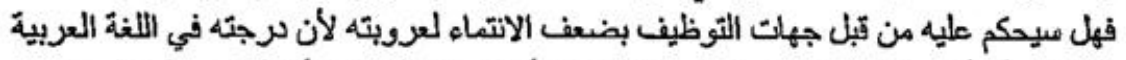

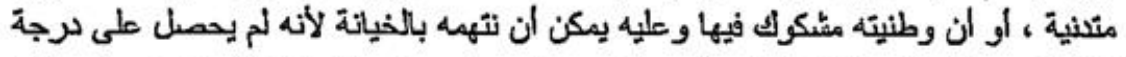

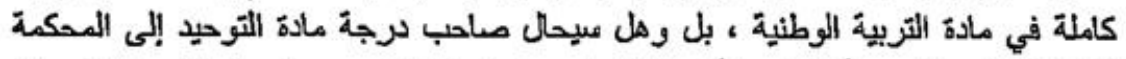

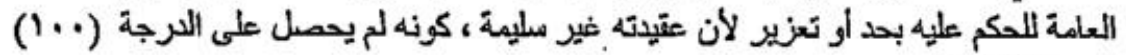
في مادة العقيدة .

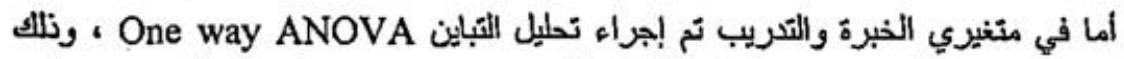

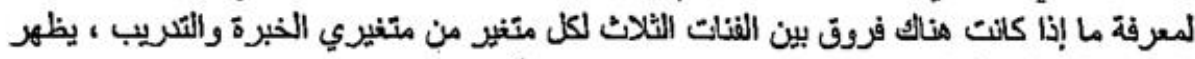

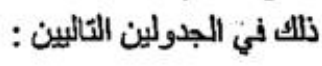

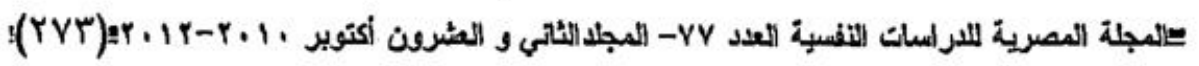




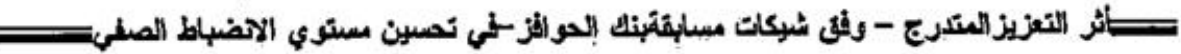

\begin{tabular}{|c|c|c|c|c|}
\hline الآتمر الت المعيلزي & المترميط & العدد & झसा & الستخيز \\
\hline $01,7$. & $r, \cdot$ & $\cdot$ & القل من • سئوات & \multirow{3}{*}{ الخيرة - الخير } \\
\hline., 79 & IV,t & ra & الن & \\
\hline .01 & $P, \cdot$ & $\circ$ & اكثر من 10 مئة & \\
\hline., $0 \mathrm{~V}$ & $\lambda, \mathbf{l}$ & $7 t$ & تلرب على إدارة المشف & \multirow{3}{*}{ النحريب } \\
\hline$\bullet$, v. & $1 \%, \Lambda$ & Yr & مكراهات موجهة فمى إدارة المش & \\
\hline.,$t r$ & $1, r$ & $Y$ & 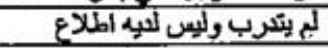 & \\
\hline
\end{tabular}

جوة (i.)

يوضنح إتجاه الفروق بين المعلمين في الدعوة للانضباط المفي ، وفق متغيري الخبرة و المتريب

\begin{tabular}{|c|c|c|c|c|c|c|c|}
\hline 年 & Fing & entions & aves & Evills & को & Wy & 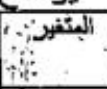 \\
\hline \multirow[t]{3}{*}{$\therefore$} & \multirow{3}{*}{$\because$ EV9 } &. .01 & $r$ &., 117 & 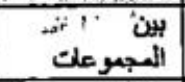 & آلتاتمن • سنوات & \multirow[t]{3}{*}{ الخبرة" } \\
\hline & & $\cdot, \operatorname{Irr}$ & $\overline{T r}$ & $\varepsilon$, rVר & المجموعلت & من & \\
\hline & & $=$ & rA & $\varepsilon, \varepsilon 9 T$ & اللهجموع & اكتر من 10 منة & \\
\hline \multirow[t]{3}{*}{., 07} & \multirow[t]{3}{*}{$\cdot, 091$} & $\cdot, \mathrm{YY}$ & $r$ & $\because, 121$. & الثجموعلت & تمرب. على إلادرة & \multirow[t]{3}{*}{ التنريب } \\
\hline & & $\because|Y|$ & Tq & $\varepsilon, r \leqslant q$ & المجموعلت & المبه الملاع على إدارة & \\
\hline & & $=$ & $T A$ & E,EqT & المجموع & الملاعتربي وليهن لميه & \\
\hline
\end{tabular}

من خلال استقر اء نتائج الجبول العابت يتجلى الاكتي :

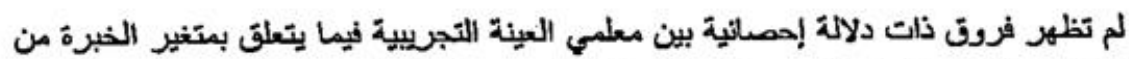

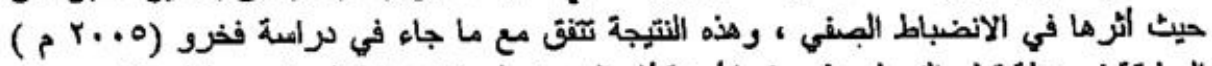

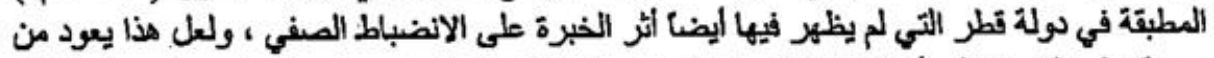

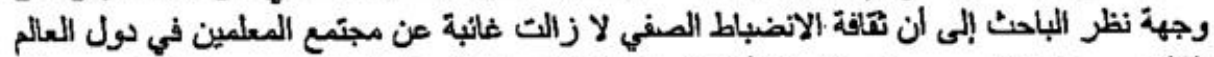

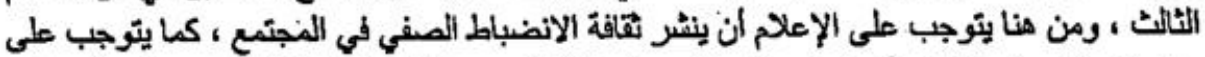

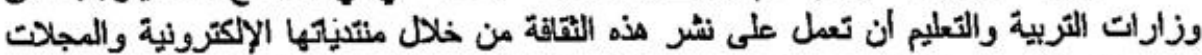

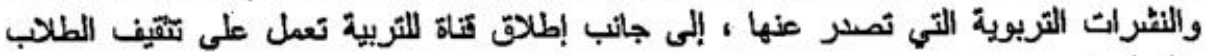
والمعلمين.

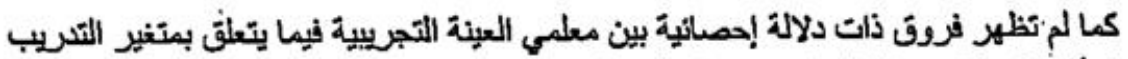

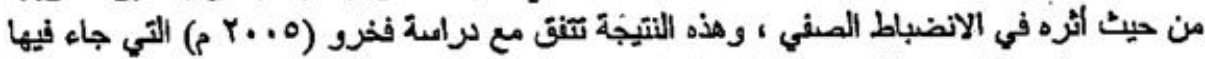

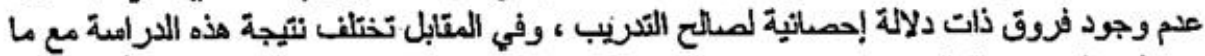

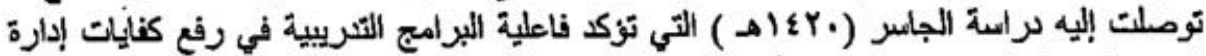

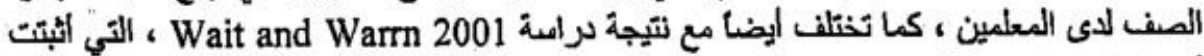
أن المعلمين الذين دربوا على مهارات إدارة الصف أكثر كفاهة من المعلمين الذين اعدوا بالطريقة

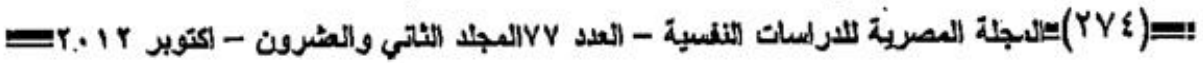


.

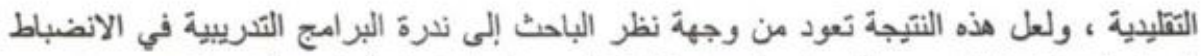

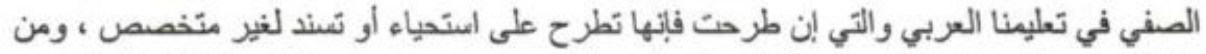

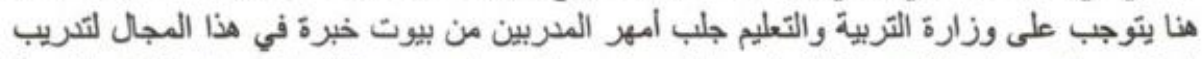

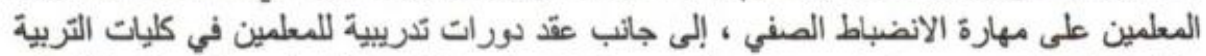

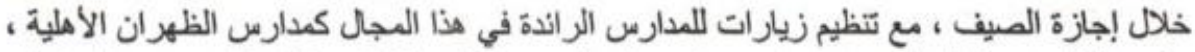

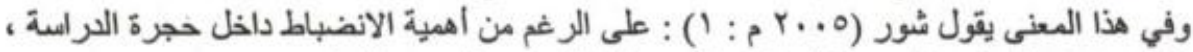

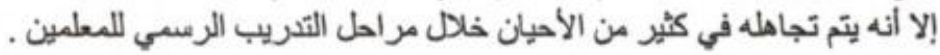
خلاصة الدراسة : (ابرز النتانج والتوصيات والمقرحات والفواند ) :

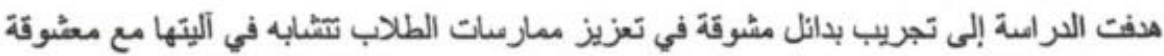

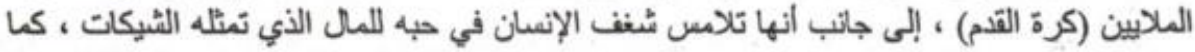

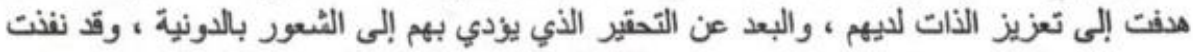

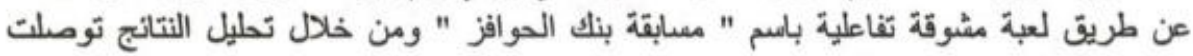
الار اسة النتائج التالية :

ماهمت معرفة الطلب بالواجبات المطلوبة منه والحقوق المترتبة عليه للمؤمسة التربوية التئي ينتمي إليها الطالب إلى ضبط سلوكه وتوافته مع معايير المجتمع الذي ينفاعل معله .

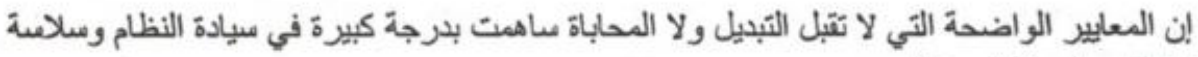
تطيبقه ، بل وتقَّله من الجميع.

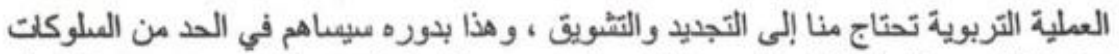

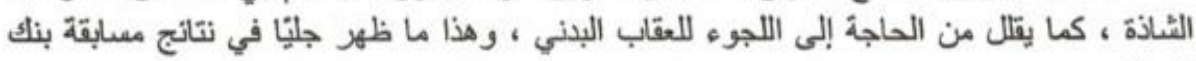

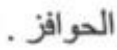

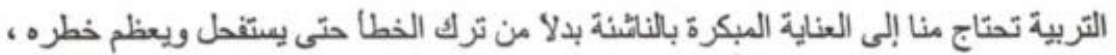

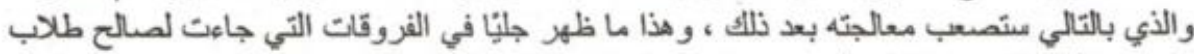

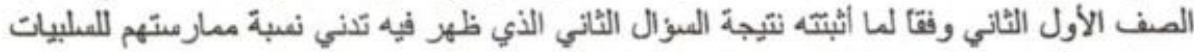

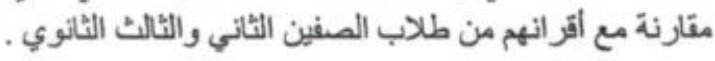

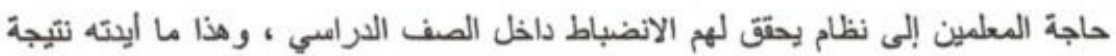

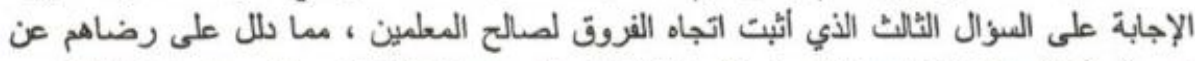

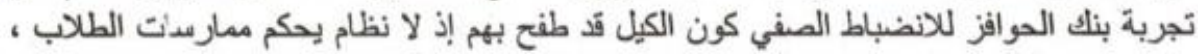
وإنما يتوقف الأمر على اجتهاد المعلم وإدارة المدرسة المبلة

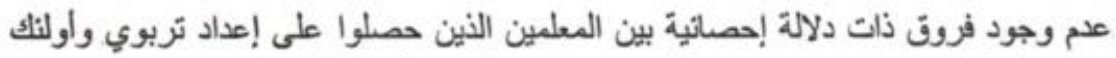

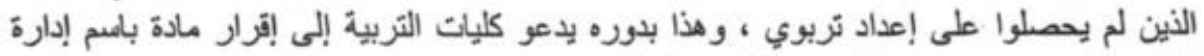

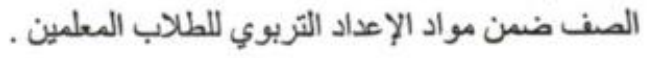

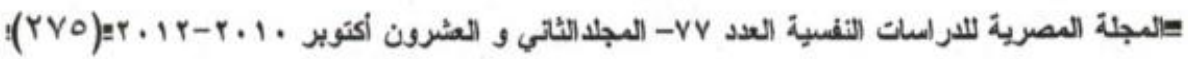




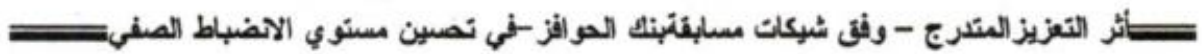

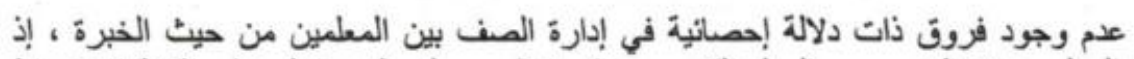

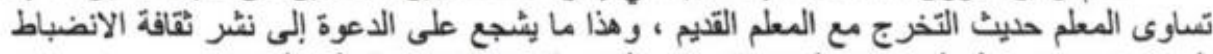

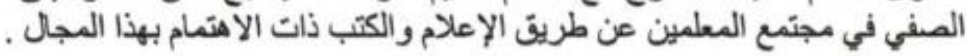

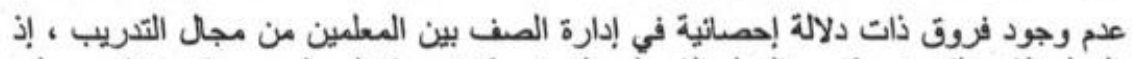

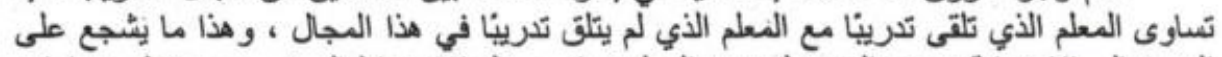

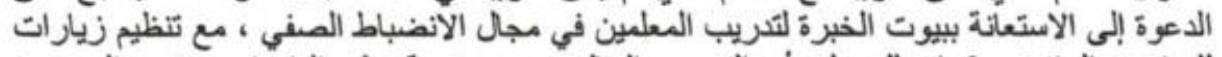

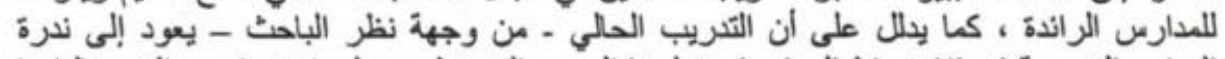

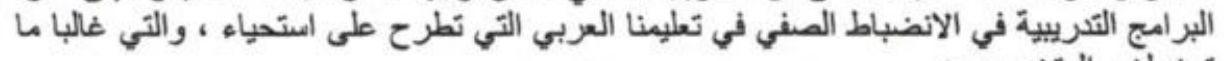

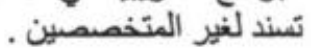

و هذه النتاتج تقود الباحث إلى التقدم بالتوصبات والاقتراحات التالية :

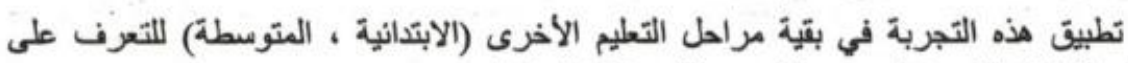

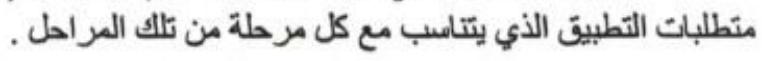

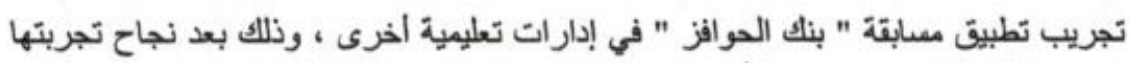

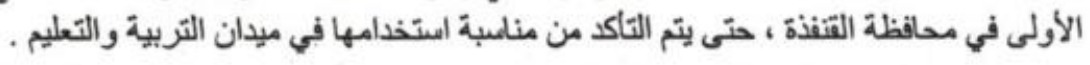
دراسة اثر الانضباط الصفي على التحصيل الدرامي في مراحل التعليم المختلفة .

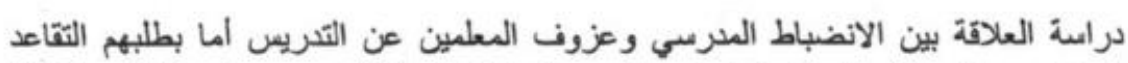

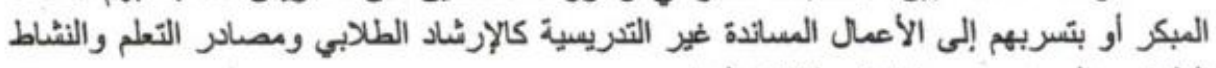

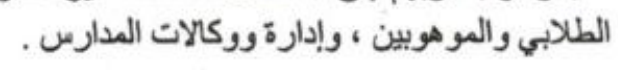

دراسة واقع تطبيق لانحة السلوك والمواظبة في مراحل التعليم العام ومعوقات التطبيق إن ولن وجنت.

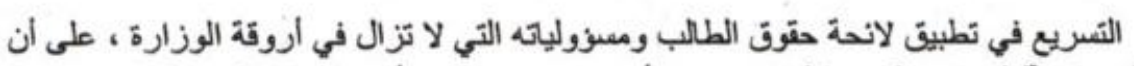

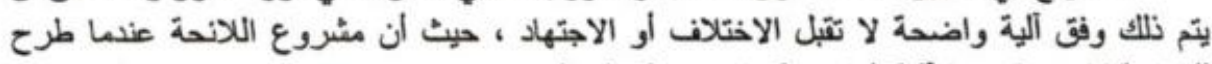

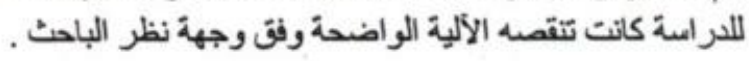

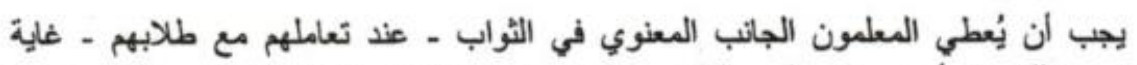

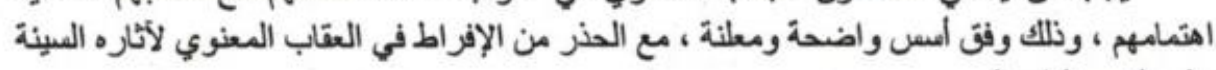

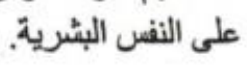

تزويد المكتبات المدرسية بالكتب التربوية ، وخاصة فيما يتعلق بالانضباط الصفي ، وتشجيع

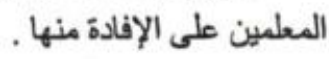

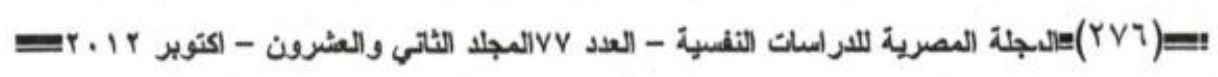




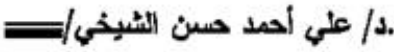

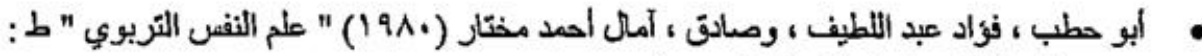

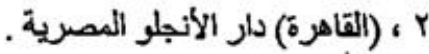

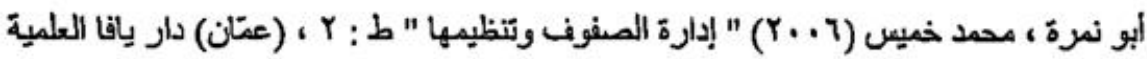

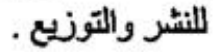

إدارة التربية والتعليم بمحافظة القففة ، مركز تقنية المعلومات ، " اللبيانات الإحصائية للعام

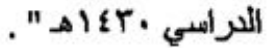

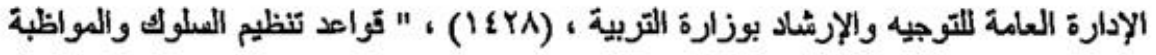

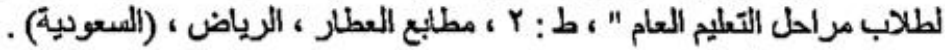
• البرت ، ليندا (1999 م ) " الانظباط التعاوني " ترجمة مدارس الظهران الأهلية (النمام) دار الكتاب التربوي اللثطر والتوزيع . لالتطباط.

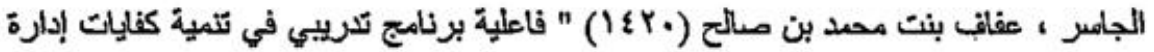

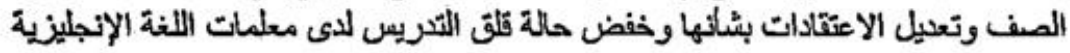

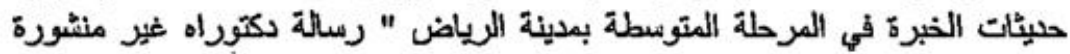

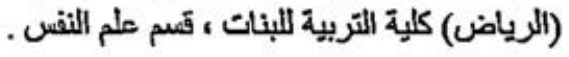
الخليلي ، امل (0 . بrم) " إدارة الصف المعرسي " (عمان) دار صفاء للانطر والتوزيع .

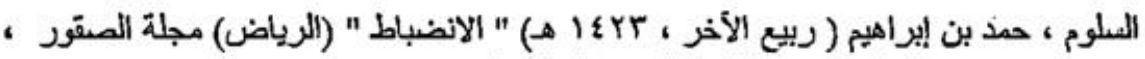

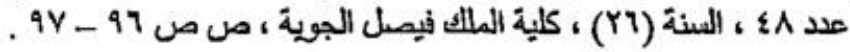

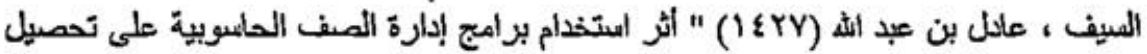

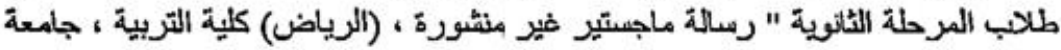

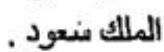

الشيخي ، علي بن أحمد حمن (وبع أ) " الثواب والعقاب بين الإفراط و التقريط " بحث مقدم لإدارة التربية والتعليم بمحافظة القنفذة .

الضحيان ، معود ضحيان (•Y乏 ( ) " العينات وتطبيقاتها في الارراسات الاجتماعية " (القاهرة)

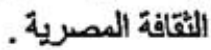

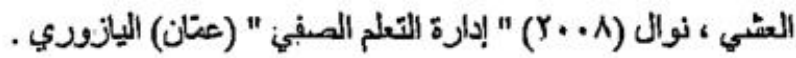

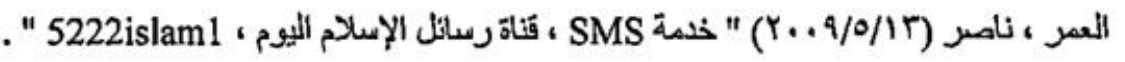
الغامدي، محمد حسن حعلين (Iاء) (I) "دور بعض العوامل التربوية في تحقيق الانضباط

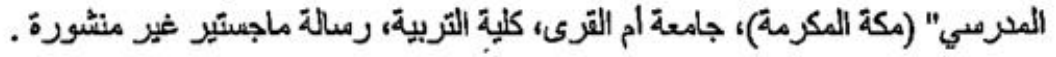

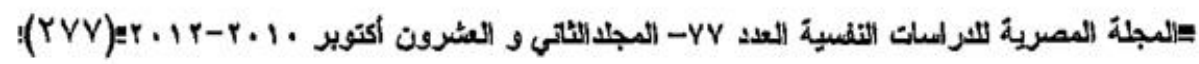




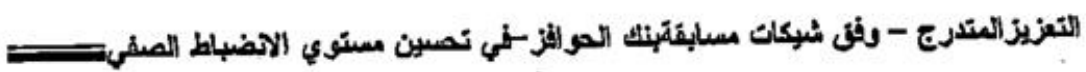

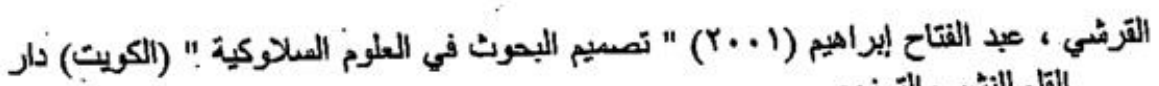

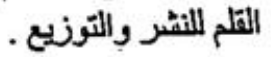

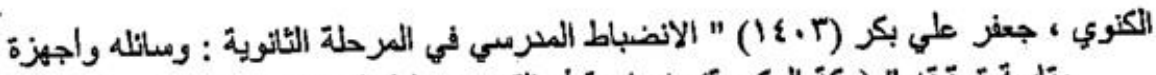

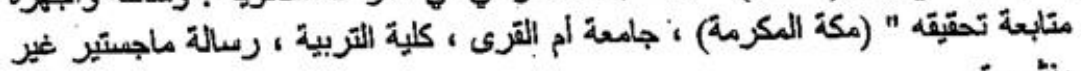

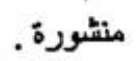

• المزيد ، الحمد عثمان (Y.III) " .0 وسيلة لتمعد نفسك ومجتمعك " (الرياض) مداز الوطن مثل

بكار ، عبد الكريم (Tr\& I ) " بناء الأجيال " (الرياض) مطابع أضواء المنتدى بمجلة البيان. .

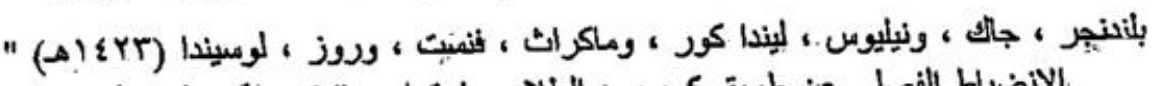

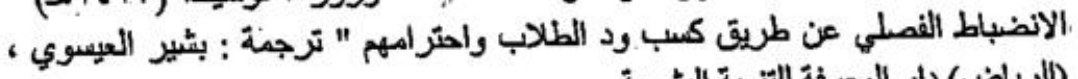
(الرياض) دار المعرفة اللتمية البشرية طئة

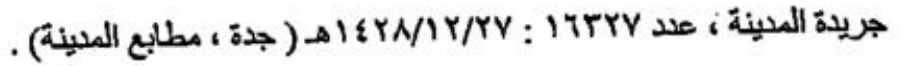
حميدة ، فاطمة إيراهيم (1991) " مداخل واستراتيجيات في إدارة الصف " (القاهرة) مكتة النهضة المصرية.

خطايية ، ماجد والسلطاني ، عبد الحسين والطوسي ، أحد (r. (Y) " التفاعل الصفي " (عتان) دار الشروق.

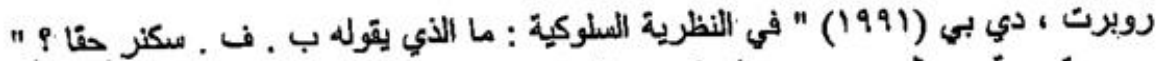

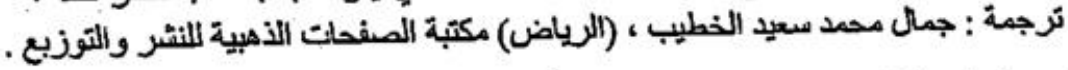

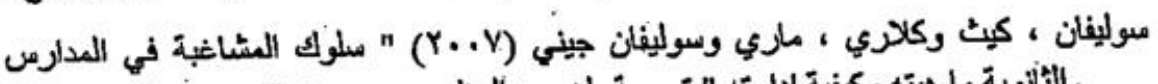

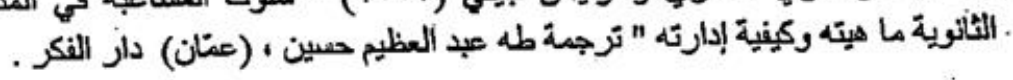

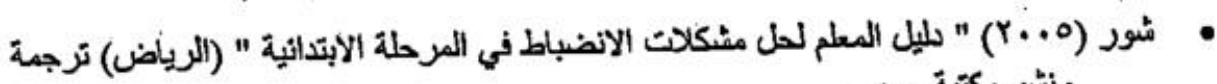
ونثطر مكتبة جرير.

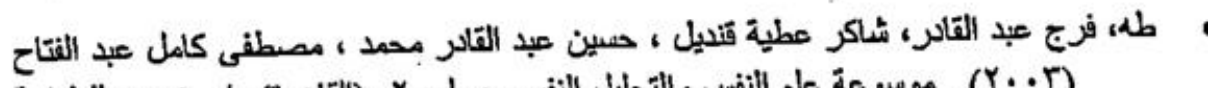

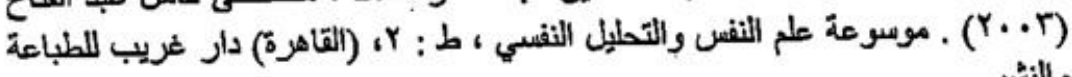
والنشر .

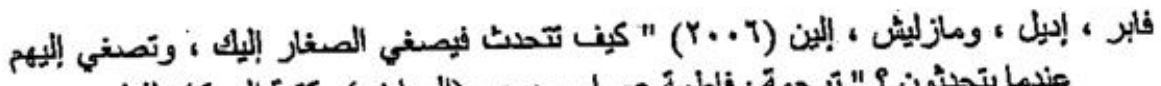

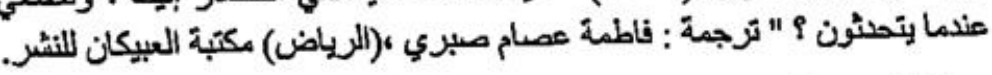

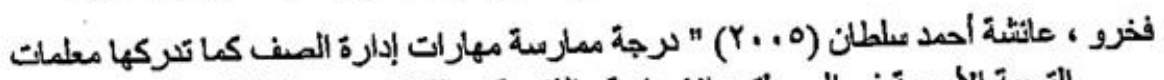

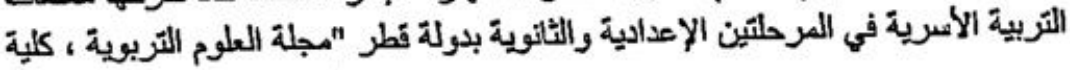

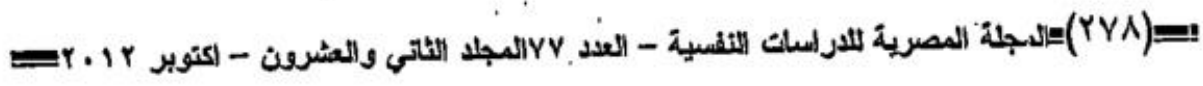




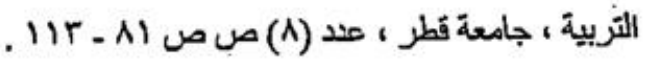

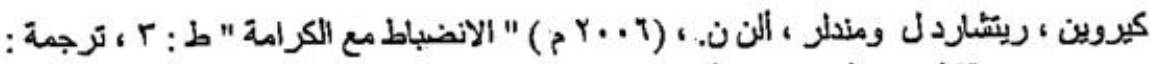

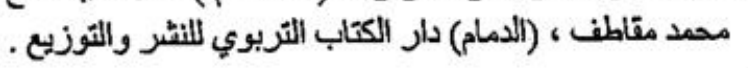

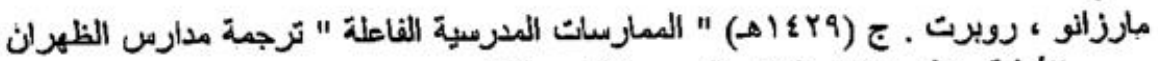

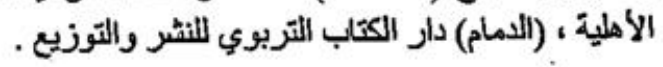

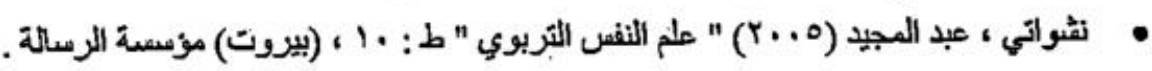

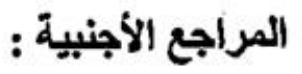

1- Brannon, Teneecia (2010). The Effects of Classroom Management Beliefs/Ideologies on Student Academic Success. Doctoral Dissertation. USA, http://www.eric.ed.gov/ERICWebportal (7/7/2012).

2. Gerdon, Lynn Melby (2001). High Teacher Efficacy as a Marker of Teacher Effectiveness in the Domain of classroom Management paper presented at the annual meeting of the American Educational Research Association .

3- Gilpatrick, Robin(2010). Classroom Management Strategies and Behavioral Interventions to Support Academic Achievement. Doctoral Dissertation. USA,

http://www.eric.ed.gov/ERICWebportal (7/7/2012). 4. Turanli , Adem Sultan :Yildirim, Ali (March 28-31,1999) .Students, Expectations of Teachers Classroom management Behaviors inEltClasses. Paper Presented at the Annual Meeting of the Nation/ Association of Research in Science Teaching (Boston, MA ).

5. Wait, Dan B. Warrn, Louisl (2001). Are Professional Development School Trained Teachers Better class room Managers? ERIC no: ED 45, 1156, U.S . California.

6. Young, Barbara N, Milligan, Barbara, Snead, Donald (2001) Jewels of Wisdom : A Study of Perceptions of Discipline of Middle School Teachers, High School Teachers, Student Teacher and Undergraduate Education Majors Enrolled in Classroom Management Course ERIC No. ED 461652.

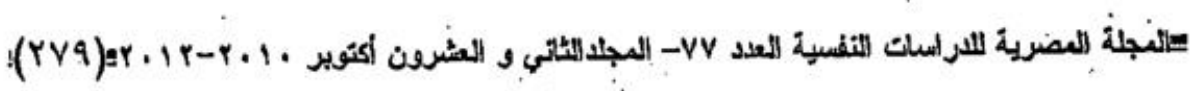




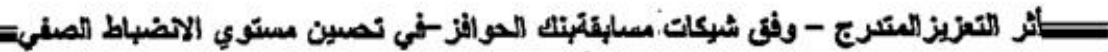

\section{The Effect of Sequential Reinforcement according to Bank of Incentives cheques in Improving classroom control for secondary stage students in Al-Qunfuthah Directorate. (Asemi empirical study)}

\section{D : Ali Ahmed Hassan Al- alsheikhi}

\section{Abstract}

The study has been built on the fact that the importance of reinforcement in education is as air for man and as water for fish. Specifically, amongst its most important goals are: testing more appealing alternatives in the reinforcement of students similar in their mechanisms to those applied in soccer games and those which appeal to the passion of the human being for his love of money represented by checks. It also aims at reinforcing the self among students and the avoidance of contempt which makes students feel inferior. And to establish what is intended, an intentional sample was taken from a number of secondary schools in Al-Qunfuthah province ( $\mathrm{Al}$-Husain Bin Ali Secondary School: experimental sample, and Al-Salamah Secondary School: referential one used as a model to judge the efficiency of the study). To supply trusted information that one can rely on to issue judgments in light of this study the "Bank of Incentives " experiment has been applied by using checks with five different colors: three for reward and two for punishment. Besides, a questionnaire was prepared by the researcher to judge the success of the experiment from the point of view of the experimental sample. The study has followed the semi-experimental method, with reliability that ranges between $(85-93)$. As to the truth of the study, all arbitrators agreed to its suitability by $100 \%$. The results have been treated according to frequencies, arithmetic mean, T. test, and variance analysis (one way anova). After careful statistical analyses, the researcher deduced the following points : the student's knowledge of his rights and duties achieves class management at schools, excitement and renewal in educational methods further 'students' interaction with teachers, the desperate need of teachers for a clear system used instead of corporal punishment which was banished without suitable alternatives, the existence of differences with statistical significance between the students of the two samples (the

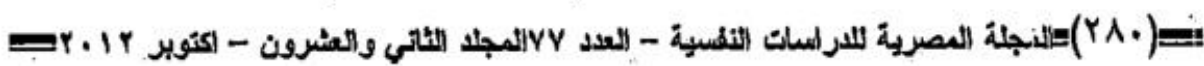




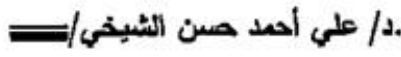

experimental and the referential ) came for the benefit of the experimental sample which was more noticeable in punishment by(4.80:46.54) and to a lesser degree in reward by (24.10:23.32)., lack of differences with statistical significance between teachers in class management according to variables such as competence, experience or training. According to the researcher, this last point is undoubtedly attributed to a number of reasons: it is due to the fact that educational preparation programs in our universities lack class management subjects it their curricula, general weakness in teachers' knowledge of class management due to deficiencies in media and the educational library, in addition to the general abstention from reverting to educational institutes in training teachers in such programs which are either scarce or conducted by non specialized personnel whenever they are presented. After careful consideration of both results and theoretical frame, and in light of former studies the following recommendations and suggestions are highly recommended by the researcher: the immediate implementation of the list of students' rights and responsibilities which were presented by the Ministry of Education and never implemented till now, applying the Bank of Incentives experiment in all educational levels for better understanding of each level's requirements, applying this experiment in other educational directorates to ascertain its success in achieving class management, and studying the real application of the list of regulations concerning behavior and attendance and its obstacles in all educational levels 